\title{
An Analysis of the Aid Effectiveness Agenda in Tonga
}

\author{
Helen Mountfort \\ Victoria University of Wellington \\ Wellington, New Zealand
}

Submitted to Victoria University of Wellington in partial fulfilment of the Master of Development Studies Degree

June, 2013 


\begin{abstract}
Over the past decade, the rhetoric of international aid has significantly changed. Increased emphasis has been placed on the full participation of aid recipient countries, which are now being urged to own and drive their development planning and policy. The 2005 Paris Declaration on Aid Effectiveness sits at the core of this international consensus that calls for alignment of donor policies and harmonisation of donor procedures. This study was undertaken to investigate the influence of the aid effectiveness agenda on Tongan development policy and practice. Using both primary and secondary sources, an analysis of the Paris Declaration Principles and their application in practice was explored. A case study of the Tonga Energy Road Map was carried out in order to illustrate a more detailed unfolding of the aid effectiveness agenda at a sector and project level. The key findings of this research suggest that there has been substantial improvement to development policy and practice in Tonga. It is unclear, however, if this improvement was the outcome of commitments made to the Paris Declaration or the result of strong relationships and leadership exerted by the Government of Tonga. However, in spite of the commitment to increase aid effectiveness made by some development agencies, many still operate with their own systems and procedures which Tonga is required to meet. Although Tonga has readily adopted the Paris Declaration Principles, the aid effectiveness challenge remains at the project implementation level.
\end{abstract}




\section{Acknowledgements}

To those in Tonga,

To my work colleagues, malo lahi 'aupito. I'm enormously grateful for the opportunity to have been able to work and experience life in Tonga. I would like to thank you all for the support, encouragement and assistance.

Ki hoku famili Tonga, 'oku ou fakamalo kiate kimoutolu ' $\mathrm{i}$ he angalelei, anga'ofa moe tokoni kotoa pe. 'Ofa lahi atu.

I am also indebted to all my research participants. Malo 'aupito ho'omou foaki taimi moe fevahevahe'aki mai ho'omou ngaahi 'ilo. Malo lahi 'aupito.

\section{To those in New Zealand,}

To my supervisor Professor Warwick Murray, for trusting me to paddle my own canoe.

To all my family and friends, thank you for your support, thoughtfulness and encouragement. You have all helped me throughout my research in many different ways. To my Dad, Mum, sister Anna and brother Paul, thank you for your continuous support and love.

To my editors and mentors, for intellectually challenging me and sharing your own experiences and insights. Your input into my thesis has been invaluable.

Lastly, I would like to acknowledge the Colin Aikman Award and the Laurie Cameron Scholarship, for providing financial assistance throughout this thesis. 


\section{Contents}

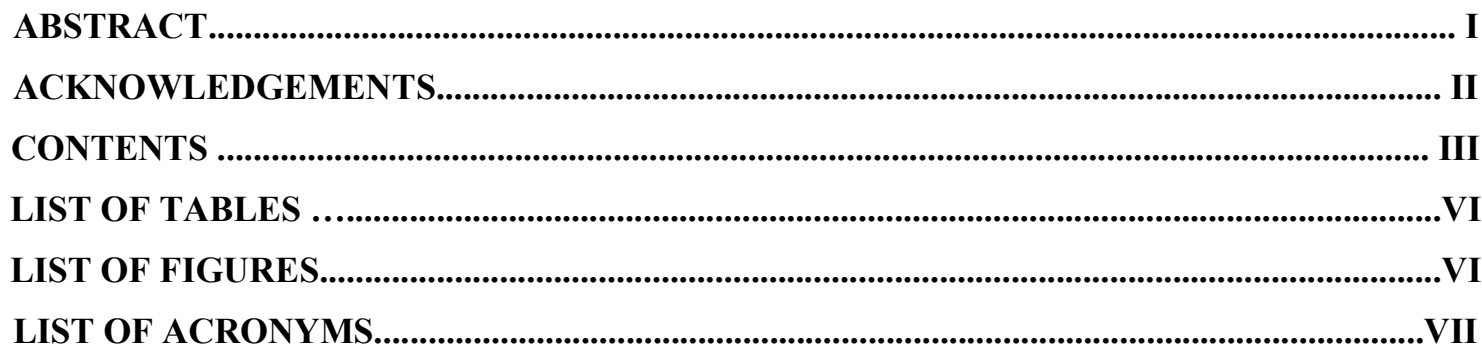

1 CHAPTER ONE: INTRODUCTION $\ldots \ldots \ldots \ldots$

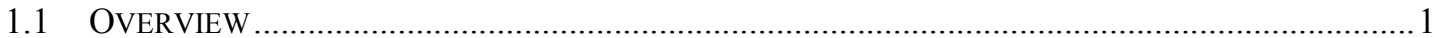

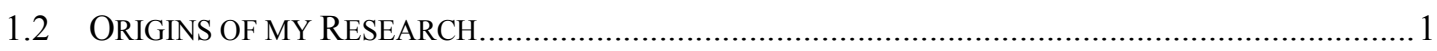

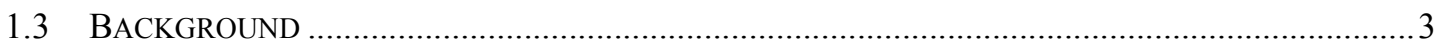

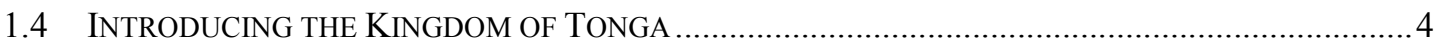

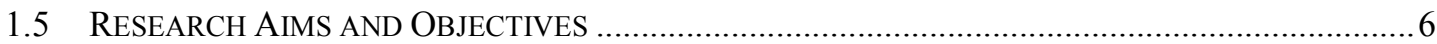

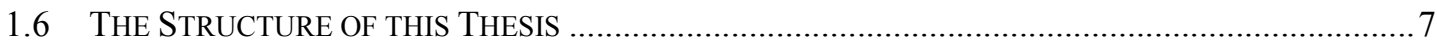

2 CHAPTER TWO: METHODOLOGY AND METHODS ......................................................9

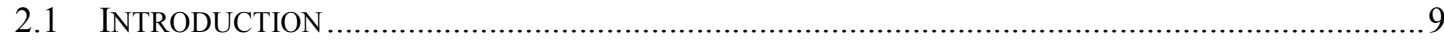

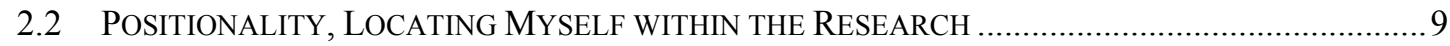

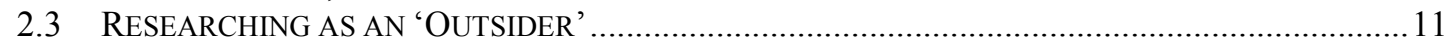

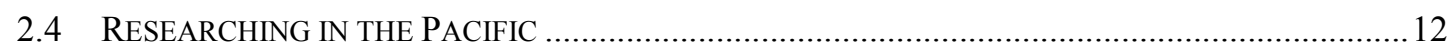

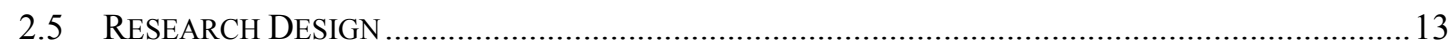

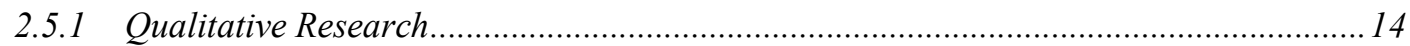

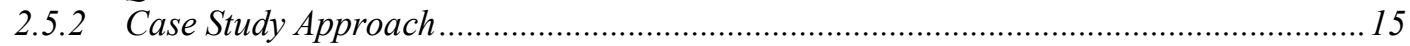

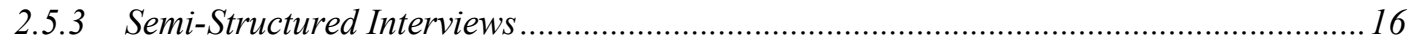

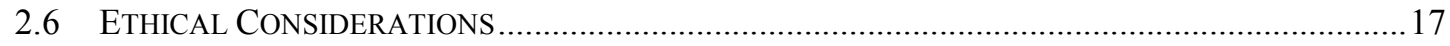

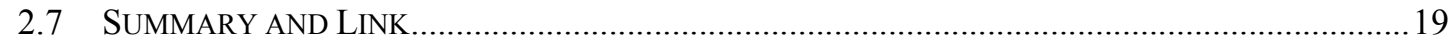

3 CHAPTER THREE: DEVELOPMENT, PARTICIPATION AND EFFECTIVE AID ........20

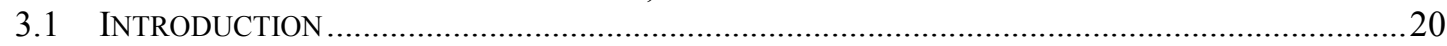

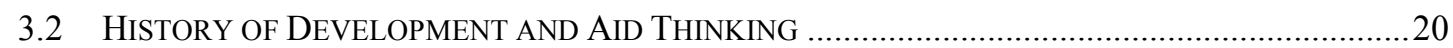

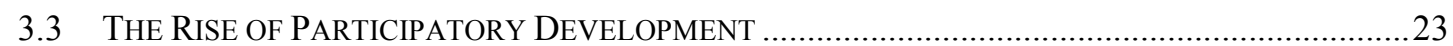

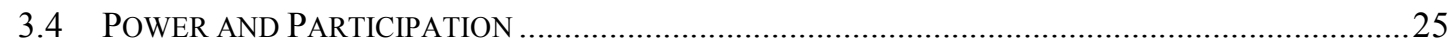

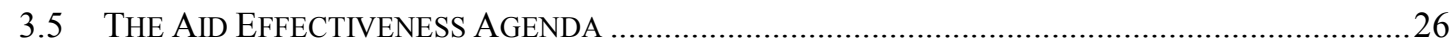

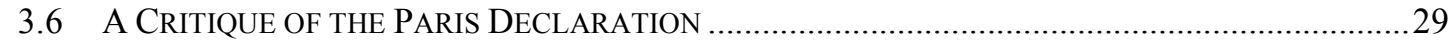

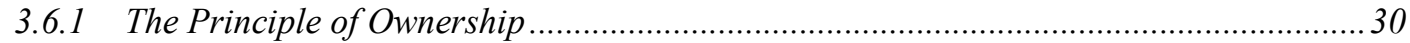

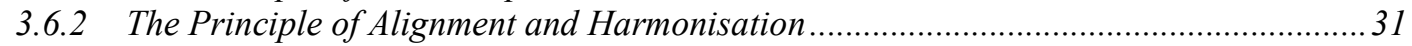

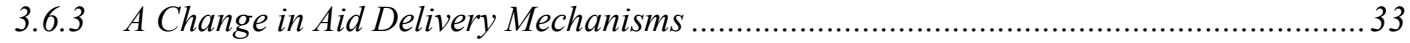

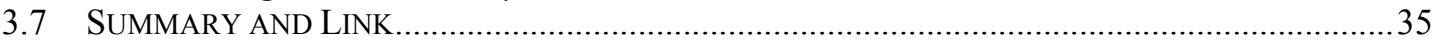

4 CHAPTER FOUR: AID IN THE PACIFIC WITH A FOCUS ON TONGA...........................36

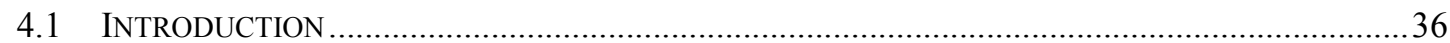

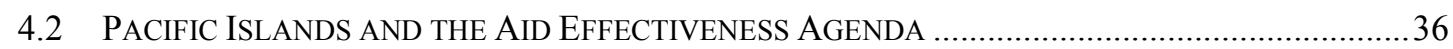

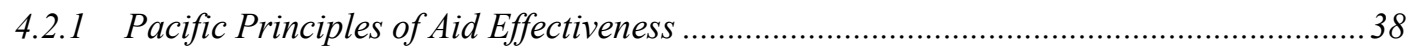

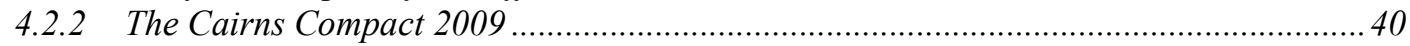

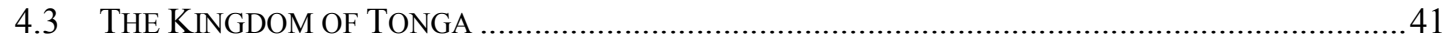

4.3.1 The Tongan Constitution and the Formation of the Monarch ….....................................42

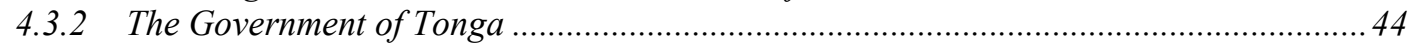

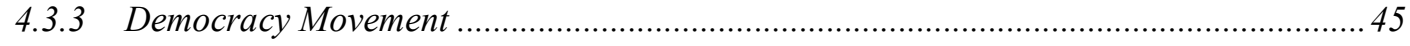

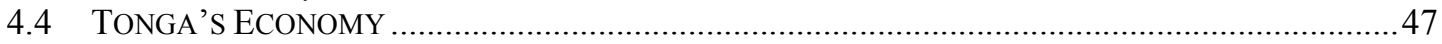

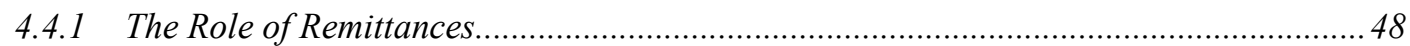

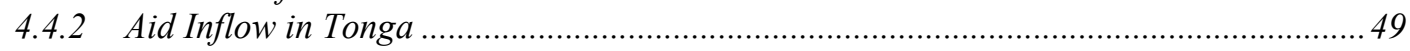




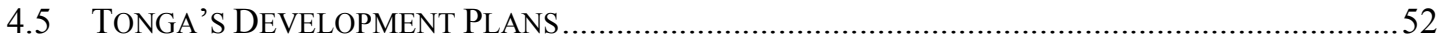

4.6 THE GOVERNMENT OF TONGA AND DEVELOPMENT PARTNER RELATIONS ............................54

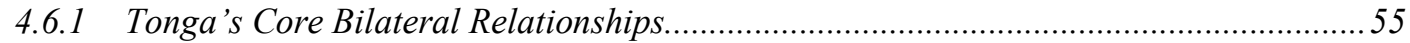

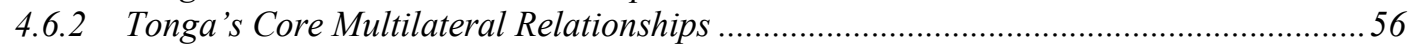

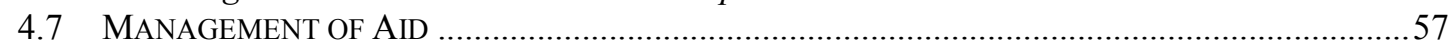

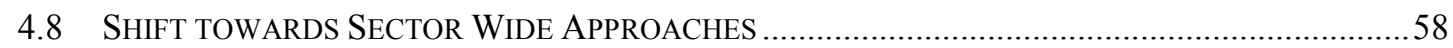

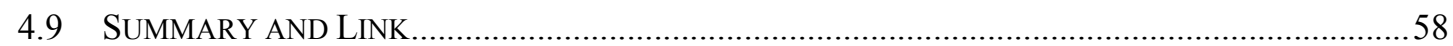

5 CHAPTER FIVE: ADOPTION OF THE PARIS DECLARATION IN TONGA .................59

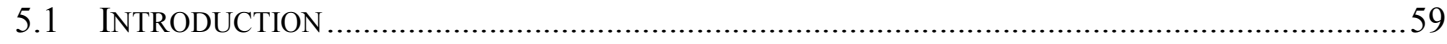

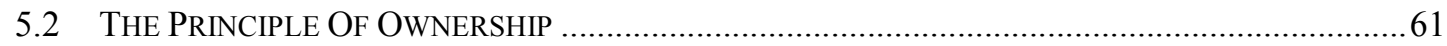

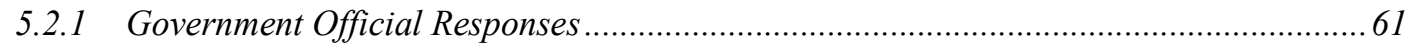

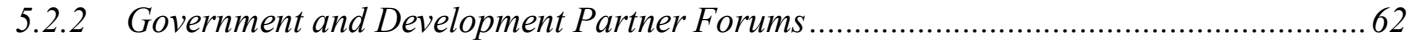

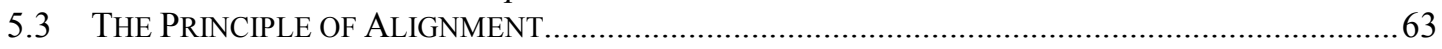

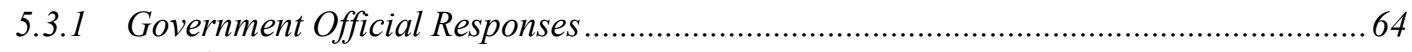

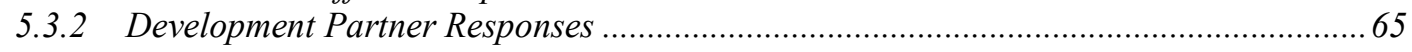

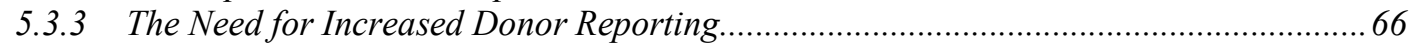

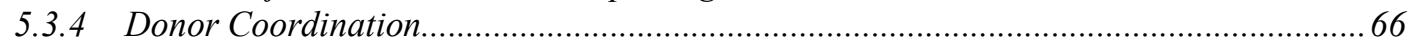

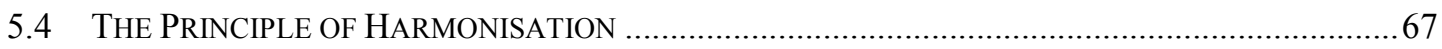

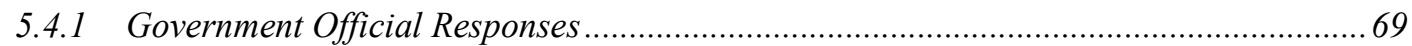

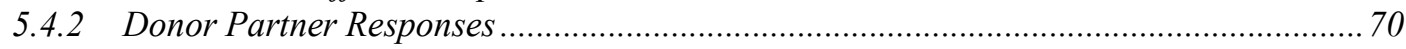

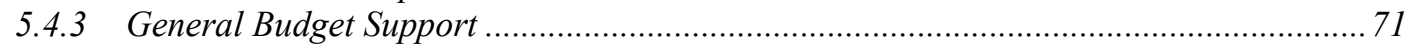

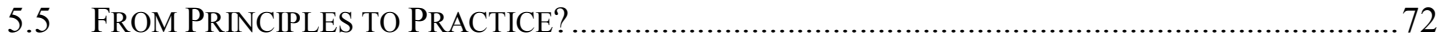

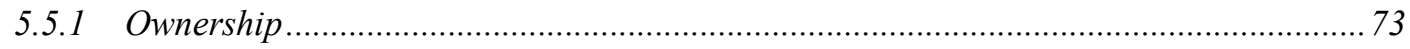

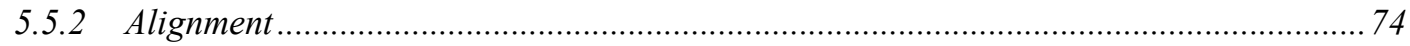

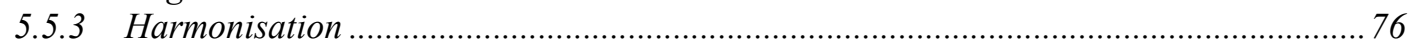

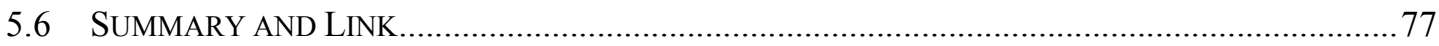

6 CHAPTER SIX: CASE STUDY OF THE TONGA ENERGY ROAD MAP ..........................78

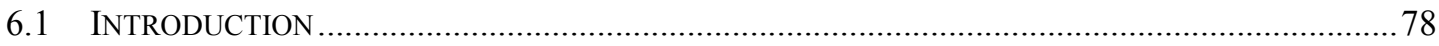

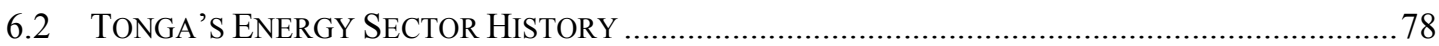

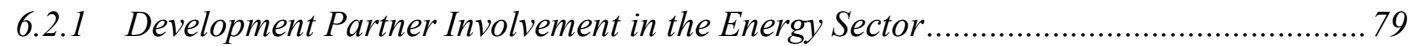

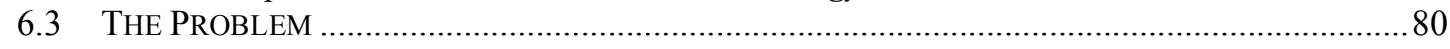

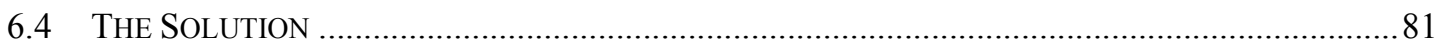

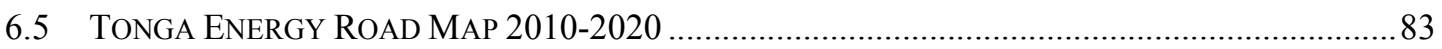

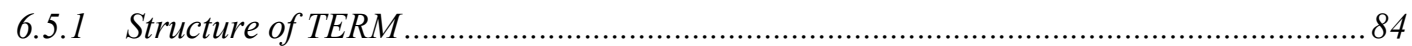

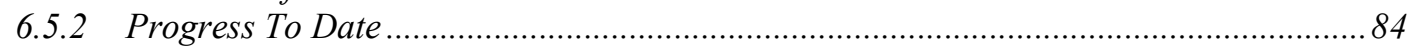

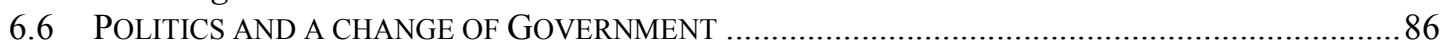

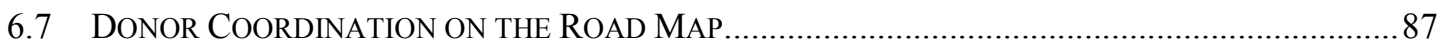

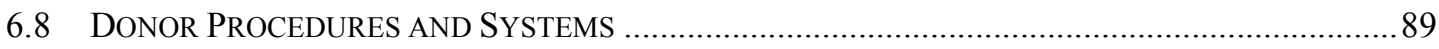

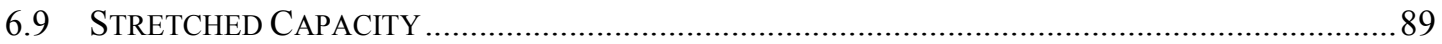

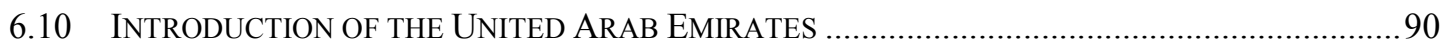

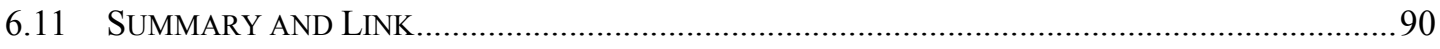

7 CHAPTER SEVEN: AID EFFECTIVENESS IN TONGA - DISCUSSION AND

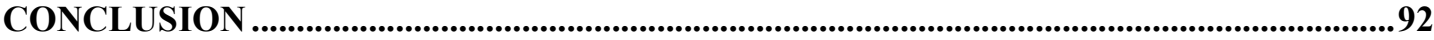

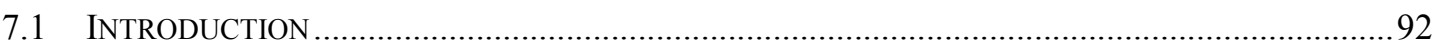

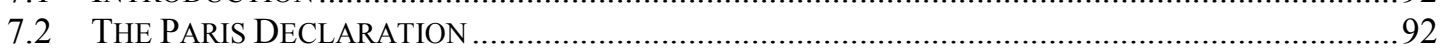

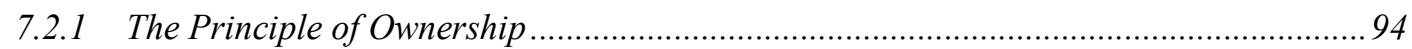

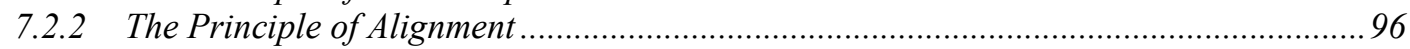

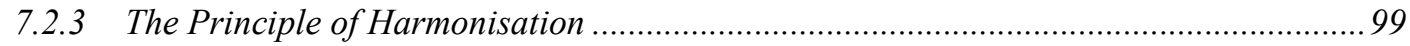

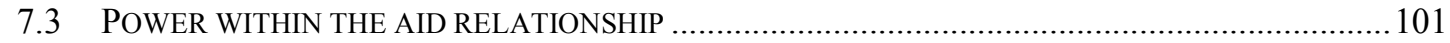

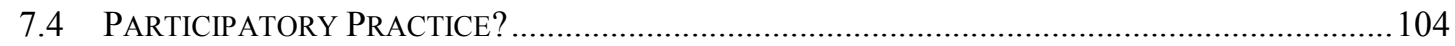

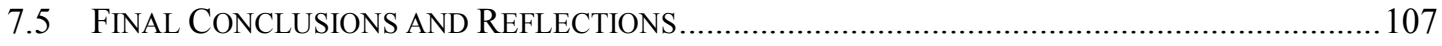

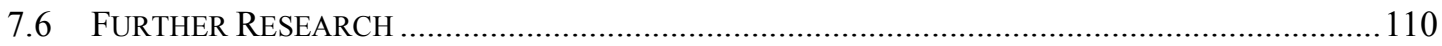

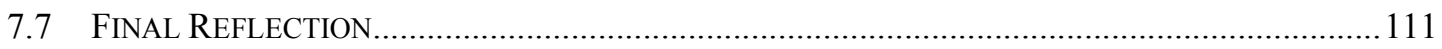




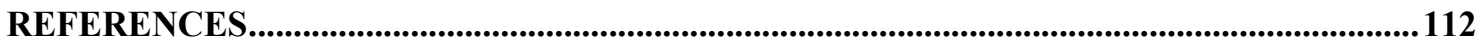

APPENDIX 1: SEMI-STRUCTURED INTERVIEW QUESTIONS ...........................................129

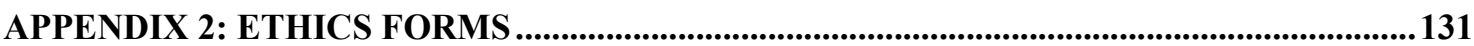

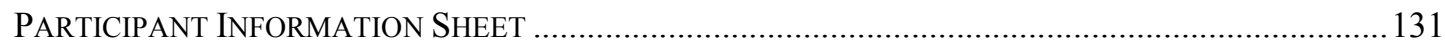

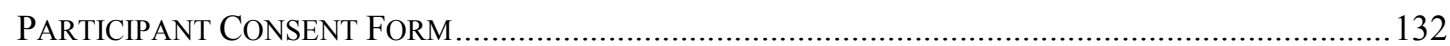




\section{List of Tables}

Table 4.1 Summary of the Pacific Aid Effectiveness Principles....................................... 39

Table 4.2 Total Grant Aid to Tonga by Donor 1970-2009 …......................................... 51

Table 4.3 Key Economic and Fiscal Indicators 2010-2013 ..........................................52

Table 5.1 Joint Declaration of Aid Effectiveness Between the Government of Tonga

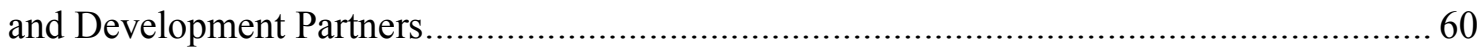

Table 5.2 Total Amount of Aid That Uses Country Systems in Tonga 2010 ....................... 64

Table 5.3 Total Number of Coordinated Donor Missions in Tonga 2010 ........................... 68

Table 5.4 Projects or Programmes over \$4m (TOP) (Summarised) .................................... 69

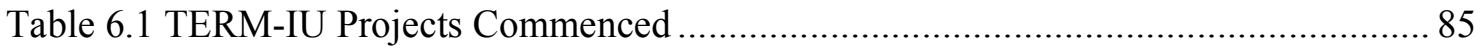

\section{List of Figures}

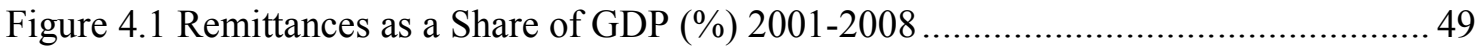

Figure 4.2 Net ODA and Official Aid Received in Tonga (constant 2009 \$m USD) ............ 50 


\section{List of Acronyms}

\begin{tabular}{|c|c|}
\hline $\mathrm{ADB}$ & Asian Development Bank \\
\hline AusAID & Australian Agency for International Development \\
\hline DRTM & Donor Round Table Meeting \\
\hline EU & European Union \\
\hline GBS & General Budget Support \\
\hline GDP & Gross Domestic Product \\
\hline GoT & Government of Tonga \\
\hline HRDMT & Human Rights and Democracy Movement in Tonga \\
\hline IBRD & International Bank for Reconstruction and Development \\
\hline IMF & International Monetary Fund \\
\hline IRENA & International Renewable Energy Agency \\
\hline JFO & Joint Focal Office \\
\hline JICA & Japan International Cooperation Agency \\
\hline MDGs & Millennium Development Goals \\
\hline MIRAB & Migration Remittances Aid and Bureaucracy \\
\hline MoFNP & Ministry of Finance and National Planning \\
\hline MECC & Ministry of Environment and Climate Change \\
\hline NCPR & National Committee for Political Reform \\
\hline NZAID & New Zealand Agency for International Development \\
\hline ODA & Official Development Assistance \\
\hline OECD & Organisation of Economic Cooperation and Development \\
\hline OXFAM & Oxford Committee for Famine Relief \\
\hline PICS & Pacific Island Countries \\
\hline PIFS & Pacific Islands Forum Secretariat \\
\hline PMO & Prime Minister's Office \\
\hline PNG & Papua New Guinea \\
\hline PRIF & Pacific Regional Infrastructure Facility \\
\hline REEEP & Renewable Energy and Energy Efficiency Partnership \\
\hline $\mathrm{ROC}$ & Republic of China Taiwan \\
\hline SPC & South Pacific Secretariat \\
\hline SPOCC & South Pacific Organisations Co-ordinating Committee \\
\hline SPREP & South Pacific Regional Environment Programme \\
\hline SRO & Single Regional Organisation \\
\hline TA & Technical Assistance \\
\hline TEPB & Tonga Electric Power Board \\
\hline TOP & Tongan pa'anga (T\$) \\
\hline TOR & Terms of Reference \\
\hline UN & United Nations \\
\hline WHO & World Health Organisation \\
\hline
\end{tabular}




\section{Chapter One: Introduction}

\subsection{Overview}

Ostensibly, the development agenda has shifted towards principles that promote full participation of aid recipients, alignment of donor policies and harmonisation of donor practices. The Paris Declaration of 2005 sits at the core of this drive towards increasing the effectiveness of aid and emphasising the need for greater recipient control over development assistance and direction. The Paris Declaration is intended to be a progressive document and although superficially laudable, it can be criticised. This research seeks to understand how the aid effectiveness agenda has influenced aid policy and practice in Tonga. In order to do so, this study will explore how the principles of the Paris Declaration have been applied to development policy and practice followed by a case study of the Tonga Energy Road Map.

\subsection{Origins of my Research}

During the summer of 2010, I worked as an intern for the Tonga Energy Road Map Implementation Unit (TERM-IU). The Tonga Energy Road Map 2010-2020 (TERM) is a ten year, sector wide approach taken by the Government of Tonga for the reformation of its energy sector. It aims to reduce Tonga's vulnerability to oil price shocks and achieve an increase in quality access to modern energy services in an environmentally sustainable manner (TERM, 2010).

My internship at TERM-IU was my first experience working in a developing country and working in the development industry. Within the TERM-IU there were a number of proposal and project concepts looking to introduce renewable energies into the network, increase energy efficiency (both in electricity supply and use) and improve access to quality electricity services. TERM staff were inundated with various administrative tasks required by the different development actors contributing to the TERM. My first task with the unit involved contacting the relevant development partners to check on the status of various proposals and to compile a list of exactly what was needed and what required attention.

Under one project looking to upgrade the low voltage network in the rural areas of Tongatapu, I had to follow two separate project proposals and budget guidelines in order to 
meet the requirements of the two donors looking to fund the project. There was no apparent logic to the duplication of time, money and resources. However, what became clear over the following weeks was that this was common practice. Development partners have their own unique systems, rules and procedures and very rarely do they match up. The implementation unit consisted of five core staff who were frantically working to meet the demands of multiple development actors funding or developing various projects and aspects of TERM.

What became apparent during my short stay was that the challenges faced by the TERM-IU were not specific to this sector plan but occurred right across government. Government officials were endlessly working to meet the demands of development partners, each with their own mission, demands and requirements. I observed an abundant number of missions from various development agencies arriving for a short period of time. Each mission would request the time and resources of local staff and there was minimal coordination among them. Government officials were continuously faced with pressures by outsiders and it became clear that they had very few resources to deal and manage every single development actor working in the region.

When I returned to Wellington I found my supervisor and other academics in my department discussing the same issues I was faced with while working in Tonga, and what other government officials had constantly relayed to me. That is, poor donor coordination, inflexible donor systems and large administrative workloads. Despite the rhetoric of donors towards harmonising and aligning with one another, there appeared to be very little change to their practices. Nicky Wrighton, a Masters student at Victoria University had produced a thesis looking at the issue of participation and consultation within the Government of Tuvalu. This study highlighted the pressures and challenges faced by Tuvaluan government officials as they worked to meet the demands of multiple donors and development actors operating in the country (Wrighton, 2010a). This study suggested that the aid effectiveness agenda that emphasised participation and consultation of recipients could be the very same agenda that makes it difficult for a small country, such as Tuvalu, to govern and manage the multiple roles they have (ibid:2010a). The themes and arguments presented in this thesis mirrored many issues that I had witnessed in Tonga.

Wrighton's (2010a) research formed the basis for a Marsden Research Project, led by Professors John Overton and Warwick Murray. This research project is an amalgamation of 
different case studies investigating the influence of changing aid modalities on development policy sovereignty in the Pacific. Analysis of this research will inform part of the above research project.

\subsection{Background}

In recent decades, aid policies have shifted towards discourses of participation and consultation in an attempt to improve the effectiveness of aid. There has been a movement away from the conventional top-down relationship between donors and recipient countries towards a more equal 'partnership'. It is now entrenched within the development field that aid recipient countries must be included, consulted and actively engaged in their own development (Easterly, 2008; OECD, 2008; de Haan, 2009).

Since the early 2000s, international development cooperation principles have focused on recipient country ownership and reducing the wastefulness of previous development efforts. There has been an emphasis placed on putting recipient countries into the driver's seat, allowing them to direct and exercise leadership over the country's development (Easterly, 2008; OECD, 2008; Okail, 2011; Collins, 2011). Development actors have also acknowledged that their own practices can dramatically reduce the effectiveness of aid, undermining local ownership with too many uncoordinated projects by too many donors (van de Walle, 2005:38).

The Paris Declaration of 2005 has become a significant juncture of the new international consensus. Heeding the call for greater recipient control over development assistance and increasing the alignment and harmonisation of donors' procedures and policies (OECD, 2008). The Paris Declaration Principles (of Ownership, Alignment, Harmonisation, Mutual Accountability and Managing for Results) have become the major pillars of the aid effectiveness agenda and are of central concern for aid practitioners. It is presumed that the principles and objectives outlined in the Paris Declaration will reduce the transaction costs for the recipient country and allow greater recipient control over the funds provided.

Although the Paris Declaration Principles and objectives are well intentioned, their translation into policies at the local level is argued to lose much of their meaning (Okail, 2011). Faust (2010) argues that the principles have 'over simplified' the complex aid 
relationship and have ignored politics and power relations. Hyden (2008) emphasises that development cooperation is no longer just about policy but politics and contends that the credibility of the Paris Declaration will be undermined if the concept of power is not addressed. The principles that were so easy to declare have in reality, been very difficult to implement (Cramer, Stein and Weeks, 2006; Monye, Ansah and Orakwue, 2010).

Despite the shift in rhetoric towards a more participatory and empowering 'partnership' between donors and recipients, it is argued that national governments have been heavily burdened with development partner administrative and managerial requirements. This decreases their ability to direct and instruct national policy initiatives and outcomes (Wrighton, 2010b; Murray and Overton, 2011b). Murray and Overton (2011b) suggest that development practice has been undeterred by the rhetoric of participation and local ownership. It is proposed that the aid effectiveness agenda may create the reverse effect of what it had intended, potentially reducing the sovereignty of aid recipient states. Murray and Overton (2011b: 272) define this as the 'inverse sovereignty effect', where "recipient states are actually losing control over their development strategies, policies and programmes".

The Pacific region has responded to the aid effectiveness agenda with eight Pacific Island countries and all major donor agencies in the region formally signing and committing to the Paris Declaration. The region has also responded with the 'Pacific Aid Effectiveness Principles' signed in 2007, adopting and shaping the principles to fit the specific issues facing the region (PIFS, 2007). To date, there has been limited research on the translation of these policies into development practice in the Pacific. This research looks to address that gap in part.

\subsection{Introducing the Kingdom of Tonga}

The Kingdom of Tonga consists of four main island groups, Tongatapu, Ha'apai, Vava'u and Niuas and has a population of 103,036 (GoT, 2011). Tonga is characterised by its political continuity, it has the longest standing constitutional monarchy in the region that has ruled for the past 135 years. Tonga is the only Pacific Island country to formally avoid colonisation, although it remained a protectorate under Britain from 1900 to 1970 (Campbell, 1992a). 
In 1875 Taufa'ahau united Tonga under the one ruler, declaring himself King George Tupou I. With the assistance of Wesleyan missionary Reverend Shirley Baker, Taufa'ahau established the Rule of Law, drafting up the Constitution and establishing the Tongan Monarchy (Campbell, 1992a). Taufa'ahau held the chiefly title of Tu'i Kanokupolu with a power base in Vava'u and Ha'apai. He abolished serfdom in Vava'u in 1835 and introduced the Vava'u Code in 1839, the first written laws in Tonga (GoT, 2010). On June 4, 1862 Taufa'ahau proclaimed an Emancipation Code which officially abolished serfdom everywhere in Tonga. June 4 is still a public holiday, emancipation day, in Tonga.

Tonga's constitutional movement in 1875 shaped social structures and created political stability within Tonga. Now in the 21st century, King George Tupou V committed to surrender his Executive Authority and completed the reform inaugurated by King George Tupou I 135 years ago. The first democratic elections were held in Tonga on November 2010. Under the new constitution, the majority of seats in Parliament went to the People's Representatives (commoners) who now hold 17 out of 26 seats in Parliament (GoT, 2010).

Tonga's geographic location combined with limited natural resources has created significant economic constraints. Tonga's economy is largely dependent on remittances and foreign aid and its small, open economy is extremely vulnerable to external price shocks (World Bank, 2010). The economic crisis in 2008 had significant impacts on Tonga's economy, decreasing the total amount of remittances and severely increasing the cost of food and fuel. Tonga is dependent on imported petroleum to meet its energy needs, with petroleum products accounting for $19 \%$ of GDP. With sharp increases in the cost of oil during 2008, the Tongan people experienced increased hardship (Sevele, 2011). The Government of Tonga responded with a $50 \%$ renewable energy target and a plan of how to achieve it, the Tonga Energy Road Map (TERM). The TERM was endorsed by Cabinet in April 2010 and has the backing and support of all development partners in Tonga (TERM, 2010).

Tonga's relationship with development partners extended following independence from Britain in 1970. British support was gradually replaced with development assistance provided by Australia, New Zealand and Japan. The three resident bilateral donors Australia (AusAID), New Zealand (NZAID) and Japan (JICA), still predominantly provide the main portion of development assistance to Tonga. However, China has played an increasingly important role in the country. Core multilateral donors include the World Bank, the Asian 
Development Bank and the European Commission. The World Bank estimates that Tonga receives on average, \$50 million (USD) per annum (World Bank, 2010).

In context of the aid effectiveness agenda, Tonga has readily adopted the Paris Declaration alongside many of its core development partners. Tonga has also produced its own 'Joint Declaration of Aid Effectiveness' in 2007, shaping the Paris Declaration Principles to fit the specific conditions in Tonga. This research will examine the extent to which the above commitments have impacted development policy and practice in Tonga. It will explore the realities of government officials as the practices of international aid emphasise the need for full participation and consultation of aid recipient countries.

\subsection{Research Aims and Objectives}

\section{Research Aim:}

The aim of this study is to investigate the influence of the aid effectiveness agenda on Tongan development policy and practice.

\section{Research Objectives:}

1. To evaluate the extent to which the Paris Declaration Principles of Ownership, Alignment and Harmonisation have been applied in Tonga.

2. To identify the responses and strategies of the Government of Tonga to the aid effectiveness agenda with particular reference to its application in practice.

3. To investigate the extent to which the Tonga Energy Road Map has incorporated the principles of the aid effectiveness agenda.

This thesis will analyse the challenges faced by Tongan government officials as they exercise leadership over the country's development policies, strategies and development actions. It will reflect on Tonga's engagement and response to the practice of development agencies in Tonga. The findings of this research will inform wider theoretical debates that surround the aid effectiveness agenda and it is hoped that sharing this analysis may have yield useful findings for other Pacific Island countries or aid recipient countries operating in a similar environment. 


\subsection{The Structure of this Thesis}

The remainder of this thesis is structured as follows:

In Chapter 2 I will outline my own position within this research, placing myself in context of researching as an 'outsider' with a temporary 'insider status' in Tonga. The chapter will illustrate the methodological aspects of my research and discuss how the methodology chosen has influenced and shaped my research. This will be followed by a description of the research methods used and a discussion of some of the ethical considerations made throughout the research process.

In Chapter 3 I will provide the theoretical background framing this research, followed by an illustration of the shifting aid agendas across the past two decades. I will specifically highlight the emergence of the participatory paradigm in the 1990s. I will then introduce the literature surrounding the aid effectiveness agenda, with particular attention given to the Paris Declaration and its accompanying principles. This is undertaken in order to place this research within the appropriate theoretical context. Chapter 4 will introduce the responses of the Pacific region to the aid effectiveness agenda, exploring the ways in which this agenda has been shaped to meet the specific challenges facing the region. Finally, this chapter will introduce the case country of this research, the Kingdom of Tonga, detailing its unique political system and development history.

Chapter 5 is the first of two chapters in which I describe the responses of government officials and development partner representatives to the aid effectiveness agenda. In particular, I will examine the extent to which the Paris Declaration Principles have been applied to development practice and policy in Tonga. In doing so, I will provide examples of various strategies employed by the government to increase control over aid delivery and management. Chapter 6 will focus the research on a case study of the Tonga Energy Road Map (TERM). I will start by outlining the history of Tonga's energy sector and outline the previous approaches taken by government and development partners in order to develop Tonga's energy sector. This chapter will then detail the formation of TERM, and some of the 
challenges encountered by both government and development partners in designing and approving to this plan. I will also outline some of the successes and problems encountered as the Government of Tonga and development actors execute this plan.

In Chapter $7 \mathrm{I}$ will bring together the findings outlined in Chapters 5 and 6, exploring the wider implications to development theory and practice. This discussion and conclusion chapter will be framed around the three themes of Paris, Power and Participatory Practice. I will reflect on the challenges faced by both government officials and development partners as they find the balance between promoting local ownership, maintaining financial risk and enhancing the effectiveness of aid. The final section of this thesis will summarise the findings and recommend where future research is needed. 


\section{Chapter Two: Methodology and Methods}

\subsection{Introduction}

Chapter one introduced the rationale behind this research and outlined the objectives that guide this study. This chapter will describe how the research was done. It will commence by locating myself within the research, highlighting how my own positionality influenced the data collected. This chapter will then detail the epistemological approach I have undertaken in order to culturally embed my research, illustrating various Tongan research frameworks, principles and tools that have been considered and incorporated into the research process. I will conclude this chapter with a discussion of the ethical conflicts and considerations relevant to this research and researching in the Pacific.

\subsection{Positionality, Locating Myself within the Research}

Sitting in the plane, filling out the arrival card as I began the descent down to the Kingdom of Tonga I was not able to tick a box that correctly identified my purpose of travel. I was not in Tonga for work, business, to visit friends or relatives, or for a holiday. As I hesitantly ticked the box of 'other', I stewed over what this would translate into when I met with the immigration officers on the ground. However giving proof that I had a departure ticket was enough.

During my first week back in Tonga I was offered a position at the TERM-IU. But I faced a conundrum, was it ethical to work and research at the same organisation? Would I be able to handle the splitting of my roles? As I debated the challenge of working as both a development professional and a researcher, I questioned what this might translate to for those I was researching. However, I also realised that this was a chance to really understand the workings of TERM, it was a chance to see the way development partners interact with the Tongan Government on a day-to-day basis and experience development coordination as it happened on a sector level. Echoing Chacko's (2004:54) reflection on positionality in rural India, I found "implications of positionality crystallised on personal and professional fronts" during field research. The personal reflections will be explored in the final section of this chapter. 
Due to the situation I was in, I felt it was critical for me to be up front about my position and identify a standpoint (Chacko, 2004). Yet, as I was in the field I found that my positionality 'fell out' naturally as Murray and Overton (2003) suggest. As I was interviewing both government officials and development partners I wanted to ensure that my role as a researcher was transparent and clear, not threatening or deceptive (Cahill, 2007). No one questioned the splitting of my roles and I felt confident that I could remain credible both as a researcher and a professional. As Tuhiwai Smith (1999:136) suggests, "consent is not so much given for a project or specific set of questions but for a person for their credibility".

Positionality is a "critical factor in framing social and professional relationships... it sets the tone of the research, affecting its course and its outcomes", however, positionality is also “contingent and contested" (Chacko, 2004:52). In Tonga, I was constantly referred to as 'palangi', (meaning white person). The colour of my skin placed me in the position of an 'outsider' and this was apparent no matter where I was in Tonga or who I was talking to. However, my previous experience in Tonga, and working for the TERM-IU meant I had achieved what Mullings (1999) terms as 'temporary insider' status. The professional relationships I had formed with many of the participants created a 'shared positional space', where I was given the opportunity to explore issues in much greater depth, and see and experience their environment as they did. This allowed me to really understand the nature of the challenges they faced.

As I was interviewing both government officials and donor representatives, I had to maintain a balance where I could see the viewpoint of both. While I have tried to equally express the opinions of each group, a greater emphasis has been placed on the voices of government officials. Often "in some Third World contexts, local voices are seldom heard commenting on development policy or contributing to mainstream development planning" and I did not want my thesis to follow a similar trend (Scheyvens and Storey, 2003:4). I may have been granted entry on the premise that I had a ticket out, but I did not want to be extracting knowledge for 'personal ladder climbing' producing something that was of no value to the participants who generously gave me their time, knowledge and experience (Thrupp, 1989:19). 


\subsection{Researching as an 'Outsider'}

Criticism surrounding the appropriateness of doing research in the Third World has been myriad and manifold. Research by 'outsiders' in developing countries has been argued as exploitative and intrusive (Sidaway, 1992; Stacey, 1991). Escobar (1995) argues that research in Third World has sought to legitimise the voices of the Western 'experts' while undermining those of local people (cited in Scheyvens and Storey, 2003:2). Many other academics and researchers also agree that the power relations, inequalities and injustices that exist between the researcher and the researched have yet to be addressed (ibid:2).

However, Narayan (1993) proposes that it is not so much about where the researcher is positioned in the research but what the motivations and intentions are of why the research is being undertaken. Narayan (1993) emphasises that we must focus our attention on the value and quality of the relationships we hold with the people we represent in our work. Bochner (2000) also contends, it is not necessarily how objective or subjective someone is, or what is determined 'reliable' or 'grounded', which largely misses the point of research. Bochner (2000:267) argues that we are so concerned with having our work "belittled or labelled unscientific or unscholarly" we forget to question if our work is "useful, insightful, or meaningful and to whom".

Criticisms surrounding the way research is conducted in the Pacific have evolved out of a long history of imposing Western perspectives and research methodologies on Pacific 'ways of being'. It is argued that various traditional western approaches and methods to research have largely hindered the researchers' ability to gain in-depth analysis that truly captures the realities of Pacific people. Thaman (2003) argues that we must understand, recognise and acknowledge the dominance of Western philosophy. We must learn to value the alternative ways of interacting, viewing and thinking about our world, "particularly those rooted in the indigenous cultures of Oceanic peoples" (ibid:3). In order to overcome some of these shortfalls of 'outsiders' conducting research, I have incorporated culturally appropriate methods and principles throughout the research process. Below I will detail a Tongan research framework that informed the intentions of my research. 


\subsection{Researching in the Pacific}

The call for Pacific researchers to develop new methodologies and alternative paradigms of knowledge that are appropriate for empowering Pacific peoples has been widely acknowledged. Consequently, there has been a range of methodologies unique to the Pacific Islands that have developed over recent years (Tuhiwai Smith, 1999; Sanga, 2000; Nabobo Baba, 2004).

Thaman (1992) developed the Kakala research framework, specific to research in the Tongan context. This metaphor compares the making of kakala (garland of flowers) to the research process, reflecting on the entire process that requires considerable skill and knowledge. Thaman (1992) emphasises that consideration of all aspects of the process are important, starting from the selection of the right materials (which flowers, which people and why?) right down to the gifting of the kakala. The methodological framework is a six-tier approach that includes;

Teu - Conceptualisation: Perceptions, beliefs and philosophies

Toli - Data collection methodologies (Talanoa and Nofo)

Tui - Analysis

Luva - Reporting and outcomes

Malie - Relevancy and worthwhileness

Mafana - Application, transformation and sustainability

Within this framework tools such as Talanoa are utilised. Talanoa means 'discussion' or 'talk' and refers to the broad exchange of ideas 'without a rigid framework' (Vaioleti, 2006:23). Talanoa is maintained to be the culturally appropriate tool to investigate Pacific people's way of life. It is subjective, mostly verbal and cooperative and as Vaioleti (2006) suggests, it can go beyond the rigid institutional control of traditional interviewing techniques. Halapua (2001:1) argues it opens up the space for in-depth, critical dialogue and "helps build better understanding and cooperation within and across our human relationships". Alongside the culturally appropriate methodological tools, Fua (2009) outlines the key principles and values that are critical to researching in Tonga. This includes faka'apa'apa, meaning respect; fototo, for humility and generosity and feveitokai'aki for reciprocity, cooperation, consensus, maintenance of good relationships (Fua, 2009:207). 
Throughout the research process these principles informed my research practice as I engaged with local government officials and listened to their experiences and understandings of development practice.

Pacific researchers have called for research that promotes a philosophy of reciprocity and care, a process that seeks cooperation, respect and humility. Acknowledging that I was an 'outsider' entering a reality that was not my own while working with participants who viewed the world differently and operated in different paradigms, challenged me to reflect on my own position. It meant I had to be extremely mindful and considerate of how the participants' voices were included and expressed in my research. I felt it was vital to incorporate Tongan research ethics and Tongan-based research tools throughout the entire research process. I did not want to further "expose the researched to greater risk" that might be more "intrusive and potentially more exploitative" than of benefit (England, 1994:249). Below I will discuss my philosophical approach and how this influenced my decisions made in the field.

\subsection{Research Design}

To understand how this research was conceived of and carried out it is important to discuss 'ways-of-knowing'. There is a range of paradigms identified within social research that locates the observer in the world and reflects the underlying assumptions of the researcher (Denzin and Lincoln, 1994). The underlying theoretical framework in this study is based on the interpretive paradigm. The interpretive paradigm supports the idea that reality is constructed by 'subjective perception'. As we cannot separate ourselves from what we know, it is assumed that values and beliefs are inherent in all phases of the research process (Bryman, 2004). It is the historical, social, cultural and political experiences that socially construct our reality, it filters what we see, what we hear and how we act (ibid:2004).

The methods employed within the interpretive paradigm ensure that there is adequate dialogue between the researcher and the researched, collaboratively constructing a meaningful reality. Through the use of interpretive inquiry, it is argued that we can move "beyond our present understanding of a given topic to some new, more generative understanding ... It combines our own experiences with the inquiry process to produce 
valuable new interpretations ... It should raise new possibilities, open up new questions, and stimulate new dialogue" (Angen, 2000:389).

This research is interpretive as it collected in-depth responses from a select few, reflecting on the experiences of both Government of Tonga officials and development partners as they interact and coordinate with one another. This research allowed government officials and development partner representatives to identify their own experiences and to express their own reality in the context of the new aid agenda. It is hoped that the findings will present a shared reality that may have resonance for other Pacific Island countries operating with similar circumstances or environments.

\subsubsection{Qualitative Research}

This study approached the aim to 'investigate the influence of the aid effectiveness agenda on Tongan development policy and practice' from a qualitative perspective. That is, emphasis was not on quantitative accounts of frequency, dollar amounts or verifiable facts that have scientific value. Rather, this study seeks to answer how government officials explore, interpret and make sense of the social world (Bryman, 2004).

As Brockington and Sullivan (2003) illustrate, qualitative methods go beyond statistics and numbers to consider the meanings of the findings. It allows the researcher to emerge into the world of the researched and problematise the data collected. It not only brings researchers into contact with the researched, it advocates closeness between them as it "seeks to understand the world through interacting with, empathising with and interpreting the actions and perceptions of its actors" (ibid:57). This research will also draw on ethnographic principles as Bryman and Bell (2003:315) highlight, it will be 'intense' researcher involvement in the day-to-day running of an organisation.

Qualitative methods include a variety of techniques such as participant observation, oral histories, group discussion, discourse and textual analysis and interviewing (Bryman, 2004; Brockington and Sullivan, 2003). It aims to place the researcher in the world of the 'other', allowing the researcher to understand the views, behaviours and culture behind the social actors. Qualitative methods therefore tend to work inductively, generating theory from observations rather than testing it. 
The primary means of data collection for this study was semi-structured interviews, with the addition of quantitative data to further illustrate the findings. Participant observation was also conducted whilst working at TERM. I had established a direct relationship with the staff at TERM, and I was able to interact with them and participate in their everyday activities. This included going to prayer group every Monday. Using the aims of observation outlined by Bryman (2004), participant observation allowed me to gain a richer understanding of what was occurring on the ground level. It allowed me to view the interactions between government officials and development partners on a daily basis and allowed me to place the data collected in the wider social context. Although no strict observation schedule was followed, notes were recorded in a journal that allowed me to reflect upon the experiences and interactions after fieldwork.

\subsubsection{Case Study Approach}

The case country for this research is Tonga. This is combined with a single case study of the Tonga Energy Road Map (TERM). Case study methodology provides an opportunity to produce a deep understanding and explanation of social phenomenon and can produce reliable, theoretical descriptions (Bradshaw and Stratford, 2010). Yin (2009) identifies the various reasons where single case study research is justifiable. These are:

- When it is a critical test of existing theory

- When it is a rare or unique circumstance

- Where it is representative or a typical case or

- Where the case serves a revelatory or longitudinal purpose (ibid: 46-52)

The TERM is relevant to each of Yin's (2009) explanations as to why case study research is valid and there are several reasons why TERM is considered a suitable case study in this research. As illustrated in Chapter one, the TERM is a sector wide approach and takes a longterm vision for the development of Tonga's energy sector. A case study analysis will highlight sector level as well as project level interactions between development partners and the government, highlighting how this plays out on a daily basis. Although it is Cabinet that sets the overall policy for the Government of Tonga, each sector is generally responsible for the development of policies that govern the sector. It is therefore relevant to see how the principles in the Paris Declaration play out at the sector level. 
TERM has been applauded by the International Development Community, referred to as "a strong practical example of the application of the Cairns Compact principle to development in Tonga" (PFIS, 2010). Or as Martin Hiller, the Director General of Renewable Energy and Energy Efficiency Partnership (REEEP) stated, TERM could be viewed as a "blueprint for other Pacific Island states that are grappling with similar challenges" (GoT, 2012a). Therefore, conclusions that are drawn from this study may be appropriate for other developing countries wishing to embark on a similar plan or shifting their approach to development towards sector wide initiatives.

However, one big criticism of case study research is the lack of generalisability, as Campbell and Stanley (1966:6) vehemently state "such studies have such a total absence of control as to be of almost no scientific value... intrinsic knowledge about singular isolated objects, is found to be illusory upon analysis". However, Baxter (2010) suggests that although case studies may not be generalisable or transferable in the statistical sense, they are in the analytical sense. People in similar situations are able to make inferences about how similar themes or issues may apply in their own context (Bradshaw and Stratford 2010). George and Bennett (2004) also support the value of case study research finding that most successful studies have generally worked with a clear and precise scope of the general phenomenon.

Bryman (2004) argues that case studies provide the context suitable to make inferences about wider processes and patterns. As Baxter (2010) argues, case studies can be used to prove, disprove, generate or explain theoretical concepts. Yin (2009) also emphasises that case study research allows the researcher to make suppositions relating to policy and theory.

\subsubsection{Semi-Structured Interviews}

Each participant was interviewed using semi-structured interviews, which was recorded using a dictaphone. A semi-structured interview process allowed me to do two things. Firstly, it allowed me to remain consistent with the research questions I was asking each group (government officials and donor respondents), enabling me to compare and contrast answers from the different participants and see if there was agreement or disagreement on certain issues. Secondly, it gave me the flexibility to explore any interesting responses or examples that participants gave. In addition, it allowed me to ask individualised questions specific to 
the role and/or organisation of the participant. For example, I had some specific questions surrounding the individual partnership agreements between the donor partner and the Government of Tonga.

Open-ended questions also allowed the space for participants to elaborate on any other issues they faced. This linked closely with the 'Talanoa approach' discussed above. In-depth semistructured interviews were conducted with; six Government of Tonga officials, five donor partner representatives and two development consultants who were contracted through various development agencies to work on specific projects within the TERM. My previous role working at the PMO meant that I was known to some of the participants and I was able to use them as 'gatekeepers', where they suggested other key individuals for me to interview (Murray and Overton, 2003). I interviewed the participants across a three month period from September to December 2011 however, following my field research, I was also granted an interview with former Prime Minister, Feleti Sevele.

My semi-structured interview questions for government officials and donor partner representatives followed a separate but similar themed interview schedule (see Appendix 1). Interviews with the development consultants loosely followed similar themes from these schedules, however some additional questions on their history, opinions on the effectiveness of foreign aid and perspectives on the workings of TERM were included. This allowed me to gain contextual information around some of the wider issues in development as these consultants had worked in the field for over 20 years. Each interview took place within a 3045 minute time frame, however, some participants were interviewed across two or three different occasions. Keeping my interviews succinct and to the point was essential, I did not want to be adding to their heavy workload.

\subsection{Ethical Considerations}

This research is based on the premise that ethical research runs much deeper than signing of the consent form (Scheyvens and Storey, 2003). Ethical research has been criticised as a 'tick the box' exercise, meaning nothing more than a negotiation of "strict codes of institutional paperwork" (Sultana, 2007:376). However, I believe it is only logical that the research ethics reflects the context and culture upon which we do research, as Hopkins (2007:387) suggests, 
the researcher must consider "what they are doing and how they are doing it, as well as thinking about who they are".

Although I followed the appropriate Victoria University Human Ethics Committee protocol, gaining signed consent from all participants (see Appendix 2) this was not the appropriate cultural means of gaining consent. I found that participants would instantly tense up as I asked for their written approval demonstrated by one participant nervously commenting 'so will this end up in the papers?' As Fonua (2004) highlights with research in Tonga, signing a consent form can be 'alienating' to the participant and it can also mean that you doubt what the participant is saying. This is particularly the case when speaking with elders or chiefs, where the act of asking them to sign can be viewed as an outright insult (ibid:2004).

Fonua (2004) suggests that face-to-face interaction is the best way of gaining consent in Tonga and this is what I did. Before each participant was given the consent form, I explained the nature of my research project and that they were able to withdraw themselves and any information provided up until the date of publication. This consent form also outlined two options for the participant, to be named in the research with attributable quotes, or, not to be personally identified. Although many of the participants agreed to be personally identified, upon returning from the field I decided that it could be counter productive to my research. I did not want to jeopardize relationships between government officials and development actors in the region and therefore referenced the responses. Although two central respondents have given permission and are named in this thesis, each government official has been referenced as G1, G2, G3 or G4 (one government official interviewed was a technical assistant placed within government and was funded by a donor); each development partner is referenced as D1, D2, D3, or D4 and; the two development consultants are coded as C1 and $\mathrm{C} 2$.

Reflecting on my positionality challenged me to identify what I was hoping to achieve and what the respondents would gain from my research. Researching in a foreign country can be testing, as Leslie and Storey (2003:119) warn, a novice researcher "may be paralysed with... [a] kind of fear, self doubt and uncertainty”. Although I did not experience any of the above, I did not have concerns about my ability to truly represent the experiences of the respondents. As I was an 'outsider', I was apprehensive about my ability to correctly understand the political and cultural realities. 
As Stacey (1991) warns, researchers have the ability to manipulate the responses of the researched through "intrusion of privacy, breaking confidentiality, [and] lack of interpretative space" (cited in Thapar-Björkert and Henry, 2004:364). Or as Tuhiwai Smith (1999:176) states, researchers "have the power to distort, to make invisible, to overlook, to exaggerate and to draw conclusions based not on factual data, but on assumptions, hidden value judgments".

Added to these concerns was the fact I was researching and working at the same Implementation Unit. I queried the ethical dilemmas behind the splitting of my roles and in order to overcome the potential shortfalls, I ensured that there was a clear distinction between materials given to me for work related purposes versus research related purposes. I confirmed with each respondent that any material received had the appropriate consent to use within this research. I did not want to undermine the Pacific knowledge and experience that was so generously communicated to me and as Tolich and Davidson (1999:73) express, "never harm the people involved in your study". This philosophy underlined the entire research process.

\subsection{Summary and Link}

In this chapter I have situated myself within this research and reflected on the challenges of holding multiple roles in an environment that is not my own. I have examined Tongan research methods and principles that have been considered and incorporated throughout the research process. As a researcher one must maintain awareness of the culturally appropriate ways of doing research and my methodology has remained consistent with conducting research in the Tongan cultural context. The following chapter will briefly outline the history of development aid and thinking and highlight the theoretical background relevant to this research. In doing so, I will highlight the international commitments such as the Paris Declaration that currently shape the aid effectiveness agenda. 


\section{Chapter Three: Development, Participation and Effective Aid}

\subsection{Introduction}

The aid landscape has transformed and reinvented itself multiple times. In order to understand the influences upon aid policy and practice in Tonga, this study must reflect on the theoretical context and the history of how current forms of development unfolded. This chapter begins with a brief outline of the history of foreign aid identifying the various shifts in development thinking. An emphasis will be placed on 'participatory' forms of development that have evolved out of the 1990s. This chapter will also detail the consequent criticisms since the adoption of this concept into mainstream development policy and practice.

The following section of this chapter will outline the shifting focus and priorities of development actors as they work towards enhancing the overall effectiveness of aid. This approach has been reinforced by international agreements such as the Paris Declaration of 2005 on Aid Effectiveness (OECD, 2008). This declaration sits at the core of the international consensus that emphasises greater recipient control and ownership of development policies is needed. The final section of the chapter will present an analysis of the Paris Declaration principles and the implications of the aid effectiveness agenda on development practice and policy.

\subsection{History of Development and Aid Thinking}

The first successful modern foreign aid initiative was witnessed following the Second World War, with the implementation of the Marshall Plan in Western Europe. The US provided \$13 billion in economic and technical assistance to assist in post war recovery. Western Europe's economy took off with unprecedented growth giving credence to the idea that "planned intervention, if rationally conceived and scientifically managed, could stimulate rapid development” (Brohman, 1996:10).

Post-war assistance and reconstruction led to the establishment of various organisations and aid institutions. For example, the United Nations was established alongside international financial institutions such as the International Bank for Reconstruction and Development 
(IBRD or World Bank) and the International Monetary Fund (IMF). There were also a number of private charities set up such as the Oxford Committee for Famine Relief (OXFAM) (Browne, 2006). These institutions placed the foundations of the 'new aid infrastructure' that shaped development actions and programmes (ibid:2006). Relationships were established and links formalised between donors, aid agencies and aid recipient countries (Pronk, 2004).

Aid practice and theory were heavily influenced by modernisation theory with the view that 'under developed' countries could be modernised with the assistance of those more 'developed' (Brohman, 1996). Modernisation theorists argued that with the introduction of capital, globalisation and technological advancement, countries would "modernise their economy and poverty and inequality would be quickly eliminated through... trickle-down" (Tarp, 2010:29). It was maintained that modernisation through capitalist industrialisation provided a general blueprint for any country's development (Brohman, 1996:17).

Despite historical instances of bilateral aid ${ }^{1}$, the Marshall Plan became the model for development assistance (Browne, 2006). Although there was a range of motivations behind giving bilateral assistance, there was a strong emphasis on aid being used to build political bridges (ibid:21). Slater (1993) argued that the development initiative was "a will to geopolitical power. It provided a discursive legitimation for a whole series of practical interventions and penetrations that sought to subordinate and assimilate the Third World Other" (ibid:419).

The actions taken in the development arena had an underlying assumption that the West 'knew what was best' and insinuated that people in developing countries were "passive recipients of state boundary, rather than active consumers with independent tastes and choices" (Browne, 2006:135; Robb, 2004). The self-interests of donors largely drove development agendas, as opposed to developing a real sense of what was required and wanted in the recipient country. As Griffin and Enos (1970:327) suggest, aid "ostensibly given in friendship, seems inevitably to lead to enmity".

\footnotetext{
${ }^{1}$ The US had provided humanitarian assistance since 1812 while the UK had also provided assistance to their colonies (see Browne, 2006:151).
} 
Throughout the 1970s, development objectives focused on poverty alleviation, income distribution and employment. It targeted methods to support poverty alleviation rather than previous top-down methods of aid delivery as questions emerged surrounding the effectiveness of the 'trickle down' approach (Tarp, 2010; Brohman, 1996). The motivations and intentions of giving aid were also queried as aid could be viewed as "an instrument of power politics. How much a country lends to another country will not be determined by its need, or its potential, or its past economic performance, good or bad, or its virtue, but by the benefit it yields in terms of political support ... is a way of safe-guarding relationships with their client states, of maintaining the status quo" (Griffin and Enos, 1970:316). Browne (2006) also argued that aid could be used as a form of patronage, serving only the interests of its donors rather than the recipient.

The first oil crisis in 1973 had a devastating impact on developing countries, creating excessive oil prices, import compression and a decline in export opportunities. This prompted commercial banks to increase lending to developing countries in order to maintain a balance of payments (Tarp, 2010). Donors also increased their level of assistance and broadened their focus to include basic essentials such as food and water, recognising that sole economic support was not enough (Rob, 2004).

The impact of the second oil shock in 1979 further deepened the balance of payments issue developing countries were facing and sparked an international debt crisis that was experienced worldwide (Brohman, 1996). Developing countries appealed to Western governments, commercial lenders and other development actors for their support. The relationship between donors and recipients shifted as poverty alleviation slipped in to the background and a 'rolling back of the state' shaped development efforts in 1980s. A change in Government in the United States and the United Kingdom also facilitated the turn towards neoliberal policy interventions with structural adjustment packages, market and trade liberalisation and the privatisation of public services (Tarp, 2010).

The World Bank initiated its first structural adjustment loan in 1980. From this period onwards, "a new aid phase of macro-economic governance began, in which the policy choices for the poorer developing countries were increasingly prescribed by Washington" (Browne, 2006:33). Although foreign aid continued to increase until the early 1990s, developing countries were becoming increasingly reliant on aid and growing scepticism 
around the efficacy of aid loomed. The various conditionalities that were placed on foreign aid funds were failing to produce the policy reforms needed for economic growth. The impacts were widespread and many Pacific Island Countries suffered the effects (Stanley, 2004; Storey, Bulloch and Overton, 2005).

As illustrated above, early post-war models of development did not include people as active participants in the global economy but as 'objects' that contributed "in the form of labour, cash or kind" (Nelson and Wright, 1995:2-3). Browne (2006) summarises the history of development in three phases; the "do-as-we-did" phase, where development was shaped through top-down forms of aid; the basic needs and bottom up paradigm phase and; the current phase, "do-as-we-say" with "new institutional agenda of good governance and respect for human rights" (Browne, 2006: 24).

What has become clear after 2.3 trillion dollars of aid and three decades of aid assistance is that foreign aid had not translated into significant improvements for aid beneficiaries (Easterly, 2006). Although some regions have greatly benefited from aid assistance overall, development assistance has failed to pull those in poverty into prosperity. The inability of theorists, policy makers, economists and other development actors to offer viable solutions for the increasing problems of developing countries is still an issue that needs to be tackled. While the debate remains among development circles, the search for alternatives continues.

One argument that gained momentum was the need for people to be included in their own development process, defining their own development agenda or as ul Haq noted "build development around the people rather than people around the development" (cited in Brohman, 1997:203; Nelson and Wright, 1997). This presented an approach where alternative 'bottom up' models were explored and a call for more people-orientated development began.

\subsection{The Rise of Participatory Development}

Participatory development influenced development thinking and policy throughout the 1990s, with the underpinning view that development would be more effective with the beneficiaries' involvement (Cooke and Kothari, 2001). Chambers identified this as shift from "the paradigm of things" to "the paradigm of people" (Chambers, 1995:33). The notion of people 
centred development with the various participatory methods has split into many different approaches and angles and what counts as 'participation' markedly differs across the board.

Participation was defined by the World Bank (1994) as, "a process through which stakeholders influence and share control over development initiatives, decisions and resources which affect them" (cited in Brohman, 1996:251). However, the concept of 'participation' created confusion as there was no consensus when defining the term or how it was to be implemented (Kakande, 2004). As Brohman (1996:251) outlines, there is no consensus as to "who participates, what they participate in, how they participate and for what reasons they participate"

Oakley and Marsden (1984) suggested that participation could be placed on a continuum, where on one end aid beneficiaries are simply impassive participants and on the other end they are actively in control over the process (cited in Brohman, 1996; Nelson and Wright, 1995). Chambers further illustrated this point defining three ways the term participation could be used; as a cosmetic label, to give the impression donor agencies and governments are using the method but their behaviour does not change; as co-opting practice, to take advantage of local resources but essentially the project is still in the hands of 'outsiders' and thirdly; as an empowering process, where local people are making their own decisions and actively involved in their development (Chambers, 1995:30). The movement along the continuum from passive participants to active participants reflects a change in the power from the hands of the outsider to the beneficiary.

Pretty (1995:1252) also provides a similar analysis of participation varying from manipulative participation, where it is there simply as 'pretence', passive participation, where people are just directed on what is going to happen and self-mobilisation, where people participate independent of outside organisations, changing the systems in place. This hierarchical view of participation illustrates that the more people participate, the more they are empowered. However, Hayward, Simpson and Wood (2004) believe the analysis of participation is not as simple or straightforward as this, illustrating that choosing not to participate can also be an act of empowerment. 


\subsection{Power and Participation}

The concept of power is intrinsic to participation. The use of participation can be utilised as a way of challenging power inequalities from the bottom up or putting the last first as Chambers (2004) illustrates (cited in Williams, 2004). Chambers advocates "for the realities of lowers to count more, and for the new high ground to prevail, it is uppers who have to change" (ibid:560). However, inherent in development agencies are hierarchy and power relations that are designed for control and upward accountability, not the use of participation (Chambers and Pettit, 2004:139). Cornwall (2008) also argues that participation can support the uppers' interests and fails to understand the real cause of the disadvantages in the aid relationship. Despite the relationship between the donor and the recipient being termed as a 'partnership,' the donor has the upper hand as they have control over the financial resources and very rarely do donors "share mutual responsibility for [the development] outcomes" (Shutt, 2006:154). This highlights an important question of who donors are ultimately accountable to. How are donors able to share responsibility or take account for development outcomes when fundamentally they are responsible to their own taxpayer (or stakeholder), not the people receiving the development assistance.

Mosse (2001) argues that participation can be limited by institutional structures that seek to control the development outcomes. "Participation is a political value to which institutions will sign up for different reasons. But it remains a way of talking about rather than doing things" (ibid:32). It is also questioned how balanced relationships can develop when they begin from such unequal power relations (Kakande, 2004:88). Chandler (2007) suggests that Western governments find it difficult to legitimise and justify the power exerted over nonWestern states, and in response, they have shifted towards more informal relations of regulation. Yet, Chandler (2007:180) emphasises that this has only blurred the relationship boundaries between recipients and donors, allowing for greater interference by Western states while at the same time, shifting the responsibility for policy outcomes to the recipient.

Regardless of whether development institutions acknowledge it or chose to ignore it, power is inherently linked within the aid relationship. Eyben (2010b) argues that it can manifest itself in multiple ways, shaping and influencing development policy and practice. Eyben (2010b) breaks down three dimensions of power that include: 
- Visible power, through formal institutional arrangements for policy making and implementation;

- Informal power, which shapes the policy agenda 'behind the façade' and;

- Invisible power, which works through people's internalisation of norms and beliefs and invisibly shapes policy choices (ibid:7).

Donors will often only address the first form of power but fail to address the later two forms of power. Despite the rhetoric of an 'equal partnership' between recipients and donors, if development institutions do not address all forms of power then they maintain the ability to influence and steer development policy and practice in recipient countries. As Lamour (2002:259) suggests, donors do not want to control the development agenda, but they will try to influence it, "donors want recipients to want what donors want".

Further literature suggests that aid agencies, whilst under the guise of participation, use it as more of a tick the box exercise, used in fashionable tokenism rather than a true push to empower communities (Cooke and Kothari, 2001; Chambers and Pettit, 2004). The language and buzzwords that evolved out of the participatory paradigm such as 'empowerment, ownership, partnership and participation' although implying a change in power and relationships, has not been matched in practice and this allows development agencies to continue with the 'same as usual practices' (Chambers and Pettit, 2004:137). Chandler (2007) suggests that while increased participation and consultation was originally a movement geared towards challenging the powerful elites, he argues that today, it is the Western states and international financial institutions that are leading the demand for participation. Chandler (2007:178) argues that this shift comes from "external institutions seeking to legitimise their technocratic agendas ethically informed by the focus on those socially and economically excluded".

\subsection{The Aid Effectiveness Agenda}

The aid industry shifted away from the neoliberal agendas by the late 1990s and a new international consensus emerged. It became evident that the lack of collaboration between donors posed a serious challenge for recipient governments to implement their own development agendas (Kakande, 2004). Donor coordination and country ownership sat at the 
core of this new paradigm, translating into policies and various aid delivery mechanisms that are argued to increase the effectiveness of aid.

There was also an emphasis placed on understanding what worked and in what environment, hoping to reduce donors' duplicated efforts and the wastefulness of previous development work (Cooke and Kothari, 2001). There was newfound optimism among the international development community that foreign aid does result in economic growth, and is good for poverty reduction (Burnside and Dollar, 1997). This created a shift away from the premise that 'aid had failed' and searched for alternatives to make aid work better (McGillivray, 2005).

The Millennium Development Goals (MDGs) adopted by the United Nations General Assembly in the year 2000 set the foundations for change (UN, 2000). With 147 heads of State, representing 189 countries, the Millennium Declaration was adopted placing poverty reduction at the forefront. The MDGs consist of eight development goals with targets and indicators to be met by 2015 (ibid:2000). The MDGs set targets that allow recipient countries to make comparisons against other developing countries. Although many of the targets are unlikely to be met by 2015, this declaration set a new precedent among development actors. Firstly, the total amount of aid would increase and secondly, a renewed focus would be placed on improving the welfare of the world's poorest. The MDGs have been adopted in the Pacific and have become a key focus for development work ${ }^{2}$ (Naidu and Wood, 2008).

Following the MDGs was the High-Level Forum on Harmonisation in Rome 2003. This forum reinforced the importance of meeting the MDGs and pledged to "harmonise the operational policies, procedures, and practices of our institutions with those of partner country systems to improve the effectiveness of development assistance" (OECD, 2003:10). In another effort to strengthen and reinforce these commitments came the Paris Declaration, endorsed on the 2nd of March 2005. The Paris Declaration solidified the premise that aid agencies had to do a better job of working together and this document has become the core foundation of the aid effectiveness agenda.

\footnotetext{
${ }^{2}$ For a critique of the Millennium Development Goals see Saith, 2006; Clemens, Kenny and Moss, 2007 and for a critique specific to the Pacific Islands see Naidu and Wood, 2008.
} 
Ministers, Heads of Agencies, Senior Officers and key development actors signed the declaration, promising to change the way aid was to be delivered and managed and committed to coordinating and harmonising future development efforts. The idea of harmonising and aligning aid was to reduce duplication and transaction costs for aid recipient countries, allowing them to work through a unified aid system. Eight Pacific Island Countries signed, including all development agencies working in the region. In 2007, the declaration was further reinforced with the 'Pacific Aid Effectiveness Principles', which will be further discussed in the following chapter (PFIS, 2007).

The declaration placed a strong emphasis on national governments being in the driver's seat, "supporting partner country efforts to strengthen governance and improve development performance" and allowing recipient governments to direct and determine how funds are spent, managed and prioritised (OECD, 2008:4). The declaration outlined five key principles (listed below) to steer development efforts. The principles were to be measured across twelve indicators with the first targets set to be achieved by 2010 .

- Ownership - Donors must support partner countries in the development of their own policies, strategies and development objectives

- Alignment - Donors must align their policies and systems to those of the partner country

- Harmonisation - Donors actions are to be harmonised with one another in order to increase the efficiency of the aid effort

- Managing for Results - Improve accountability and implement aid with a focus on desired results to inform better decision-making

- Mutual Accountability - All donors and partners are accountable for development results

The Accra Agenda for Action signed in 2008 further reinforced the commitment of development agencies to achieve these goals and make aid more effective for recipient countries. The adoption of these principles has received both praise and criticism. While some progress has been made, it is argued that previous "promises made by donor countries in Monterrey and Rome have failed to concretise ... as donor countries struggle to turn their 
commitment to improved aid practices and into concrete behavioural changes at international and country level" (de Renzio, 2005:21).

\subsection{A Critique of the Paris Declaration}

Armon (2007) claims that the Paris agenda is vague and unclear and has failed to outline the instruments appropriate to reach such goals, or the particular context in which they apply. Faust (2010) argues that the principles are over simplified and ignore the politics and power relations involved within the aid relationship. As Dijkstra (2011:130) also raises this concern, "this donor-induced neglect of politics is not only leading to limited aid effectiveness, it is also harmful".

There is no dispute over the good intentions that back this push for more effective aid, however, the resulting outcomes for recipient countries beg the question of whether donor agencies are truly able to institute and promote this change. It is argued that internal and external pressures within the aid organisations will constrain the coalition for change (van de Walle, 2005). Murray and Overton (2011b) call into question whether the aid effectiveness agenda, characterised by principles of ownership, alignment and harmonisation, are creating the reverse effect of what it intended to achieve, further diminishing development policy sovereignty of recipient countries. Murray and Overton (2011b) argue that it is neostructuralism that informs the aid effectiveness agenda and that this shift is just an extension of the neoliberal orthodoxy. Although various policies have changed, the goal remains the same, free market capitalism (ibid:2011b).

The new aid regime has fundamentally restructured the role of the state and placed large amounts of pressure on the proficiency of aid spending without determining the effectiveness of the development outcomes (Action Aid, 2008). Murray and Overton (2011a:316) argue that the new aid regime has pushed the administrative and management systems of recipient countries to resemble that of their donors and ultimately, "recreated the state in the image of the West". It is suggested that despite the rhetoric of the aid effectiveness agenda, relations of power and dependence are essentially deepened in favour of the donor (ibid:316). This critique sits at the core of this thesis as we explore the extent to which the Paris Declaration principles (a central component of the aid effectiveness agenda) have been applied to development practice and policy in Tonga. 


\subsubsection{The Principle of Ownership}

The principle of ownership urges recipient governments to take ownership of development policies in the form of exercising control over the design, implementation and monitoring of development projects and programmes (OECD, 2008). The principle of 'ownership' is measured under the Paris Declaration by a country's operational development strategy and is defined by the partner country's ability to "exercise effective leadership over their development policies, and strategies and coordinate development actions" whilst donors "respect partner country leadership" and "strengthen their capacity to exercise it" (OECD, 2008:3). It is argued that without it, aid cannot be effective in reducing poverty and promoting sustainable economic development (ibid:1).

To date, there has been no consensus as to what the country has ownership of, and for what. There is also controversy over defining a set of numerical indicators to measure ownership as this is argued to miss the complex and diverse dynamics within aid relationships (Whitfield and Maipose, 2008:2). The paradoxes that surround the principle of ownership are manifold as it promises to give control and responsibility to the recipient in the face of financial dependence. Ownership can also be argued as something inherently internal, not something that can be constructed and given from the outside (Sobhan, 2004). "The driver of the car may well be the owner, but who decides where to go? Who made the road map? How does one recognise strong recipient ownership when it is there?" (Jerve and Hansen, 2008:8).

It is difficult to ignore the contradictory nature of the concept, which Eyben and Ladbury (1995:195) define as the 'paradox of aid agencies' where donors "exert influence while desiring to build up local self-capacity and participation". Winckler and Therkildsen (2007) argue that it is challenging to operationalise the concept of ownership as it is based on a number of assumptions. It assumes that the recipient governments political objectives are at the forefront and are reflective and representative of all local stakeholders. It also implies there is a sufficient level of institutional capacity within the recipient government in order to plan and implement their priorities and decisions. The lack of information as to how aid will influence the recipient countries ownership also raises some concerns. Is this concept just another façade that allows donors to intrude further, or is it simply a disclaimer to pass over responsibility so that any blame of failing to develop will then sit with recipient countries? 
(Collins, 2011). It is argued that development practice still continues to face trade offs between donor control and 'quick wins' in place of 'lasting long term solutions' (Lomoy, 2010). Is it 'a term whose time has gone?' (Buiter, 2007).

\subsubsection{The Principle of Alignment and Harmonisation}

The principle of alignment is measured by the reliability and total use of public financial management and procurement systems; the alignment of aid flows to national priorities and; the percentage of untied aid (OECD, 2008). In general, the principle of alignment aims to decrease the amount of duplication and fragmentation of aid. In order to achieve this a decentralised aid system and a shift in aid delivery mechanisms is also required, for example, General Budget Support (GBS). The principle of alignment represents a breakaway from the 'one-size-fits all' mentality as there are now differentiations based on the recipients capabilities, priorities and needs (ibid:2008). However, this principle is argued to focus donors and recipient governments on the process rather than what they are trying to achieve, averting attention to the indicator, rather than the resulting impacts. As Curtis and Poon (2009) suggest, it is easy to define the desired end goal, but far from easy to identify how to achieve it. The application of the alignment principle has resulted in mixed outcomes. While there has been an increase in mechanisms such as GBS and Sector Wide Approaches (SWAps), it is argued that donors still want to participate and be involved in every decision. As long as this continues, the transaction costs for recipient countries will remain high (Winckler and Therkildsen, 2007).

The principle of harmonisation is measured through the use of programme-based-approaches (PBAs) and the extent to which donors and recipient countries conduct joint missions and analytical work. This principle has been critiqued as being a vehicle for donors to 'gang up' on recipient countries as they present their case with a united front, limiting the political space of the recipient government. Eyben elaborates, "donors used to meet behind closed doors to agree what we were going to play before going to the official co-ordination meeting," highlighting that the principle of harmonisation becomes a vice to "strengthen long-standing donor habits of pretending that poverty is not political” (Eyben, 2007:642643). Winckler and Therkildsen (2007) suggest that although donors may participate in the rhetoric of harmonisation and participation, in reality, donors still maintain control as they want to be involved and have a say in every development decision. 
The varied progress of the harmonisation and alignment principles is a major issue for recipient countries who now face an increasing number of development actors and an increasing level of development assistance. Each development actor comes to the region with their own procedures, practices, policies and interests and very rarely do they align or harmonise with one another or to the recipient country. It generates an assorted 'web' of rigid and complex donor systems taxing the scarce capacity of local staff (Eyben, 2006).

The final two principles of mutual accountability and managing for results tend to be overshadowed by the other principles within the aid effectiveness debate labelled the 'orphans of aid effectiveness' (Egan, 2008). It is argued that the reason why these principles have been largely ignored is because this is where the commitments 'bite' ${ }^{3}$. However, in order to limit the scope of this research a similar trend has been followed. This thesis will be focusing on the ownership, alignment and harmonisation principles.

One of the major concerns regarding the Paris Declaration of 2005 is the lack of reference to the political and power dimensions of aid. Development partners "are part of a political process in which the issues of development and politics are closely interwoven" (Hyden, 2008:260). Hyden (2008) argues that there needs to be a closer and more open dialogue to establish a more trusting, collaborative partnership. Eyben (2007) argues that if power and politics continue to be ignored then donors will perpetuate the institutions that keep people poor. Eyben (2010) also believes that the aid effectiveness agenda has placed increased pressure and control over recipients, as development partners seek greater influence in trying to ensure that every dollar spent is spent effectively. As Bergameschi (2007:13) argues, donors ultimately want someone answering the phones and following up for them on the ground, "not an administration that would be efficient for and accountable to the population".

All major development partners have readily adopted the Paris Declaration, however, at present the spirit and goals of the Paris Declaration are far from being achieved (de Renzio, Whitfield and Bergamaschi, 2008:1). The Danish International Development Agency concluded that the biggest challenge facing the Paris Declaration is to ensure the end result is

\footnotetext{
${ }^{3}$ For further analysis on these two principles see; Hammer and Whitty (2011); Egan (2008); Eyben (2008); Dunkly (2007).
} 
the goal, not the principles themselves (DANIDA, 2006). Collins (2009:182) suggests that we need to "pay better attention to the relationship between aid effectiveness policy and its relevance, interpretation, and implementation on the ground". Donors are now focusing on the processes and mechanisms of delivering aid, without looking at the impact these changes have on recipient countries. As Hyden (2008:273) concludes "donor partners are no longer the 'solution' but also part of the problem".

\subsubsection{A Change in Aid Delivery Mechanisms}

Alongside this call for 'good practice' a change in aid delivery mechanisms has also been initiated. As national governments increased in capacity, donors were able to increase the total amount of Official Development Assistance (ODA) and assign more responsibility. This required a strengthening of management and administrative systems and facilitated a shift from project and programme aid to SWAps. SWAps involve the financing of a specific sector and generally deliver aid under sectoral investment plans through budget support. GBS is based on an agreed set of performance indicators, such as institutional or policy reform, and allows recipient governments to receive block annual grants, enabling them to guide their own development strategy (ibid:2006). It is anticipated that as recipient countries go through a series of checks and balances, ultimately they will reach GBS (van Reesch, 2006; Koeberle and Stravreski, 2006).

This shift in aid delivery mechanisms has resulted in a greater emphasis being placed on capacity building particularly around financial management and procurement systems of recipient countries. Correspondingly, there has been an emphasis placed on 'good governance' with guiding principles of 'accountability' and transparency' that are required by donors to have confidence in use of recipient countries' systems (Tarp, 2010). Recipient countries have placed a big emphasis on revamping and improving their aid management systems (public financial management and procurement) in order to meet the standards and requirements of donors. The reliability of such systems, and the use of them by donors are used as an indicator for the principle of alignment under the Paris Declaration as illustrated above.

Murray and Overton (2011a:316) suggest that these particular shifts and demands can place a heavy burden on national governments that "do not have the expertise or resources to 
implement or operate such systems". It can weaken the development policy sovereignty that such principles were intended to create (ibid:2011a). Capacity constraints are still a major barrier for recipient countries and although development actors are great at pointing out what should be achieved, there is very little information on the process to get there (Curtis and Poon, 2009; Therkildsen, 2005). Therkildsen (2005:30) illustrates that the "causes of poor organisational capacity, and the relevant remedies, depend on many factors both inside and outside organisations, and that these are not just technical and financial but also relate to power and politics," two concepts which are largely ignored within development policy and practice.

Jerve and Hansen (2008) suggest that it is this power and politics that come into play as recipient countries try to shape their systems to meet the requirements of donor partners. There is pressure on recipient governments to fit to the systems of the West, despite the major shift in donor rhetoric with the declared 'new aid architecture' to "respect partner country leadership and strengthen their capacity to exercise it" (ibid:5). Major donors still influence, shape and steer development practice as they walk a fine line balancing between minimising financial risk while using recipient country systems and promoting country ownership. Inherently passing over responsibility and power to the recipient. As Brinkerhoff (1996:1399) states, "the priorities donor agencies advocate, the pressures they exert, the procedures they follow and the resources they command significantly shape the 'what, who and how' patterns of policy implementation". But what if "the things that make for good policy are quite different from those that make it implementable?" (Mosse, 2004:640). This can lead to a dichotomy between what donors say, what they actually do, and what they realistically can do (Easterly, 2008). There is a lot of emphasis placed on following 'correct' and 'appropriate' methods of practicing development but not so much emphasis placed on the value of its outcomes. "Between good intentions and effective actions lies an awkward question of means" (Curtis and Poon, 2009:840). It is the 'means' or the process that hampers development institutions effectively creating change, as Curtis and Poon elaborate, "giving freedoms with the right hand and denying them with the left" (ibid:840).

Arguably, the challenges recipient countries face in the context of the new aid agenda were predicted by Little and Clifford in 1965 (reprinted in Little and Clifford, 2006). They believed that recipient countries would be better off working with a single multilateral donor housed in-country, noting that if every development actor was to "impose its own ideas about 
what development policies should be followed, the result would be chaotic" (ibid:201). It would have an adverse effect on development no matter how efficient, well-planned or wellexecuted the recipients' policies are (ibid:200). The current aid environment for many recipient countries is exactly what Little and Clifford predicted, 'chaos'. Each recipient country has multiple development actors working in the region each pushing their own agenda and imposing their own systems and procedures. In the following chapter we will look at specific examples of this in the Pacific.

\subsection{Summary and Link}

This chapter has reflected on the historical and theoretical background that has led to the current aid regime, emerging from modernist theories of development towards more participatory forms of development. However, there is uncertainty whether new reforms have truly been initiated or if it is just repackaging of the old. Engagement with the aid effectiveness agenda allows us to question what is driving this agenda, what the underlying assumptions are and what the resulting impacts and outcomes are for aid recipient countries.

The above international agreements and commitments have been significant in the quest to improve aid effectiveness across the globe, however, their translation into policy and practice is disputed. Are these agreements and commitments truly a step towards more effective aid? Or are terms such as ownership and partnership placed in lukewarm waters, intended to look good on paper but not put to practice? At the core of this research we will be looking at the gaps between theory and practice. What are the impacts of these international commitments and declarations on development practice in Tonga? What are the underlying assumptions that reinforce existing power relationships? What are the responses to this agenda and what are the obstacles the Government of Tonga faces in this new aid environment?

The next chapter will look at the aid effectiveness agenda in context of the Pacific, outlining the regional response to the aid effectiveness agenda. The second half of the chapter will move onto Tonga sketching a picture of its history, geography and political environment. 


\section{Chapter Four: Aid in the Pacific with a focus on Tonga}

\subsection{Introduction}

Chapter three illustrated the different development agendas that have evolved over the past 40 years, highlighting the shift towards aid modalities that emphasise recipient country ownership, alignment of development partner procedures and harmonisation of donor practices, policies and processes. However, the international level commitments and agreements (such as the Paris Declaration of 2005) have been criticised to act counterproductively to what it is trying to achieve (de Renzio, et al., 2008; Murray and Overton, 2011a, 2011b). The fragmented delivery of development partner assistance continues to hamper aid recipient countries' ability to direct and drive their own development goals. Despite the commitment to the international agreements, many argue that minimal progress has been witnessed on the ground (Monye, Ansah and Orakwue, 2010; Eyben, 2010a; Wrighton and Overton, 2012).

The size of many Pacific Island countries can exemplify these issues as each country has limited human and resource capacity, combined with high volumes of aid (Bertram and Watters, 1985; Warrington, 1998). The multitude of different approaches, systems and requirements of each development partner reduces the local government's ability to direct and manage development policies and outcomes (Wrighton, 2010a; Wrighton and Overton, 2012). In order to reflect upon Tonga's intersection with the current aid regime, this chapter will examine the Pacific as a region and their response to the aid effectiveness agenda, followed by an analysis of Tonga itself.

\subsection{Pacific Islands and the Aid Effectiveness Agenda}

The South Pacific Secretariat (SPC), founded in 1947, was set up as an intergovernmental organisation by six participating governments' including: Australia, France, New Zealand, the Netherlands, the United Kingdom and the United States of America (SPC, 2012). SPC was originally established to promote stability in the Pacific Islands following the Second World War. SPC changed its name to the Pacific Community in 1997 to reflect the organisation's Pacific-wide membership, which currently includes 22 Pacific Island countries and territories (ibid, 2012). SPC's mission (stated in their 2007-2012 corporate plan) "is to 
help Pacific Island people position themselves to respond effectively to the challenges they face and make informed decisions about their future and the future they wish to leave for the generations that follow" (SPC, 2008:9).

Following the set up of SPC, the Pacific Islands Forum was established in 1971 (originally called the South Pacific Forum). This Forum has become the central regional development agency for the Pacific. The Pacific Islands Forum is a political grouping of 16 independent countries $^{4}$. The Pacific Island Forum Secretariat (PIFS) is the administrative arm to the Forum and was initially established as a trade bureau in 1972. It is now assigned to "coordinate the implementation of the Pacific Plan for strengthening regional cooperation and integration" (PIFS, 2012).

The overarching mission for the PIFS "is to ensure the effective implementation of the Leaders' decisions for the benefit of the people of the Pacific," with guiding goals to "stimulate economic growth and enhance political governance and security for the region" (PIFS, 2012). This is achieved through the provision of policy advice, the coordination and assistance in implementing the decision of Leaders and supporting the Leaders' meetings, ministerial meetings, and associated committees and working groups (ibid:2012a). The PIFS aims to represent the views of all Pacific Island nations and bring a unified front for the region to the global stage. It has played a pivotal role in promoting the aid effectiveness agenda in the region despite the fact it has been creating awareness around these particular issues since its inception in 1972 (PIFS, 1972).

The importance of aid coordination was first noted at the 1974 communique with the PIFS commissioning a detailed report to review the "wide-ranging issues involving all aspects of the aid relationship". This report was later presented at the 1976 communiqué (PIFS, 1976:2). The communiqué in 1984 also pushed for a single regional organisation (SRO) to assist with cooperation and coordination of activities among the various regional institutions and by 1989, a South Pacific Organisations Co-ordinating Committee (SPOCC) was established

\footnotetext{
${ }^{4}$ These countries include: Australia, New Zealand, Cook Islands, Republic of Marshall Islands, Federated States of Micronesia, Fiji, Tonga, Solomon Islands, Samoa, Tuvalu, Vanuatu, Kiribati, Nauru, Niue, Palau and Papua New Guinea.
} 
(PIFS, 1989). Alongside SPOCC, there have numerous regional agencies set up to assist Pacific Island countries' development ${ }^{5}$.

As illustrated above, the lack of coordination and harmonisation by development actors has been an issue impacting the region for over 40 years. Recently, the region has seen an increase in the number of development actors and the total amount of development assistance (Crocombe, 2008). This has only served to heighten the importance of addressing these issues faced by small developing Pacific Island countries. Wrighton's (2010a; 2010b) study in Tuvalu illustrated the high levels of consultation required by development partners. Tuvalu had 900 development visitors over a 12 month period, equalling approximately $10 \%$ of Tuvalu's total population. Wrighton (2010a) argued that government officials were inundated with the managerial and administrative requirements of each donor, relentlessly taxing the capacity of local systems and impacting their ability to function on a day-to-day basis. Wrighton (2010a) concluded that there is little evidence to suggest that any improvement in practice was a result of the international commitments and obligations development agencies have signed up to.

\subsubsection{Pacific Principles of Aid Effectiveness}

In 2007, the Paris Declaration principles that were signed in 2005 were adopted to fit the Pacific region, labelled as the 'Pacific Aid Effectiveness Principles'. Seven principles were designed and tailored to meet specific issues that faced the region. The document also included various recommendations and actions required of both development partners and Pacific Island Countries to improve aid effectiveness in the region. Table 4.1 outlines the seven Pacific Aid Effectiveness Principles.

\footnotetext{
${ }^{5}$ For example, the Pacific Financial Technical Assistance Centre (PFTAC) is an office of the International Monetary Fund that is responsible for providing technical assistance and training to Pacific Island Countries; Also, SPC Applied Geoscience and Technology Division (SOPAC).
} 
Table 4.1 Summary of the Pacific Aid Effectiveness Principles

\begin{tabular}{|l|l|}
\hline Principle 1 & $\begin{array}{l}\text { Country leadership and ownership of development through an accountable and } \\
\text { transparent national development planning and financial management } \\
\text { system/mechanism which is adequately resources from the national budget }\end{array}$ \\
\hline Principle 2 & $\begin{array}{l}\text { Multi-year commitments by development partners and countries aligned nationally } \\
\text { identified priorities as articulated in national sustainable development strategies, or } \\
\text { the like, with agreement on performance indicators and monitoring and evaluation } \\
\text { mechanisms }\end{array}$ \\
\hline Principle 3 & $\begin{array}{l}\text { Greater Pacific ownership of regional development, Development Partners' Pacific } \\
\text { Regional Strategies designed and formulated with the Pacific Plan and other } \\
\text { Regional Policies as their corner stone }\end{array}$ \\
\hline Principle 4 & $\begin{array}{l}\text { Pacific Development Partners and Countries pursue a coordinated approach in the } \\
\text { delivery of assistance. Encouraging harmonisation will be a priority for both. }\end{array}$ \\
\hline Principle 5 & $\begin{array}{l}\text { Strengthened institutional mechanisms and capacity in countries to enable } \\
\text { increased use of local systems by development partners. }\end{array}$ \\
\hline Principle 6 & $\begin{array}{l}\text { (i) Provision of technical assistance (TA) (in such a way that ensures that } \\
\text { capacity is built with tangible benefits to the country to support national } \\
\text { ownership) } \\
\text { Short term TA, that address local skills gaps to conduct studies, are } \\
\text { culturally sensitive. }\end{array}$ \\
\hline $\begin{array}{l}\text { Use of an agreed monitoring and evaluation framework that will ensure joint } \\
\text { assessments of the implementation of agreed commitments on aid effectiveness. }\end{array}$ \\
\hline
\end{tabular}

Source: PFIS, (2007)

The Pacific Principles, along with the Paris Declaration Principles, cannot be legally governed. However, the adoption of both these agreements illustrates the positive effort by Pacific Island countries and development partners to utilise aid in a more effective way. The above principles closely align to the core Paris Declaration Principles of Ownership, Alignment, Harmonisation and Mutual Accountability however, there are also some differences. For example, 'Managing for Results' has not been included in the Pacific principles.

Papua New Guniea (PNG) took the lead among Pacific Island countries following the Paris Declaration in 2005. The PNG Government developed a plan of action to engage with development partners, titled the Madang Plan of Action (MPoA) 2006 (PNG, 2008). This 
plan questioned the very essence of development and called for a robust restructure of the development 'partnership'. PNG also developed the Kavieng Declaration on Aid Effectiveness in 2008 in which the Paris Declaration principles were adapted to meet the local environment and conditions. "It aims to give meaning to the principles in the Declaration within PNG and set monitorable targets and actions to improve aid effectiveness over the period of 2007-2012 beyond" (ibid:1). This document served to reinforce the commitment donors had made to coordinate and harmonise their development assistance, placing set targets to be met by 2012 . For example, $90 \%$ of aid expenditure had to be aligned to the country's assistance strategies, $30 \%$ of aid has to go through the governments procurement systems, and no more than 150 missions were allowed annually (ibid:2008).

\subsubsection{The Cairns Compact 2009}

Another step reinforcing the aid effectiveness agenda in the Pacific was the Cairns Compact. Leaders of the Pacific Islands Forum signed the Compact on 'Strengthening Development Coordination in the Pacific Islands' on August 7, 2009. The aim of this compact is to "drive more effective coordination of available development resources from both Forum Island Countries and all development partners, centred on the aim of achieving real progress against the MDGs" (PIFS, 2009). It is an agreement among the Pacific leaders to focus efforts on reducing aid fragmentation, ease the burden of aid administration and improve aid effectiveness (ibid:2009).

The Cairns Compact can be recognised as a Pacification of the Paris Declaration of 2005 and Accra Agenda for Action 2008. It conveys the same principles of country ownership, harmonisation, alignment and mutual accountability and flows on from the Pacific Principles on Aid Effectiveness. One of the outcomes from the Cairns Compact is a reporting template that requires development partners to annually report on their efforts towards reducing aid fragmentation and reducing the burden of aid administration. There has also been a process established of regular peer reviews where Forum Island Countries' (FICs') are requested to review each others' national development planning and budget processes, giving a detailed account of coordination at a country level. This process is said to allow mutual learning between the countries, illustrating the different strategies employed by each country to address and overcome development challenges. 
The Development Partner Reporting Analysis Report (2010) highlighted various areas of concern in relation to development partner efforts to support country leadership and their efforts towards aligning and harmonising to recipient country objectives, priorities and systems. The overall findings included;

- Operational development strategies were not on track to reach targets

- The quality of country systems has increased, however the use of them is poor

- There is a lack of common approaches by development partners to policy dialogue

- There is a lack of capacity within Pacific Island countries to coordinate and lead development activities and;

- Donors must strengthen and support country capacity. It has not been prioritised or sequenced and there is limited understanding on the issue (PFIS, 2010).

The above report argued that development coordination was patchy across the region and found that overall, it is not going as far and as fast as all participants would like it to (PIFS, 2010). What is promising with the above agreements is the drive and determination at both a regional and national level from the Pacific. Aid effectiveness is at the top of everyone's agenda, however, there are still issues of power that need to be addressed. There is no mechanism that enforces development partners to use or incorporate these aid effectiveness principles and there are no consequences for failing to meet the commitments made. It is easy for development partners and aid organisations to sign up to commitments such as the Paris Declaration, however, it is questionable whether officials in both donor organisations and recipient countries are able to understand and implement the principles in practise. The question still remains, are donors willing to hand over the reins to recipient countries or will the relationship continue to perpetuate 'Pacific Island dependency' as Naidu (1995) proposes. As we have outlined the regional response to the aid effectiveness agenda, we will now turn to the Kingdom of Tonga.

\subsection{The Kingdom of Tonga}

The speckled set of islands across the vast Pacific Ocean holds a wealth of distinctive cultures, languages, customs and political environments with varying histories of colonial and post colonial relations. The Kingdom of Tonga is the only country in the Pacific not subjected to direct colonial rule throughout the era of European hegemony (Campbell, 1992a). It is no historical accident that Tonga retained its independence and this section of 
the chapter will detail a short history of this unique political environment. Understanding Tonga's history and learning what has shaped and influenced Tonga is required to reflect and comprehend the contemporary challenges that hamper development.

Tonga's constitutional movement in 1875 placed a solid foundation that has shaped social structures and created political stability within Tonga. As Kennedy (1972:5) states, "freedom and independence is the Tongan way of life". Now in the 21 st century Tonga has undertaken political reforms with the first democratic elections held in November 2010. The long process of political reform was born out of a call for greater democracy and an increasing concern over the abuse of privilege from the monarchy and nobility. No longer could people ignore the controversies that overtly pointed to such poor levels of governance and accountability. The first election under the new constitution has handed the majority of seats in parliament to the people's representatives (commoners) who now hold 17 out of 26 seats in parliament. Traditionally, it was a small circle of nobles that had run parliament, selected by the King who also elected the Prime Minister and cabinet.

\subsubsection{The Tongan Constitution and the Formation of the Monarch}

George Tupou I ${ }^{6}$, with the assistance of Wesleyan missionaries instituted the Kindgom's first legal framework, the Code of Vava'u in 1839. This was later advanced as the Code of 1850 and the Emancipation Act of 1862, where George Tupou I abolished serfdom and set in motion the first laws in Tonga. On Decemeber 4, 1845 George Tupou I was titled King of a united Tonga. King George Tupou I with the assistance of Rev. Shirley Baker drafted the Constitution and in 1875 submitted it for deliberation at the Opening Ceremony of the Legislative Assembly, in November 1875 (GoT, 2010).

For over 135 years Tonga's constitutional monarchy ruled. The Constitution of Tonga, passed in 1875 is one of the oldest constitutions in the World. King George Tupou I established the rule of law and a constitutional government, creating political structures and stability in the region (Campbell, 1992a; Powles, 2009). King George Tupou I called a meeting to address the other chiefs and present the constitution for adoption, he stated,

\footnotetext{
${ }^{6}$ Taufa'ahau was the son of Tupouto'a, the 17th Tu'i Kanokupolu and Houmofaleono, daughter of Lord Ma'afu of Vaini. Taufa'ahau assumed his fathers title of Tu'i Ha'apai when he passed away in 1820. In 1831 Taufa'ahau was baptised and installed as George Tupou I. George Tupou I also assumed the paramount title of Tu'i Vava'u in 1833 (GoT, 2010).
} 
"I praise God that he has allowed me to see this day. The thing of most importance to me is that Tonga should achieve a systematic form of Government in my lifetime... I have called you together to establish a Constitution... and I, with those who succeed me, will rule constitutionally. This Constitution will become the protection of Tonga forever" (cited in Rutherford, 1977:162).

The Constitution was an advanced document for its time and ensured the continuity of the Taufa'ahau's position as King. He placed rival chiefs into landed hereditary nobles, creating twenty chiefly titleholders (this later increased to thirty) (Rutherford, 1977; Powles, 2007). The Constitution declared the freedom of the Tongan people and dealt with three particularly important matters; a Declaration of Rights, ensuring equality for all; the formation of a Government, a cabinet and a legislative assembly and thirdly; it dealt with the issue of land. The Constitution prohibited personal ownership of land however, control was divided between the Government and Nobles, where the government owned all town and beachfront land while the nobles divided up the rest (Campbell, 1992a). Entrenched in law, Tonga became a three-tiered society, the monarchy, the nobles and the commoners.

The Constitution ensured the sovereignty of Tonga as King George Tupou I demonstrated Tonga had the political stability to govern itself, without the need of interference from outsiders. King George Tupou I signed bilateral treaties of friendship with France in 1855, followed by those with Germany, Britain and the United States (GoT, 2010). King George Tupou II came to power after the passing of King George Tupou I in 1893. In 1990, "His Majesty was coerced into signing a new Treaty of Friendship which, amongst other things, allowed Britain to control Tongan Government relations with all foreign countries and grant Britain to jurisdiction over all non-Tongan residents" (GoT, 2010:8). The Supplementary Agreement in 1905 further reinforced British control where the Government of Tonga was made to consult the British Agent and Consul on financial matters.

Queen Salote Tupou the Third ascended to the Throne in 1918 bringing "a new warmth to the Royal Palace" (GoT, 2010:8). In 1927, a further amendment was made to the Treaty, ensuring the Government would seek advice of the British Agent and Consul on "all new legislations; all new appointments to civil service; all financial matters; all foreign relations and defense matters. That did not leave the Tongan Monarch and Government much room for manoeuvre" (ibid:8). Tonga remained a protectorate of Britain for 70 years, only gaining full 
sovereignty and independence in 1970 and consequently, Tonga is a culmination of "chieftainship, Christianity and British concepts of government and law" (Powles, 2009:140).

King George Tupou V ascended the Throne in 2006. He "voluntarily committed to surrender his Executive Authority to an elected Prime Minister and Parliament ... he granted that due processes commence to put into effect, thereby completing the democratic reform inaugurated 135 years ago by King George Tupou I" (GoT, 2010:24). Parliament enacted the Constitutional amendments, decentralising the Monarch's executive authority and other reforms related to power and functions of the Privy Council, Cabinet, Legislative Assembly and Judiciary (ibid:24).

\subsubsection{The Government of Tonga}

The Constitution divides the Government of Tonga into three branches, the King, Privy Council and Cabinet, the Legislative Assembly and the Judiciary. The Tongan Privy Council is appointed by the King and is chaired by the Prime Minister. The Privy Council is the highest executive branch and assists the monarchy in forming laws and policies that are subject to review by parliament.

The members of the Privy Council are also members of the Legislative Assembly that comprises of nine nobles and nine people's representatives. Elections are held every three years. The Prime Minister is elected by parliament and is appointed by the King, just as the Queen appoints the New Zealand Prime Minister. The Prime Minister chairs the Cabinet, which is responsible for the day-to-day operations of government.

In 2006, the Government of Tonga employed $18.8 \%$ of all paid workers in the country $(23,438)$. On average, the government employ 4,254 staff a year (taken from 1997 to 2008). Tensions rose between the civil service and government over issues of pay resulting in a strike that lasted six weeks in August/September 2005. Staff demanded a 60-80\% increase in salaries and 3000 public servants went on strike. This served to deepen the crisis of political rule and as Campbell (2008) argues, this was the turning point for modern Tonga, with a spectacle of events that then transpired. 


\subsubsection{Democracy Movement}

Challenges surrounding the structure of government and the role of the Monarchy had long been brewing highlighted by the Pro-Democracy Movement that began to pave the way in 1992. It "succeeded in tapping a vigorous stream of discontent, most of it connected with particular grievances, perceptions of corruption both in government and among the nobility, and disappointment at the King's apparent indifference or inability to correct abuse issues" (Campbell, 2005:94). However, the reform movement was met with various challenges, some of which resided within the organisation as they struggled to grapple with the concept of being pro-democracy and pro-monarchy. The discussions of the group focused on the abuses of government that included "nepotism and misuse of power, corruption at high levels... and the general lack of accountability by ministers to parliament for their actions" (ibid:97).

'Akilisi Pohiva was one member who led the discussions, broadcasting over the radio and later launching attacks through his newspaper, 'Ko e Kele'a'. Pohiva was elected into parliament in 1987 and continued to push for a more democratic system of government. Akilisi began to work closely with the informal Pro-Democracy Movement that gained further momentum throughout the 1990s, becoming a formal organisation in 2002, changing their name to Human Rights and Democracy Movement in Tonga (HRDMT) (Campbell, 2008).

During this time, the government was involved in a number of blunders, one that included the selling of Tongan passports (Campbell, 1992a). The King's lack of response or action to the misdemeanours further ignited the discontent felt by the Tongan people. Around 2000 people marched to the palace in protest and this action further strengthened the HRDMT's argument for constitutional change (Campbell, 2005). Scandals continued to emerge without any remedial action, despite a number of proposed changes delivered to the government and a number of public forums and conventions covered by the international media. "Whether the King bore responsibility or not, the glaring fact now was that the problem was constitutional" (Campbell, 2005:97).

During 2004 and 2005 the HRDMT began to make headway. In November 2004, the Prime Minister announced that two people's representatives, and two nobles' would be appointed to cabinet following elections in March 2004. "This would form the pattern at subsequent 
elections until the entire cabinet was filled with people chosen by the people and the nobles" (Campbell, 2008:4). In the 2005 elections, Dr Feleti Sevele was appointed to cabinet as one of the two people's representatives. Dr Sevele was an economist and businessman that had been associated with the pro-democracy movement throughout the 1990s (ibid:2008). Following Prime Minister Prince Lavaka's resignation in February 2006, Dr Feleti Sevele was appointed as Prime Minister. As part of this appointment the King gave the new Prime Minister the ability to appoint his own Cabinet and he took this opportunity to do so, appointing the first ever female Cabinet Minister.

The Parliament created the National Committee for Political Reform (NCPR) in December 2005, surveying the people's views about political changes in Tonga. Pohiva and Sevele were the two people's representatives on this committee. However, Pohiva resigned to form his own 'People's Committee for Political Reform' and what was supposed to ease tensions and create a shift towards democracy "sparked bitter political wrangle" (Campbell, 2008:6).

The NCPR report and recommendations was presented to Parliament during October 2006 and was 'adopted in principle' on 9 November $2006^{7}$. On the morning of 16 November 'Akilisi Pohiva and his supporters stood outside Parliament however, the Speaker of Parliament refused to convene on the recommendation of a Parliamentary Select Committee on members' security. By the afternoon the Prime Minister convened a special meeting in the Cabinet Room at the Prime Minister's Office to try and resolve the standoff. The meeting included members of Cabinet, Nobles Representatives and most of the People's Representatives. During the meeting Akilisi Pohiva demanded 'specific undertakings' from the Prime Minister that a reformed Parliament would have 21 People's Representatives and 9 Noble's Representatives. The Prime Minister agreed to those specific undertakings and as 'Akilisi Pohiva and the People's Representatives departed from the Prime Minister's Office, riots broke out (Lopeti Senituli, personal communication, June 2012).

\footnotetext{
7 “The NCPR report and recommendations was presented to Parliament during 3-12 October 2006 and during the ensuing debate, the Prime Minister presented Cabinet's own recommendations for political reform on 19 October and 'Akilisi Pohiva presented those of the People's Committee for Political Reforms on 9 November. Although it disagreed with some of NCPR's recommendations, the Government's opinion was that it should be "adopted in principle" and be given together with its own recommendations and those of the PCPR, to a Tripartite Committee of Parliament (with equal representation from Cabinet, Nobles and People's representatives) to continue the dialogue and to seek a consensus model out of the three sets of recommendations before Parliament. A Tripartite Committee was not formed" (Lopeti Senituli, personal communication, June 2012).
} 
The destructive storm that took over the city targeted some government buildings however many business offices also became a focus. The events that transpired were not predicted or anticipated by Government (or the democracy movement) and unfortunately several looters lost their lives. The entire country was left in shock and disbelief with blame being attributed to five 'people's representatives', one being Pohiva (Powles, 2007:140).

A Constitutional and Electoral Commission Bill was passed in Parliament in July 2008, creating a fresh investigation into constitutional and electoral reform. The Constitutional and Electoral Commission carried out its work in 2009 and by April 2010, an amended constitution was passed which included a new 26 seat Parliament.

On 10 November 2010, Tonga had their first democratic elections. Those in Parliament, rather than the King, elected the Prime Minister. Akilisi's 'Friendly Islands Democratic Party' (FIDP) won 12 out of the 17 people's representative seats. A total of 9 seats were assigned to nobles. Towards the end of December the Prime Minister was announced, a Tongatapu noble, Lord Tu'ivakano. "After a quarter of a century of agitation, and over a century of parliamentary, constitutional government, Tonga at last became a democracy although of a limited kind" (Campbell, 2011:226). Credit for the reform has been given to King Tupou V who completed the reforms his father had begun, and as Campbell concludes, "its achievement however, is not simply the happy ending to a story of drama and tragedy, but it is the beginning of a new story with undetermined possibilities" (Campbell, 2011:232).

\subsection{Tonga's Economy}

Throughout Tonga's protectorate under Britain (1900-1970), the Tongan economy remained largely independent. Economic policies and development decisions were driven by the Government of Tonga and paid for by government revenues (Campbell, 1992a:66). However, Tonga's geographic location combined with limited natural resources has created significant economic constraints. Traditionally, Tonga's exports were predominantly copra while wood and kava were also exported. The economy transformed over the years shifting from a subsistence based economy towards a more cash based economy. During the 1960s the Government looked to expand the nation's economic base investing in commercial fisheries and financing the start up of a coconut factory (ibid:1992). Tonga has remained largely as a 
primary product exporting country with agricultural exports, such as fishing, that make up around two-thirds of all exports.

In the 2006 consensus, the total number of employed people $(35,290)$ was divided between paid workers (66\%) and subsistence workers (32\%). Many of the paid workers were based in the agriculture, fishing, quarrying or in the manufacturing sectors (accounting for $56 \%$ of workers). While a large number of workers were also employed in the craft and trades category, totalling $33 \%$ of employed workers.

However, Tonga's small open economy is heavily reliant on imports, external investment and remittances. Tonga's economy is extremely vulnerable to external price shocks and fluctuations (World Bank, 2010). Tonga's vulnerability was highlighted with the economic crisis in 2008, where the cost of fuel and food significantly increased, and inflation reached as high as $12.6 \%$. The economic crisis also led to a reduction in the total amount of remittances, it decreased national income and had a significant impact on the government's fiscal position. While the government has undertaken various initiatives to improve their financial situation, increased donor funding has been sought to cover the shortfall in revenue.

\subsubsection{The Role of Remittances}

Tonga has one of the highest remittance flows as a percentage of GDP in the world. There is a large proportion of Tongans work abroad, predominately in New Zealand, Australia and the United States, sending money back home to their families in Tonga. Over $80 \%$ of households reported receiving remittances in the Household Income and Expenditure Survey conducted in 2009 (GoT, 2009). Remittances accounted for 31\% of GDP in 2008, however this dropped to $22 \%$ in 2009 (World Bank, 2011). Figure 4.1 highlights the annual total remittance flows as a percentage of GDP into Tonga from 2001 - 2008. This figure also compares Tonga's remittance flows against Samoa, Kiribati and Fiji. 
Figure 4.1 Remittances as a Share of GDP (\%) 2001-2008

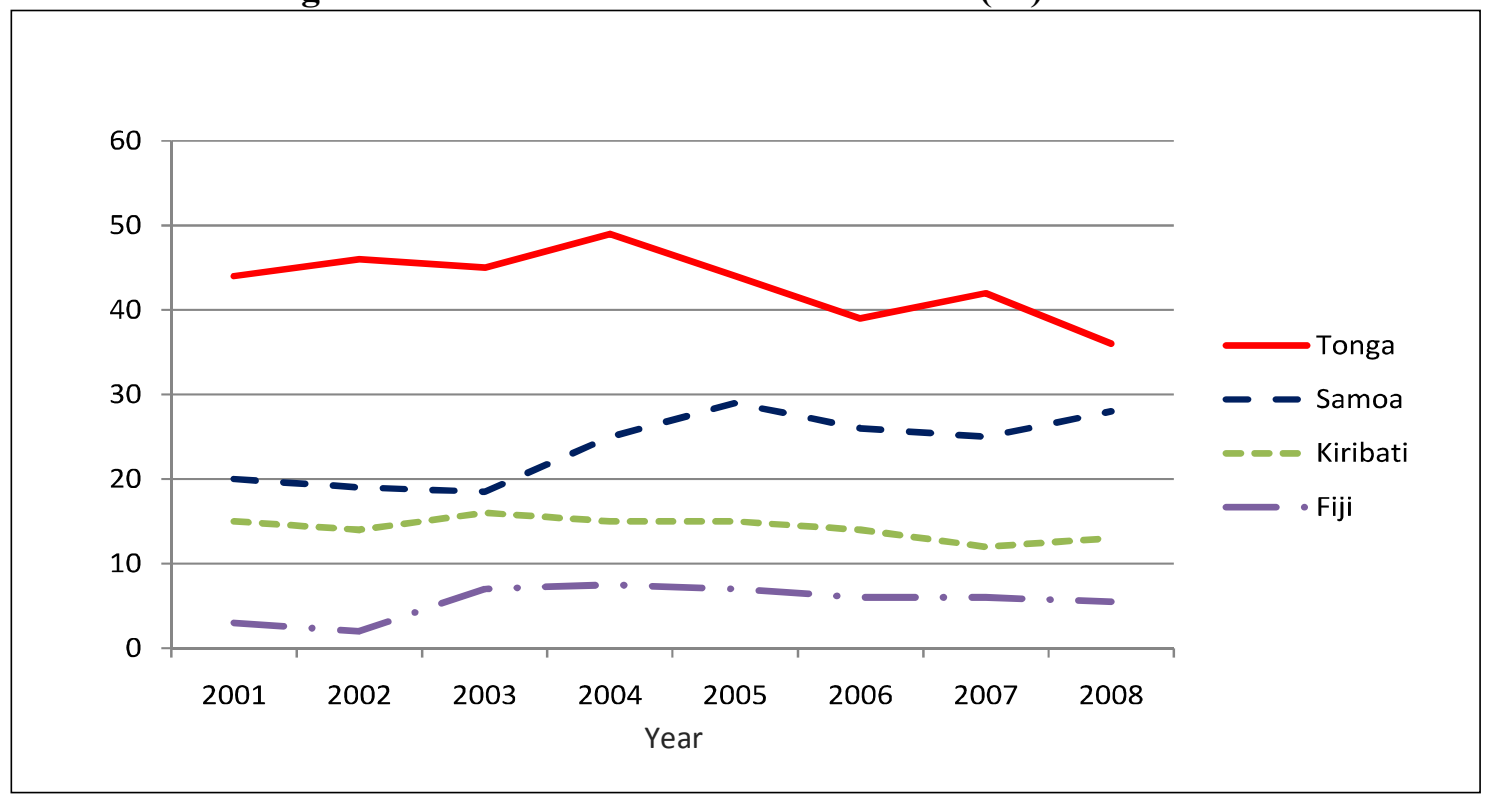

Source: IMF (2010) Country Report Article IV

As illustrated in figure 4.1, in a relative sense, Tonga is the highest recipient of remittances across the Pacific. While remittances have remained a fairly stable source of income, they are on the decline (World Bank, 2011). The total remittances dropped from \$280.4 million (Tongan Pa'anga TOP) in September 2011, to \$194.2 million in March 2012 (GoT, 2012c). As remittances are continuing to fall, the consequences are having a direct and adverse impact on household disposable income and growth of the Tongan economy.

\subsubsection{Aid Inflow in Tonga}

Aid inflow has played a significant role in the Tongan economy since independence in 1970 . While the statistics of total aid inflow to Tonga vary greatly across different sources, the OECD Tonga country data set amounted to \$1.3billion USD from 1970 to 2009. Figure 4.2 illustrates the total net official development assistance and official aid received in Tonga from 1960 to 2009. 
Figure 4.2 Net ODA and Official Aid Received in Tonga (constant 2009 \$m USD)

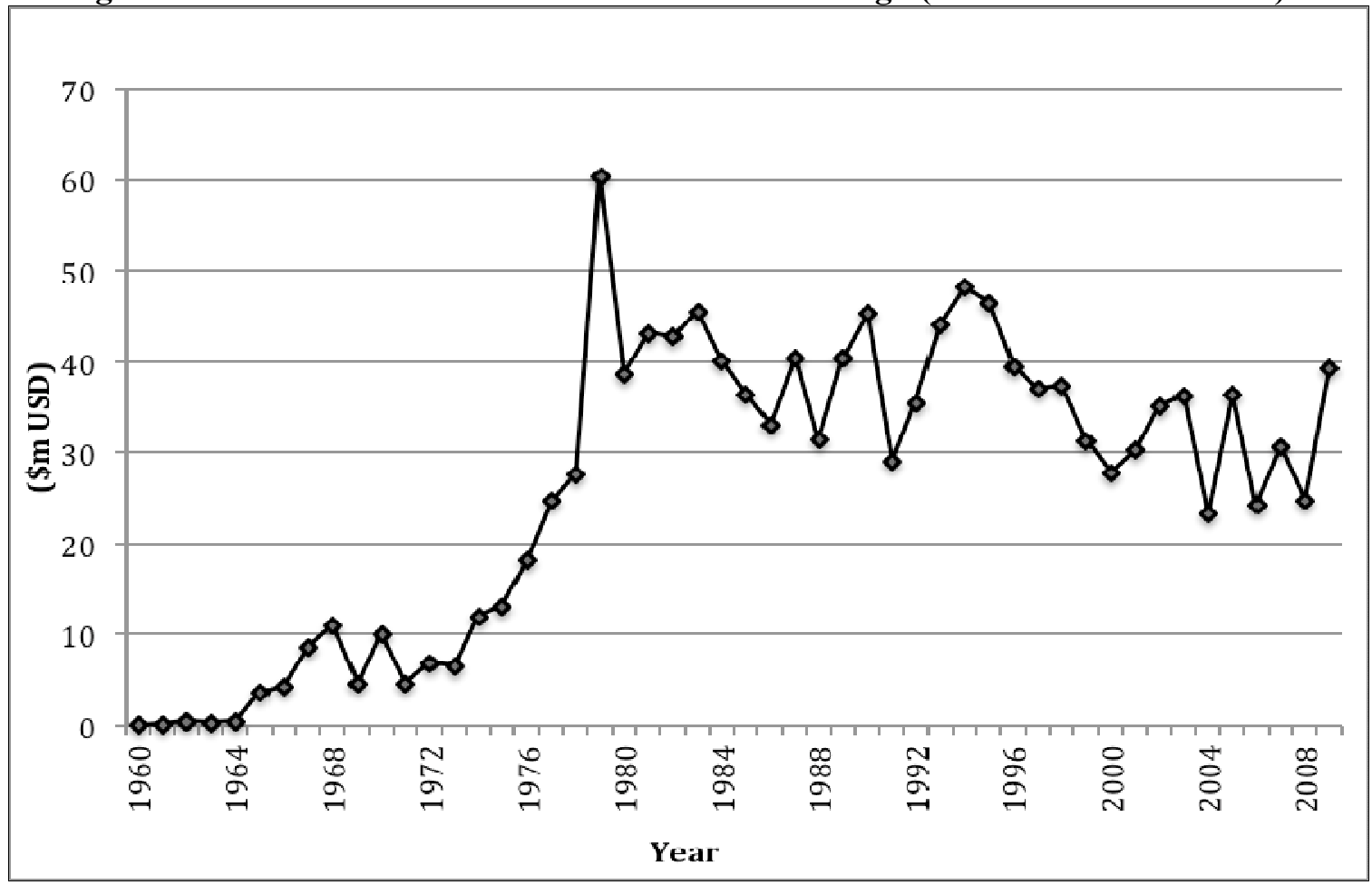

Source: OECD, (2011)

*Note: Above amount presented in Constant Prices (2009 USD \$millions)

Figure 4.2 highlights the highly volatile nature of foreign aid flows to Tonga. The spike in 1979 was predominantly from an increase in recorded development assistance from Germany. Assistance jumped from \$.5m (USD) in 1978 to \$26.65m (USD) in 1979 when it provided new shipping resources for Tonga, Germany's assistance to Tonga then dropped to \$5.4 (USD) the following year (OECD, 2011).

Aid volatility has been shown to create negative impacts on economies, governments and the people of aid recipient countries (Lensink and Morrissey 2001; Bulir and Hamann, 2008). Clarke et al. (2007) conducted a study on aid allocation volatility to small island states and found that the Asia-Pacific region has higher levels of aid volatility than any other region. The study found that on 17 separate occasions, Pacific Island countries experienced a reduction of more than $90 \%$ of aid receipts, followed by 27 different instances of a reduction between $75-90 \%$ of aid receipts (ibid:16). Iulai (2010:33) conducted research on aid volatility in Tuvalu, flagging it as a significant issue with consequences of "uncompleted and high cost of overrun of projects, problems in fiscal planning, 'Dutch disease', and lowered economic and social value of aid". The issue of aid volatility was recognised in the Rome Declaration 
of Aid Harmonisation in 2003, and again at the Paris Declaration of 2005. In order to overcome this issue, it was advised that development assistance focus on budget support and programme or sector support.

Table 4.2 shows the breakdown of total grant aid in the period of 1970 to 2009 by aid donor. While no data was available for the Republic of China, Former Prime Minister Sevele's economic and strategy advisor estimated that China has provided US\$5 million in grant funding per annum from 2009 onwards (Solomon, personal communication, May, 2012). Australia, New Zealand and Japan provide approximately $67 \%$ of all grant flows, followed by the multilateral institutions that provide $22 \%$ of total grant aid to Tonga.

Table 4.2 Total Grant Aid to Tonga by Donor 1970-2009

\begin{tabular}{|l|c|c|}
\hline Donor & $\begin{array}{c}\text { Total Grant Aid Inflow } \\
\mathbf{1 9 7 0 - 2 0 0 9 *}\end{array}$ & \% of Total Inflow \\
\hline Australia & 391.72 & $30.64 \%$ \\
\hline New Zealand & 227.1 & $17.76 \%$ \\
\hline Japan & 232.91 & $18.22 \%$ \\
\hline UK & 53.76 & $4.2 \%$ \\
\hline $\begin{array}{l}\text { Multilateral, Total } \\
\text { (inclusive of } \\
\text { EU Institutions) }\end{array}$ & 280.68 & $22 \%$ \\
\hline Others & & $7.22 \%$ \\
\hline Total & 92.41 & \\
\hline
\end{tabular}

Source: OECD (2011) Country data set.

*Note: Above amount shown in Constant Prices (2009 USD \$millions)

In addition to programme and project aid, Tonga also received budget support in 2010, amounting to $\$ 23.6$ million $\left(\mathrm{TOP}^{8}\right.$ ). Australia, New Zealand, the Asian Development Bank, the World Bank and the European Union provided assistance through this budget support mechanism.

In Tonga's Budget Statement (2012-2013), the overall donor (cash and in-kind) funding for 2011/2012 totalled TOP\$157 million. This included major projects such as the Vaiola Hospital Reconstruction (Japan, \$19m), Road Improvement projects (PRC \$32m), Popua Solar Plant (NZ \$6.3m) and the Post Tsunami Recovery Project (World Bank, \$7m). Table 4.3 outlines the key economic and fiscal indicators for the 2010-2013 period.

\footnotetext{
${ }^{8}$ TOP $-\$ 1$ Tongan Pa'anga is approximately equivalent to \$0.56 USD.
} 
Table 4.3 Key Economic and Fiscal Indicators 2010-2013

\begin{tabular}{|l|c|c|c|}
\hline & $\begin{array}{c}\mathbf{2 0 1 0 / 2 0 1} \\
\mathbf{1}\end{array}$ & $\begin{array}{c}\mathbf{2 0 1 1} / \mathbf{2 0 1} \\
\mathbf{2}\end{array}$ & $\begin{array}{c}\mathbf{2 0 1 2} / \mathbf{2 0 1} \\
\mathbf{3}\end{array}$ \\
\hline Real GDP Growth & $4.7 \%$ & $-0.2 \%$ & $0.4 \%$ \\
\hline $\begin{array}{l}\text { Total Budget Support as \% } \\
\text { of GDP }\end{array}$ & $3.3 \%$ & $3.6 \%$ & $2.9 \%$ \\
\hline $\begin{array}{l}\text { Total Project Aid Funding } \\
\text { (cash') as \% of GDP }\end{array}$ & $3.7 \%$ & $5.0 \%$ & $5.7 \%$ \\
\hline $\begin{array}{l}\text { Total Project Aid Funding } \\
\text { (in-kind) as \% of GDP }\end{array}$ & $16.4 \%$ & $17.2 \%$ & $13.5 \%$ \\
\hline
\end{tabular}

Source: GoT (2012c)

The above tables and figures illustrate Tonga's reliance on foreign aid. In spite of Tonga's long-standing constitutional rule, it still remains vulnerable to external pressures, as it is heavily reliant on bilateral and multilateral donors to sustain the country's economy. Tonga is also characterised by a large government bureaucracy. The government's salary bill for $2011 / 2012$ was budgeted at $\$ 85.5$ million. This equates to around $70 \%$ of government revenue and leaves very little to be spent on public utilities and services. At present, the economy cannot keep up with the demand for employment, yet at the same time, there have been multiple initiatives to try and cut back on the number of postings, and salaries paid in Government.

Sturton (1992:3) argues that,

"the Tongan economy displays all the characteristic markings of the "Dutch disease," where a dominant export activity attracts a disproportionate command over resources, pushes up domestic production costs, and reduces inter- national competitiveness. In the Tongan case the "booming" sector has become development assistance and migrants' remittances".

\subsection{Tonga's Development Plans}

The first development plan by the Government of Tonga was published in June 1965. The plan focused on encouraging economic activity in the country, improving agricultural

\footnotetext{
${ }^{9}$ Cash refers to money that goes through the Government systems such as GBS. In-kind is money spent in the country that doesn't go through government.
} 
efficiency and the promotion of public services in health and education. The development plan formed the basis for engagement with development partners however, it was not expected that they would entirely fund the plan. "At this time, growth in foreign aid was neither expected nor envisaged, and the recognition of and aspiration for self-reliance was clearly evident" (Campbell, 1992a:67). Although there was the potential for development partners to assist the government in achieving its development goals, the Government of Tonga had the intention of funding the majority of it. The government created the Development Coordination Committee to coordinate and liaise with the development partners and act as the centralised focal point, with the Prime Minister chairing the committee.

The vision of the Government to fund Tonga's development plans continued through to the 1970s however, by the Third Development Plan, 97\% was financed by foreign aid. Although "it offered the disclaimer, 'nevertheless, it remains the Government's long-term objective to achieve economic independence and reduce the Kingdom's reliance on foreign aid for development in the future" (cited in Campbell, 1992a:69). Clearly the idea of a 'development industry' was not anticipated and by the Fourth Development Plan, there was no further mention of economic independence (ibid:1992a).

In February 2009, the Sevele government produced Tonga's National Strategic Planning Framework, shifting away from the previous development plans and taking a new strategic planning approach. It took a "long-term strategic approach that focuses on the key determinants of economic and social development... Rather than the broad and all inclusive approach used for SDP8 and its predecessors, this plan focuses on a limited number of uniquely national or whole of government priorities ${ }^{10}$, with action in other supporting areas being required of Ministers through their Ministries' corporate plans" (GoT, 2009:2).

The new government in 2011 revised this framework, producing Tonga's latest Strategic Development Framework 2011-2014 (TSDF). The nine outcome objectives of the plan are listed below:

1. Strong inclusive communities

2. Dynamic public private sector partnership as the engine of growth

\footnotetext{
${ }^{10}$ It is important to note that "the National Strategic Planning Framework is not a comprehensive master plan or fixed blueprint. Instead it offers a perspective on Tonga's long-term spatial development" (GoT, 2009:9).
} 
3. Appropriate, well planned and maintained infrastructure that improves the everyday lives of the people and lowers the cost of business

4. Sound education standards

5. Appropriately skilled workforce to meet the available opportunities in Tonga and overseas

6. Improved health of the people

7. Cultural awareness, environmental sustainability, disaster risk management and climate change adaptation, integrated into all planning and implementation of programmes

8. Better governance

9. Safe, secure and stable society

The TSDF provides linked strategies for the achievement of each outcome objective, with each outcome objective sectorally focused. There are also individual three-year ministry plans that are broken down into annual implementation plans. The TSDF has been linked to five Millennium Development Goals (MDGs), designed specifically to meet the conditions in Tonga. This document highlights Tonga's priority areas and aims to direct the funding decisions of donors.

\subsection{The Government of Tonga and Development Partner Relations}

Formal engagement between the Government of Tonga and development partners originated in the 1950s where government officials participated in programmes initiated by the South Pacific Commission, now formally known as the Secretariat for the Pacific Community (SPC). However previously, relationships had developed between the United States and New Zealand forces as they used Tonga as a base during the Second World War. Infrastructural projects were commenced in order to improve the roads and the port and an airfield were constructed. Tonga had also received assistance from the World Health Organisation under an environmental sanitation scheme in 1957 (Campbell, 1992a).

Tonga's first bilateral agreement was in 1965 where the United Kingdom gave Tonga a loan of 514,000 pounds for the establishment of the Queen Salote Wharf (Campbell, 1992a). Tonga became part of the Commonwealth in the 1970s, extending relationships to Australia and New Zealand. Tonga also joined the Asian Development Bank in 1972. To date, Tonga 
has formed partnerships with a number of bilateral and multilateral donors however its three core bilateral partnerships are with New Zealand, Australia and Japan. The three core multilateral arrangements are with the World Bank, the Asian Development Bank and the European Commission.

\subsubsection{Tonga's Core Bilateral Relationships}

In 2009, Australian Prime Minister Rudd and Tonga's Prime Minister Sevele signed the 'Australia-Tonga Partnership for Development' at the Pacific Islands Forum in Cairns. "This partnership seeks to advance Tonga's development vision as articulated in the National Strategic Planning Framework (NSPF)" (Government of Australia, 2009:1). This document focuses on four (out of the seven) of the primary outcome objectives outlined in the NSPF 2009; a more efficient and effective public sector; improved health; improved technical and vocational skills and; develop infrastructure to improve the everyday lives of people. Within this agreement, there is a major emphasis placed on aligning to Tonga's priorities, increasing coordination and "mutual respect and responsibility for improved development outcomes" (ibid:1).

In July 2011, New Zealand and the Government of Tonga signed a 'Joint Commitment for Development'. This document has seven priority sector commitments that include: energy; private sector development; tourism; police; targeted sector budget support; education and training and; New Zealand partnerships. The New Zealand Aid Programme has significantly changed its focus over the past two years with a shift towards reducing dispersal and focusing on larger, long term investments in Tonga (Government of New Zealand, 2011:3).

Japan and Tonga established diplomatic relations in 1970. Japan's assistance to Tonga is largely based around infrastructure projects. Japan's latest project in Tonga was a major upgrade to the country's main hospital in Nuku'alofa. It was expressed by former Prime Minster Sevele's economic and strategy advisor Rob Solomon, that Japan sets these projects some three to four years in advance to ensure proper project planning for large infrastructure projects (Solomon, personal communication, May, 2012).

Solomon also noted that over the years, Tonga has been courted by both Beijing and Taipei. However in 1998, Tonga cut ties with Taiwan and formally recognised the one-China policy 
and the People's Republic of China set up an embassy in Nuku'alofa. Solomon stated that during a visit to Fiji in 2006 to meet Pacific leaders Premier Wen announced a significant increase in aid to the Pacific. Premier Wen established a US\$375 million fund for development in the Pacific. Tonga, following the riots in 2006 obtained a US\$50 million concessionary loan from this fund and also obtained a further US\$45 million concessionary load for the road and infrastructure upgrade programme in 2010 (prior to this fund closing). Solomon argued that Tonga has been criticised for taking out the second of these loans as it has raised Tonga's levels of external debt to what some believe to be unsustainable levels. It was noted that Tonga receives around US\$5 million in grant funding from China per annum (Solomon, personal communication. May 2012).

\subsubsection{Tonga's Core Multilateral Relationships}

Tonga has been a member of the Asian Development Bank since 1972. The most recent agreement between the ADB and Tonga is the 'Country Operations Business Plan' 20122014 (ADB, 2011). This Plan has selected three priority sectors from the Tonga Strategic Development Framework (TSDF) 2011-2014); (i) a dynamic public and private sector partnership (ii) infrastructure that improves the everyday lives of the people and (iii) integration of cultural awareness, environmental sustainability, disaster risk management, and climate change adaptation into all planning and implementation of programs (ibid:2011).

Tonga became a member of the World Bank in 1985. The World Bank ${ }^{11}$ has a wide focus across Tonga's development but is largely involved in the energy, transport, health and education sectors. The Asian Development Bank and the World Bank established a Joint Development Coordination Office (Joint Focal Office (JFO)) in April 2009, housed in the Ministry of Finance and National Planning. This JFO is intended to improve collaboration between the $\mathrm{ADB}$ and $\mathrm{WB}$, strengthen coordination and harmonisation, and improve the ADB, WB country portfolio management and performance.

Tonga also qualifies for European Development Fund (EDF) assistance supplied by the European Commission. In October 2005, the EU announced the focal point of its future assistance in the Pacific. This was largely on sustainable management of natural resources.

\footnotetext{
${ }^{11}$ Tonga Health Sector Support Project; The Tonga Education Support Project (TESP); The Tonga Transport Sector Consolidation Project; Post-tsunami reconstruction; Energy (TERM); Development policy support; Broadband connectivity.
} 
The 10th EDF specifies water and energy as targets for country allocations. Tonga has chosen the energy sector (in particular renewable energy) with around US 7.5million allocated under the 10th EDF National indicative programme (World Bank, 2010; Solomon, personal communication, May 2012).

\subsection{Management of Aid}

The management of aid was originally coordinated across multiple ministries in Tonga. The Ministry of Foreign Affairs previously coordinated the management of all bilateral assistance through the Central Planning Department. Bilateral assistance was received predominantly from Australia, New Zealand and Japan. While the Ministry of Finance coordinated assistance with the large development banks such as the International Monetary Fund (IMF), World Bank, and Asian Development Bank. Other multilateral assistance was coordinated by each of the various ministries (UN, 2002). Regional development organisations (such as PFIS and SPC) directed assistance through the Ministry of Lands, Survey and Natural Resources.

In July 2006, the Ministry of Finance and the Central Planning Department combined to become the Ministry of Finance and National Planning (MoFNP). The organisational structure has been divided into five divisions: Budget, Corporate Services, Policy and Planning, Project and Aid Management, and the Treasury Operations Division. MoFNP is currently responsible for the overall management of aid in Tonga and coordinates through the Aid Management Division (AMD). The Aid Management Division takes responsibility for the general oversight of aid, coordination of donor requests and ensures that development is reflective of Government priorities. It acts as a gateway for the majority of development missions and projects in Tonga.

The Government of Tonga also has a Project and Aid Coordination Committee (PACC). This committee is chaired by the Minister of Finance and includes chief executive officers of the major sector-representative public enterprises. The committee is allowed to approve development projects up to \$2million (TOP), however, any project above this level must obtain approval of the Expenditure Review Committee (this is a Cabinet sub-committee). 


\subsection{Shift towards Sector Wide Approaches}

The Aid Management Division has stated in the aid policy management plan (2010) that the 'effectiveness of development assistance will be enhanced if it is programme orientated, based on sectoral frameworks'. The Government of Tonga has pushed for sector wide initiatives as they believe it will greater align and harmonise development partners in the pursuit of 'common agendas'. The Government of Tonga has undertaken numerous sector approaches, some of which include; the Tonga Energy Road Map (TERM); the Police Programme, which is a joint between New Zealand and Australia; the Technical and Vocational Education and Training (TVET) programme and the Tonga Education Support Programme (TESP). TESP is a joint venture between the World Bank and New Zealand and aligns to Tonga's strategy for the development of its education system over the medium to longer term (a period of approximately 15 years).

\subsection{Summary and Link}

As a case study, Tonga provides a fascinating account of a fiercely independent nation fighting for its own sovereignty, yet it has come to be characterised by a similar dependence on foreign aid to that of other Pacific Island nations (Crocombe, 2008). Tonga is facing significant fiscal challenges that have been further heightened with the financial economic crisis in 2008. Tonga has turned to development partners to support the government through mechanisms such as budget support. Concurrently, Tonga has been undergoing major political reforms and is at crossroads in so many ways. Development in Tonga is unfolding in a complex and multifaceted environment, which not only provides purpose for this research but opens up a platform for discussion of the wider theoretical challenges of development.

The following chapter will detail how the aid effectiveness agenda has been promoted and endorsed by Tonga and its development partners. It will detail the research findings from the semi-structured interviews held with Tongan government officials and development partner representatives. It will outline various approaches and strategies taken by the government to strengthen country ownership and increase control over development planning and policy. It will also highlight some challenges and tensions faced by both government and development partners in context of the aid effectiveness agenda. 


\section{Chapter Five: Adoption of the Paris Declaration in Tonga}

\subsection{Introduction}

The overarching aim of this thesis is to investigate the influence of the aid effectiveness agenda on Tongan development policy and practice. The Paris Declaration of 2005 is a significant juncture shaping international efforts towards increasing the effectiveness of aid. Tonga and its core development partners formally adopted the Paris Declaration in 2005 and also produced its own 'Joint Declaration on Aid Effectiveness between the Government of Tonga and Development Partners' in 2007. The Asian Development Bank, NZAID and AusAID met in Nuku'alofa in March 2007 to discuss the ways development work could be better coordinated for the following five years. The discussions focused around the Government's Strategic Development Plan (SDP8) and explored various ways to improve the effectiveness of aid delivery. The Government of Tonga and development partners committed to the agreement that is summarised in table 5.1 below.

This chapter is structured around an evaluation of three Paris Declaration Principles, Ownership, Alignment and Harmonisation. It will explore how these principles have been applied to development policy and practice in Tonga. This chapter will present quantitative data for each principle extracted from the OECD Paris Declaration Survey carried out in Tonga in $2010^{12}$ (OECD, 2010). This will be followed by the findings from the semistructured interviews held with government officials (G1-G4), development partners (DP1-5) and donor partner consultants (C1-2) during field research in September through to December 2011. Findings from interviews conducted in January 2012 with former Prime Minister Lord Feleti Sevele, will also be presented. Various strategies and examples will be explored to highlight recent changes to aid practice and policy in Tonga, combined with responses from government and development partner representatives.

${ }^{12}$ A complete copy of the OECD Paris Declaration Survey is available online: www.oecd.org. The individual country tables can be found at this link: http://.oecd.org/dataoecd/49/28/48726803.pdf. 


\section{Table 5.1 Joint Declaration of Aid Effectiveness Between the Government of Tonga and Development Partners}

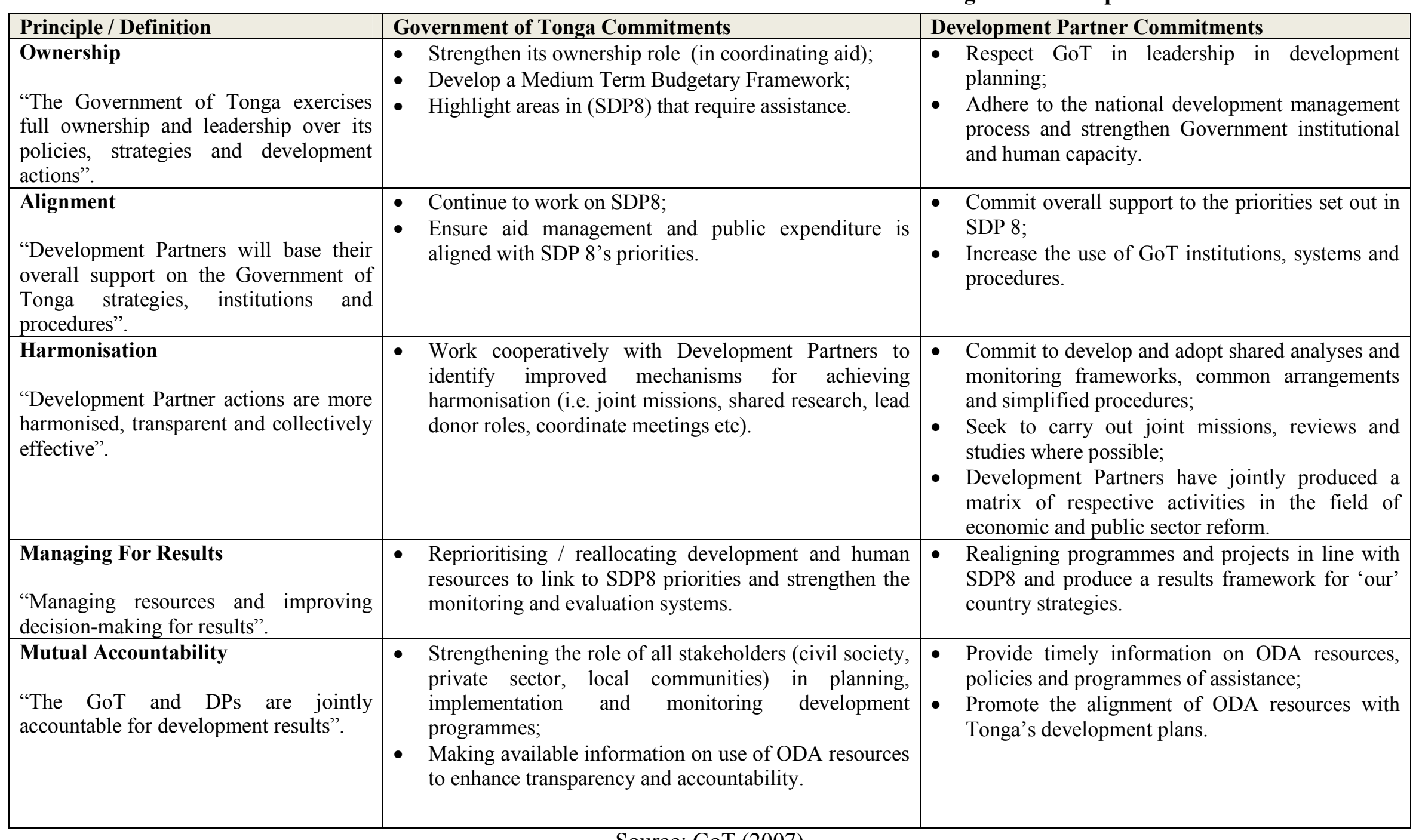

Source: GoT (2007) 


\subsection{The Principle Of Ownership}

The principle of ownership implies that recipient countries will set and drive the development agenda. The Declaration measures this principle through the country's operational development strategy, if one exists, and its operational value (i.e. the extent priorities are established and whether these policies are costed and linked to the budget). The World Bank collected and analysed information for this indicator in 2005 and 2006 which was then translated into a 5-point scale, allowing each country to receive a rating from A (the highest score) to $\mathrm{E}$ (the lowest score). Tonga scored a $\mathrm{D}$ for the operational value of its National Development Strategy (NDS) in the Paris Declaration Survey (OECD, 2010).

The NDS critiqued in the OECD survey was Tonga's National Strategic Planning Framework 2009. However, Tonga's NDS was updated in 2010 and is now labelled Tonga's Strategic Development Framework (TSDF), covering the period 2011-2014. The 2009 NDS was critiqued in this survey for not including an underpinning long-term vision or providing prioritised targets (OECD, 2010).

\subsubsection{Government Official Responses}

Clearly stated within Tonga's National Strategic Planning Framework (2009-2014) is that the framework outlined is "not a comprehensive master plan or fixed blueprint. Instead it offers a perspective on Tonga's long-term spatial development" (GoT, 2009). There were mixed responses from government officials in regards to Tonga's NDS and as respondent G2 felt, the NSPF provided the country's long term vision however it was not a practical document in that it does not set the countries priorities or leading sequenced programmes. Respondent G3 believed there has been a significant change behind the driver of the plan, suggesting that now it is a "national priority programme, before it was a donor driven programme".

The importance of having a plan and prioritising sectors was emphasised by all of the respondents. This was argued to give the government "control so we can say 'no,' we don't want to do that, our priorities are this" (Respondent G1). Respondent G1 explained that in order for donors' to further align with Tonga's priorities, "Tonga has to confirm what their priority is first ... because once we have those and the related costing of those projects we can easily ask development partners [for financial support]”. Respondent G2 also noted, "if 
Tonga could get its systems in order, and its basic admin disciplines in place, then we would be in a position to reinforce our expectations to donors that they comply with it".

Respondent G1 felt that there was a balance to be maintained between the "need to maintain control on the policies and development outcomes [while] at the same time try to buy-in the donors". However Lord Sevele suggested, "it is up to the government of the day in my experience here, for us to state what we want and how we would like it done ... What I think has happened in some cases, certain individuals from both sides, tend to be domineering, to state their 'so called' policy. Often this is at the official level, and if that is the way you [donors] want it then you can keep your dollars, we're not going to have it. Let's agree on the procedures, and let's agree on the mode of operations and move forward, otherwise you will not dictate to us how we should do things". Lord Sevele stressed that during his time as Prime Minister, he had not experienced "too much in a way of where donor countries would insist that they determine the shape and form of the project relationship, whatever the project may be".

Conversely, respondent C1 warned,

"in all official declarations, it's all local ownership, but in practice what we see is that donors have preconceived ideas of particular sectors they want to go into, so it's basically take it or leave it. If you want our assistance these are the three sectors we are interested in ... But already if you have no influence over what sectors donors go into then you already have very diminished local ownership".

Development partner respondents found that Tonga's NDS (TSDF 2011-2014) created a clear channel that allowed them to concentrate on individual core sectors, creating "a greater focus within country" as respondent DP2 noted. However, respondent DP1 found that although "there is commitment from government to do things ... they are not champion at driving it".

\subsubsection{Government and Development Partner Forums}

In order to strengthen ownership over development policy, the Government of Tonga initiated official Donor Round Table Meetings (DTRM) in 2010. These forums take place biannually, one before the budget (March/April) and one after the budget (September/October). For each meeting, there is a presentation by the government on the 
state of the nation, macro conditions and financial conditions. Respondent G2 explained that the meetings look at budget preparation and post budget progress to "see how we are going, how we are travelling ... and according to the World Bank, that's Pacific best practice”.

All respondents supported this initiative and there was a general consensus around the value of these forums. Respondent DP3 found that recent Tongan led forums were "less about development partners putting out what they are doing and what they want, and more about what Tonga's needs are and their constraints".

\subsection{The Principle of Alignment}

The principle of alignment recognises that development work must be aligned to the recipient country policies and systems in order to be effective. The Declaration has set various indicators to measure the principle of alignment that include; the reliability of country systems including public financial management (PFM) and procurement systems; alignment of aid to national priorities and; the proportion of untied aid (OECD, 2010). Building reliable and robust country systems is essential for donors to align aid with national development strategies and increase the overall effectiveness of aid. Analysing each indicator under this principle is out of the scope of this study, therefore, a focus has been placed on the proportion of untied aid and the use of Tongan procurement and PFM systems.

The proportion of untied aid into Tonga accounted to $83 \%$ in 2010 , meeting the target set under the OECD Paris Declaration Survey (2010) (OECD, 2010). It was noted that the majority of Tonga's development partners, particularly Japan, Australia, and New Zealand have significantly increased united aid in Tonga since 2008. There has also been a shift towards the use of budget support as a mechanism of aid delivery. This will be discussed in further length under the principle of harmonisation.

The World Bank created a scale running from 1 (very weak) to 6 (very strong) for the quality of PFM systems. In the Paris Declaration Survey (2010) Tonga scored a 3.5 on the reliability of its PFM system. This meets the 2010 target that was set by the Paris Declaration. Despite the reliability of the PFM system meting the 2010 target, the use of the PFM and procurement system was measured extremely low in this survey. Table 5.2 outlines how much aid for the 
government sector used country systems with only $37 \%$ of aid channelling through the PFM system and only $36 \%$ of aid through Tonga's procurement system.

Table 5.2 Total Amount of Aid That Uses Country Systems in Tonga 2010

\begin{tabular}{|c|c|c|c|c|c|c|c|}
\hline \multirow[b]{2}{*}{$\begin{array}{c}\text { Development } \\
\text { Partners }\end{array}$} & \multirow{2}{*}{$\begin{array}{c}\text { Aid } \\
\text { disbursed by } \\
\text { donors for } \\
\text { GoT } \\
\text { (USD n) } \\
\text { a }\end{array}$} & \multicolumn{4}{|c|}{ Public Financial Management } & \multicolumn{2}{|c|}{ Procurement } \\
\hline & & $\begin{array}{c}\text { Budget } \\
\text { execution } \\
\text { (USD n) } \\
\text { b }\end{array}$ & $\begin{array}{c}\text { Financial } \\
\text { Reporting } \\
\text { (USD n) } \\
\text { c }\end{array}$ & $\begin{array}{c}\text { Auditing } \\
\text { (USD n) } \\
\text { d }\end{array}$ & $\begin{array}{c}2010 \\
\% \text { avg } \\
\text { (b,c,d) } \\
\text { /a }\end{array}$ & $\begin{array}{c}\text { Proc, } \\
\text { systems } \\
\text { (USD n) } \\
\text { e }\end{array}$ & $\begin{array}{c}2010 \\
\% \\
\\
\text { e/a }\end{array}$ \\
\hline $\begin{array}{l}\text { Asian Dev. } \\
\text { Bank }\end{array}$ & 6 & 6 & 6 & 6 & $100 \%$ & 0 & $0 \%$ \\
\hline World Bank & 9 & 8 & 5 & 8 & $85 \%$ & 6 & $75 \%$ \\
\hline $\begin{array}{l}\text { United } \\
\text { Nations }\end{array}$ & 1 & 1 & 1 & 1 & $53 \%$ & 0 & $23 \%$ \\
\hline New Zealand & 10 & 8 & 1 & 5 & $45 \%$ & 5 & $47 \%$ \\
\hline Australia & 15 & 2 & 2 & 0 & $9 \%$ & 8 & $51 \%$ \\
\hline Japan & 10 & 0 & 0 & 0 & 0 & 0 & $0 \%$ \\
\hline $\begin{array}{l}\text { EU } \\
\text { Institutions }\end{array}$ & 2 & 0 & 0 & 0 & $0 \%$ & 0 & $0 \%$ \\
\hline Total & 52 & 24 & 15 & 19 & $37 \%$ & 19 & $36 \%$ \\
\hline
\end{tabular}

\subsubsection{Government Official Responses}

Government officials reiterated the development partners' poor use of Tonga's systems as respondent G1 felt, "donors haven't really fully come in and used the country system". However, this respondent did find that donors were taking the steps to help strengthen those systems, "providing assistance on some of the key reforms that will help us to strengthen the system”. Respondent G4 noted that the World Bank, New Zealand and Australia had recently increased their focus on accountability and financial management systems in the Ministry of Finance and National Planning, but emphasised that this should also be the focus of every single ministry. Respondent G2 felt that "over time there is opportunities there to utilise Tongan systems more, and certainly they [donors] intend to”.

Respondent G3 believed that donors' alignment with the Government of Tonga came down to a case-by-case basis, explaining that government and development partners "both use both 
ways. Sometimes we align with Government of Tonga policy and sometimes with [the] donor policy”. This respondent felt that if Tonga could prepare a prioritised action plan for each ministry then donors could focus their resources on that. This would then increase their alignment with the Government of Tonga.

Lord Sevele felt that donor partners had made an greater effort to increase their alignment and stated that both "Australia and New Zealand work closely together and they tend to align their policies and their procedures. For us, we have had no difficulty with that. We have had a very close working relationship between the Prime Minister's Office and the two High Commission Offices here, and that is the way it should be”.

\subsubsection{Development Partner Responses}

Respondent DP1 emphasised that "Tonga has to develop a procurement system that fits for Tonga". Although the majority of development partner respondents also supported this, there were still some reservations held. Respondent DP2 stated that although they use government procurement systems they also "have some additional safe guards in place".

Respondent DP3 elaborated,

"[it is] hugely nerve racking for donors when you have to be accountable to the tax payer, yet you are going to be funding ministries ... when you see recent financial problems. It's a challenge where the principles are important but the reality of another government being accountable to its tax payers and to its ministers... [you must ensure] there is an appropriate level of risk and risk mitigation".

This development partner respondent also believed that this was "a huge challenge for development partners and part of the reason people find it hard to get money out of the door sometimes".

The Government of Tonga has implemented a number of strategies to increase alignment with their development partners and reduce the fragmentation of aid. Points 5.3.3 and 5.3.4 highlight some of the response to, and strategies employed for the government to achieve this. 


\subsubsection{The Need for Increased Donor Reporting}

The need to increase reporting on donor expenditure and intended expenditure was an area government officials felt could be vastly improved. Respondent G2 stated that the "Government of Tonga has been making an effort to get this required information from donors" and commented on the "donors general poor response". If the government did not know the numbers to put in to the budgets, then the budgets were guesses. "We are then asked to be accountable for our budget. How can we be accountable for something we have guessed?"

The Government of Tonga has recently requested quarterly financial reporting. This was required by the government in order to accurately plan, monitor and be accountable for expenditures. Respondent G2 felt that this would give the government more control and oversight as many officials commented on the fact that at present, it is very difficult to keep the finger on the pulse with every development project going on in the country. Respondent DP4 commended this initiative by government,

"they have recently asked us to start completing a quarterly report to them on how money is being spent. I think that is an excellent initiative and I am very supportive of us doing that. Having more detail back and forth, regular conversations ... I think that is to be welcomed".

\subsubsection{Donor Coordination}

All respondents agreed on the value and importance of having a centralised office dealing with the overall management of aid in Tonga. The Aid Management Division was created as part of Ministry of Finance and National Planning in 2005. Donors agreed on the importance of this office as it created one focal point for government and allowed for greater communication and coordination. As respondent G2 explained, the Aid Management Division wants to,

"be the interface between donors and the government. When someone has an activity they want to do, they should run it past us. We would be a filter, but we don't want to be a filter that delays things unnecessarily. A filter that in the first instance looks at the activity from the point of view with compliance to the TSDF and does it basically follow a logical approach". 
However, capacity within this office to deal with every donor request and mission is burdensome. Respondent G2 suggested that the harmonisation argument should be turned around on the donors, stating,

'AUSAID you have 10 people in the high commission doing aid, New Zealand, you have the same number in yours. We have just four people to cover all the donors against [the] 20 in your two missions alone. We can not and do not have the capacity or the capability of coordinating you guys [donors] so that we play the music and you dance to our tune".

Despite some of these challenges, government officials noted that Tonga has been very successful in developing relationships with development partners and this has been highlighted with a number of partnership and development strategies that have transpired since 2009. Lord Sevele stated, “in my time I made it a point that we consulted each other often, and enough that the issues warranted at the time ... I have had a very good relationship with the Australian Government ... and similarly with the New Zealand Government ... We had a very good understanding of issues and a very cordial relationship".

\subsection{The Principle of Harmonisation}

The principle of harmonisation refers to both development partners and recipient countries coordinating their approach to aid management and aid delivery. The Paris Declaration measures this principle on two dimensions of aid, the use of common arrangements within programme based approaches and the number of joint missions and coordinated analytical work. The OECD Paris Declaration Survey (2010) found no targets on harmonisation were met for, or by Tonga, in 2010 (OECD, 2010).

The OECD Paris Declaration Survey (2010) measured the total proportion of Official Development Assistance (ODA) used within programme-based-approaches, finding that only $22 \%$ of aid was used in this way in Tonga. This was sizably lower than the target set of $66 \%$. The major donors varied in score ranging from $88 \%$ by the Asian Development Bank, 36\% New Zealand, 52\% Australia, the World Bank 61\% and the UN at 5\% (OECD, 2010). Table 5.3 outlines the total number of donor missions and coordinated donor missions. 
Table 5.3 Total Number of Coordinated Donor Missions in Tonga 2010

\begin{tabular}{|l|c|c|c|}
\hline \multicolumn{1}{|c|}{$\begin{array}{c}\text { Development } \\
\text { Partners }\end{array}$} & $\begin{array}{c}\text { Co-ordinated } \\
\text { Donor missions }\end{array}$ & $\begin{array}{c}\text { Total Donor } \\
\text { missions }\end{array}$ & $\begin{array}{c}\mathbf{2 0 1 0} \\
\mathbf{( \% )}\end{array}$ \\
\hline World Bank & $\mathbf{a}$ & $\mathbf{b}=\mathbf{a} / \mathbf{b}$ \\
New Zealand & 6 & 12 & $50 \%$ \\
EU Institutions & 2 & 5 & $40 \%$ \\
United Nations & 2 & 6 & $33 \%$ \\
Australia & 6 & 21 & $29 \%$ \\
Asian Dev. Bank & 4 & 36 & $25 \%$ \\
Japan & 0 & 1 & $11 \%$ \\
\hline \multicolumn{1}{|c|}{ Total } & $\mathbf{1 6}$ & $\mathbf{9 7}$ & $0 \%$ \\
\hline
\end{tabular}

Source: OECD Paris Declaration Survey $(2010)^{13}$

As highlighted in the table 5.3 above, only $16 \%$ of donor missions were conducted jointly in 2010. This is substantially below the target set at $40 \%$. This creates a lot of pressure on government officials with the individual donor demands each taking up time and resources of local staff. It is also interesting to note that the total number of missions in 2010 registered at 97. This equates to 'one mission per 1000 inhabitants' in Tonga.

Table 5.4 highlights the project or programmes in Tonga that amount to over $\$ 4$ million (TOP). This was taken from the 2012/2013 Budget Statement (GoT, 2012). However, many of these projects began operation in 2010 or earlier. The UN has no project over the \$4million (TOP) threshold, yet, has one of the highest number of development missions in Tonga as shown in table 5.3. This indicates an inverse relationship between the total aid received by donor, versus the number of missions.

\footnotetext{
${ }^{13}$ The total of coordinated missions has been adjusted to avoid double counting. A discount factor of $35 \%$ is applied.
} 
Table 5.4 Projects or Programmes over \$4m (TOP) (Summarised)

\begin{tabular}{|l|c|c|}
\hline \multicolumn{1}{|c|}{ Project Name } & Donor Partner(s) & Estimated Cost \\
\hline Supporting Vulnerable Groups & WB and ADB & $\$ 7.8 \mathrm{~m}$ \\
\hline Tonga Tourism Support Project & NZ & $\$ 6 \mathrm{~m}$ \\
\hline Tonga Energy Roadmap Support & WB & $\$ 7 \mathrm{~m}$ \\
\hline Tonga Fiji Submarine Cable & WB and ADB & $\$ 54 \mathrm{~m}$ \\
\hline Transport Sector Consolidated Project & WB & $\$ 12 \mathrm{~m}$ \\
\hline Vava'u Solar Electrification Project & UAE & $\$ 4.5 \mathrm{~m}$ \\
\hline Pacific Aviation Investment Program & WB & $\$ 50 \mathrm{~m}$ \\
\hline $\begin{array}{l}\text { Nuku'alofa Urban Sector Development } \\
\text { Project }\end{array}$ & ADB & $\$ 12 \mathrm{~m}$ \\
\hline Development Scholarships & NZ and Aus & $\$ 6 \mathrm{~m}$ \\
\hline Tonga Education Support Project & NZ and Aus & $\$ 10 \mathrm{~m}$ \\
\hline Tonga Health Support Program & Aus & $\$ 4 \mathrm{~m}$ \\
\hline Assistance to Climate Change & Aus & $\$ 4 \mathrm{~m}$ \\
\hline
\end{tabular}

Source: GoT (2012b)

\subsubsection{Government Official Responses}

Each government official interviewed believed there was a lot more work to be done amongst donors to coordinate better with each other. Respondent G1 used an example where two donors were doing work on the same community project but each donor had to do their own study and investigation, duplicating time, resources and money. Wasting time and money of not only of each donor, but of the local community. "We asked why [donor a] couldn't use the [donor b] team to carry out [the work], but there are some issues".

Government officials emphasised that there was a large amount of donor overlap and each respondent agreed that there was a huge scope for donors to streamline their approach with the government and with each other. However, the examples used focused on the smaller sized projects, versus the larger sector wide programmes. Respondent G2 argued that this was where the real politic comes in to it, "this is where the rhetoric of aid is turfed-out the window, because they are not going to share... The reality is different, because they do not talk to each other, and when they do talk to each other it's a beauty show".

There was also a strong emphasis placed on the lack of capacity that restricted their ability to implement, monitor and control all projects and programmes. As respondent G1 stated, "the lack of our resources tend to hinder [progress] ". A lack of capacity within each ministry was 
also emphasised by respondent G3. The ministry does not "have the capacity to manage all the projects coming in from bilateral or multilateral donors". This is where respondent G2 expressed,

"all the donors dream the idea but they do not dream the process. And that's the problem, it's the process that kills it. Tonga does not have the capacity to implement the process ... unless it is driven by the donors it won't happen. We will just have a hodge podge approach to all of the sectors".

Respondent G1 also felt that "development partners have a big say because they have the resources to provide things, and if we are not careful, they will determine what [happens in Tonga]". Respondent G2 stated,

"it boils down to the fact that they all have different missions and objectives and very rarely will they sing from the same hymn sheet. They each have different administrative systems with various bilateral interests, dressing it up to suit Tonga. There is nothing different in the donor philosophy, they are all in the pursuit of their own interests".

However, Lord Sevele stated, "I do not subscribe to the criticism that donor partners dictate. Certainly, they have certain procedures and that has to be respected, that is the decisions of their respective governments". This dichotomy between government official responses and Lord Sevele's view illustrate the different levels at which the principles are interpreted and engaged with. At the political level, there are no major concerns raised regarding the principles and engagement was characterised by consensus. However, at the level of project implementation, government officials clearly voiced their concerns with regards to capacity, donor duplication and lack of alignment and harmonisation.

\subsubsection{Donor Partner Responses}

Each development partner respondent interviewed agreed that there could be much more harmonisation of development partners in Tonga. As respondent DP2 sated, “there isn't a lot of donors in Tonga so it's not so difficult to coordinate and know what they are doing. But that said, no one is perfect" [sic]. Respondent DP3 also noted that their administration was open to joint missions, "and [we] definitely do not see ourselves marching along on our own, but I think there is still a lot of work to be done in making it easier for us all'. Respondent 
DP3 highlighted the benefits of joint programmes stating, "we have quite a limited aid budget so in terms of what we can do with our money ... you get better bang for your buck if you join with a partner".

Respondent DP4 found that when two donor programmes were "not getting along it's largely because of the demands that each organisation places on its own practices. They can conflict when you are trying to give a united front to Tonga in terms of requirements". They found that "it's challenging but it's like two companies working together on a joint project. The advantage being that we are both in the same business, providing development aid and at the end of the day, the processes are seeking the same thing”. Despite development partner respondents acknowledging there could be more done to harmonise their approaches, the respondents felt that overall there had been an increased effort in coordinating and working collaboratively with other donor partners in the country. Each respondent was able to list a number of examples where they were participating in a joint venture between two or more donors despite the statistics in the OECD Paris Declaration Survey (2010) indicating only $16 \%$ of missions were coordinated (see table 5.4) (OECD, 2010).

\subsubsection{General Budget Support}

The shift towards General Budget Support (GBS) as a mechanism for aid delivery in Tonga was initiated in 2009. Originally the European Commission had approved a GBS modality earmarked in the $10^{\text {th }}$ EDF National Indicative Programme. This was linked to the implementation of Tonga Energy Road Map. In 2010, following the elections, the new Government of Tonga further indicated its preference for GBS. The World Bank, Asian Development Bank, European Union, AusAid, and New Zealand were to work with the Government to discuss and guide policy dialogue on future budget support operations.

Previously, development assistance provided to Tonga in the form of GBS was divided. As respondent DP1 illustrated, “ADB were doing their own policy matrix, Australia were doing their own agreement with Tonga, New Zealand was doing their own their own agreement ... everyone was doing their own bits and pieces". Respondent DP1 recalled that one government official came to the office and argued that they did not have the energy or resources to implement and follow each development partner request. The government 
official said, "it's all targeting the same thing, why can't you guys sort out one policy matrix?"

The World Bank was tasked with leading the development partner inputs to produce a joint policy matrix. As the World Bank was already engaged with the TERM, it was agreed that a number of the targets were linked to the TERM indicators (i.e. GBS would be granted through the achievement of a number of deliverables set under TERM). The World Bank acted as the coordinating agency and focal point for all donors giving GBS. This allowed donors to coordinate among themselves and agree on a limited set of priorities. The World Bank designed a single page policy matrix of conditions (or policy actions) for the Government of Tonga.

Respondent G2 found "they all worked as a unit ... we only had to deal with one donor, and it really worked very well. We ended up with a single page matrix of policy actions". The donors also responded positively to the one page policy matrix as respondent DP1 commented, "now we come here and team talk, it is very much coordinated". Respondent DP4 also agreed, "we should be able to do that in Tonga, there are very few donors here and there is only a subset of those interested in budget support. So we should be able to get our stuff together and I think we have".

Tasking one donor to coordinate the actions of the other donors could be an initiative undertaken in each of Tonga's priority sectors. This would reduce the administrative and managerial burden of multiple donors working in the country. Respondent G2 noted that Sector Investment Plans is an initiative that the government are working towards. However, this was only in the preliminary stages.

\subsection{From Principles to Practice?}

The Government of Tonga and development partners' commitment made to the Paris Declaration in 2005, and the Joint Declaration on Aid Effectiveness in 2007, has resulted in several successful outcomes to development practice in Tonga. However, there are significant challenges that remain. The adoption of the Paris Declaration Principles faces both practical and political constraints and this raises an important need to address some of the conceptual and empirical issues that surround the Declaration. 
Firstly, there are some concerns regarding the reliability of the data produced in the OECD Paris Declaration Survey (2010) (OECD, 2010). Lord Sevele's former economic and strategy advisor, Rob Solomon highlighted that during his time in Tonga, the quality of reports produced by both government and outside consultants raised some serious concerns. Solomon suggested that often when filling out surveys there could be an inconsistency in what figures were used and how people understood the questions asked (Solomon, personal communication, May 2012). Although discrepancies in the data used in the OECD Paris Declaration Survey (2010) is possible, this is the only publically available data and the only officially recorded information evaluating the principles in Tonga. It has therefore been used in this research. However, this argument only serves to illustrate the difficult nature of capturing and measuring the Paris Declaration Principles. It is not only difficult to measure with numerical indicators but can often miss the complex and multifaceted environment that characterises aid relationships (Whitfield and Maipose, 2008).

There is also a difference in opinion held towards the practicality and effectiveness of the principles. At the political level of engagement (between Prime Ministers and Ministers) the principles rarely caused any major challenges or disagreement. However, at the implementation level, where these principles are implemented in practice, government officials often noted the tensions and contradictions. The following section will summarise the main findings under each principle, however, further discussion and analysis will be presented in Chapter 7.

\subsubsection{Ownership}

The OECD Paris Declaration Survey (2010) rated Tonga's NDS a D. However, Tonga's NDS has now changed to a National Strategic Planning Framework (NSPF, 2009, followed by the TSDF, 2011-2014). Therefore, the measurement and critique of the plan is out of date.

The responses of government officials clearly indicated their limited capacity to deal and manage each development mission and consultant arriving in Tonga. Without the capacity to exercise control over the implementation and monitoring of development policy and practice, little progress can be made towards achieving the principle of ownership in the Paris Declaration. As respondent G2 noted, there are simply not enough people within the 
department to do the work required. While New Zealand and Australia have at least 10 people working on their development programmes, the local Aid Management Division has four staff to respond to and manage each development partner working in Tonga. This can act as a major inhibitor towards the progress of the Paris Declaration Principles as without sufficient capacity the government is unable to set its own development agenda, let alone ensure that donors comply with it.

As Winckler and Therkildsen (2007) argue, in order to operationalise concepts such as ownership, a certain level of capacity is required. The Paris Declaration makes the assumption that each recipient country has this capacity, without truly understanding what the human and resource capacity of the recipient country is. This raises the question of whether donors are seeking 'quick wins' over long term and more sustainable results (Lomoy, 2010). "Without adequate capacity, recipient countries cannot carry ownership responsibilities in a meaningful way" (Winckler, and Therkildsen, 2007:18). Without the sense of ownership, the Government of Tonga will have less incentive to drive forward, implement and monitor their development plan.

The recent Donor Round Table Meetings directed and run by the government were agreed among respondents as a positive initiative taken to increase dialogue and engagement with development partners. It creates the chance for donors to come together twice a year, discuss development plans and issues, and respond to requests from the Government of Tonga. This can be viewed as a response from the government to assert more control over development and assist with increasing the coordination among development partners. As respondent G1 found, "we have started to work more closely and have more regular dialogue ... I think our relationship is getting better [especially when] trying to work together with what they [GoT] need and what we need". However, whether this initiative will continue to effectively translate into donors becoming more flexible and able to respond quicker to meet Tonga's needs is not clear.

\subsubsection{Alignment}

Some of the qualitative statistics presented under the principle of alignment illustrate a disconnect between what donors promise to do, and what donors do in reality. The 'Joint Declaration of Aid Effectiveness' (2007) clearly states that development partners commit to 
make increasing use of Government of Tonga institutions, systems and procedures. Yet only $36-37 \%$ of aid utilises government PFM and procurement systems. This is interesting to note as Tonga's PFM system has been based off the World Bank's PFM system.

It is well documented throughout the aid effectiveness agenda that the divergent interests of donors can serve to undermine the recipient countries priorities and objectives (Armon, 2007; Eyben, 2007). Without a harmonised and aligned system, which embodies a common set of objectives, rules and standards, the Government of Tonga has less space to lead the process. Although on the surface development partners state that they are aligning to Tonga's national development framework, in reality, what we see to some extent, is donors funding only what fits with their own agenda. As highlighted by respondent G1's response, "development partners have a big say because they have the resources to provide things". This hidden reality illustrates the unequal power relationship between development partners and government. This issue will be further explored in Chapter 7.

However, it was noted by government officials that development partners were increasing their efforts towards utilising Government of Tonga systems, and where they were not, an emphasis was placed on strengthening them. In general, there was a positive response towards development partners' efforts in meeting and acting on their commitments made in the Paris Declaration. It was not an 'all or nothing approach'. While it is not clear what the incentives for donors to promote collaboration and collective actions are, the signing of the principles and the need to demonstrate good practice one would have thought would be incentive enough.

The recent actions taken in the budget support process highlight a significant change in donor behaviour. The use of GBS is considered an important step in promoting local ownership and increasing alignment and harmonisation. It also allows the channelling of funds to utilise government systems. In the example of GBS, tasking one donor to do the coordinating and managing of the other donors represents a clear shift away from "donors running around doing their own thing” as respondent G2 stated, towards a more inclusive, harmonised approach.

Such an approach reduces the number of complex aid systems that the government must negotiate within, and allows for a singular embodying framework. As government officials 
noted, it helps to ease the administrative burden and reduce transactions costs. It allows for a common set of negotiators, one set of agreed priorities (or conditions), and allows for government to work with common standards and routines. The budget support process is still in its infancy and what it now requires is consistency. GBS that will be provided in the future will rely on the trust developed between the Government of Tonga and its development partners.

\subsubsection{Harmonisation}

The value and effectiveness of aid is significantly reduced when poorly coordinated. In Tonga, the harmonisation of aid delivery procedures and the adoption of common arrangements were measured very low. Only $40 \%$ of aid used programme-based approaches, and only $16 \%$ of missions to the field were conducted jointly (OECD, 2010). This poor coordination creates an increased burden on government, placing too many demands on their limited capacity and resources. The complex donor administration systems continue to challenge the government. Despite the shift in rhetoric of donors towards increasing harmonisation, to some extent, each donor still wants to be involved and participate in every decision. This was particularly evident at the level of project implementation.

Respondent G5 explained that in some cases they could have over five missions visiting in one week. This placed a huge strain on the respondent's workload as they explained the entire week consisted of one meeting after the other, reducing the time available to attend to their own daily work which just stacked up. This respondent felt that much of the responsibility of coordinating the development actors was placed on the recipient government departments and institutions. Yet it was a paradox because the donors then "come in and tell you that you don't have the capacity to organise it and give you the system to work within" (respondent G5). While New Zealand and Australia have engaged in dialogue to further harmonise with one another (both signing a 'Partnership for Development Cooperation in the Pacific' in 2007), "Japan, China and the EU institutions have systems and bureaucracies that are complex and rigid, impeding harmonisation" (OECD, 2010:13). 


\subsection{Summary and Link}

Tonga has made some significant achievements over the last five years in facilitating and strengthening relationships with development partners. However, government officials interviewed clearly voiced their concerns with regards to capacity and the need for donors to communicate and coordinate better among themselves at the level of project implementation.

The quantitative statistics from the OECD Paris Declaration Survey (2010) presented in this chapter reflects a rather gloomy picture of progress on the Paris Declaration in Tonga. However, the use of such statistics is unable to capture the changing attitudes of donors towards strengthening their practice. This was evident in the interviews held with each development partner representative. Also, these statistics do not include the informal donor coordination that does take place on a daily basis. The Pacific Islands development community is a tight knit group of donors, consultants and development workers, including both local and international staff. They are often meeting or bumping into one another at the local café or dining together, informally discussing programmes and projects. The statistics in the PD Survey are unable to take this into account. It is in my view that the development partner responses reflected a genuine commitment towards implementing and endorsing the Paris Declaration Principles. Each respondent had a positive attitude towards working more closely with other donors in the region and making aid more effective for Tonga. However, what remains to be seen is whether there is effective translation into practice.

The next chapter will outline Tonga's energy sector providing a case study of the Tonga Energy Road Map (TERM) 2010-2020. The Government of Tonga has recently taken a new approach to the development of its priority sectors and TERM is an example of a sector wide initiative taken by the government to reduce their reliance on imported fuel. The chapter will begin with a brief history of the energy sector and previous approaches to Tonga's energy sector. This will be followed with the formation of TERM with an outline of the particular

challenges faced. Chapter 7 will then bring together the findings from Chapters 5 and 6 to discuss the wider implications to development practice in the context of relevant theory. 


\section{Chapter Six: Case Study of the Tonga Energy Road Map}

\subsection{Introduction}

The Tonga Energy Road Map 2010-2020 (TERM) is a multi-donor funded, sector approach taken by the Government of Tonga for the development of Tonga's energy sector. This chapter will outline a short history of Tonga's energy sector and the efforts of development partners and government to reform this sector over the past decade. This will be followed by an introduction to TERM, detailing how it evolved and the challenges that were faced in turning a goal into a reality. The last section of this chapter will outline a select few issues the TERM has faced since inception.

\subsection{Tonga's Energy Sector History}

In 1950 the first Tongan-owned diesel generation reticulation system began operation in Nuku'alofa by the Nuku'alofa Electric Power Board (TERM, 2010). The board supplied electricity primarily for the port, commodities board, churches and government offices. In the 1970s the Nuku'alofa Electric Power Board became the Tonga Electric Power Board (TEPB) and increased supply of grid electricity to the main urban areas of Tongatapu, 'Eua, Lifuka and Vava'u. By 1995, the TEPB had expanded to supply electricity to all communities on Tongatapu (ibid:2010).

Ownership of the electricity assets have changed hands twice in Tonga. The Government of Tonga privatised the energy generation utility in 1998, creating the first locally owned independent power producer, the Shoreline Power Company. The owner was Crown Prince Tupouto'a who thought he could give Tonga's electricity users a better deal. However, while the power costs initially dropped, the price of oil continued to increase. Shoreline had to increase the charge of electricity to the consumers and this caused public outrage. The prodemocracy movement, alongside many others, placed pressure on the government to buy back the assets. Prince Tupouto'a also wanted out because of the increasing opposition held against Shorelines involvement in the generation and the distribution of power (Keith-Reid, n.d.). In 2001, the government bought back the assets and created a state-owned enterprise, Tonga Power Limited (TPL). The TEPB was dissolved and a new regulator, the Electricity Commission was introduced. 
Historically, Tonga's institutional structure of the energy sector was spread across multiple bodies rather than a centralised one ${ }^{14}$ (UN, 2002). In 2001, Cheathams conducted a study to advise the Government of Tonga on sustainable energy development and current policies on sustainable energy (ESCAP, 2001). Overall, Cheathams found that the institutional management for the energy sector was widely fragmented across different ministries, governing agencies and regional bodies, resulting in overlaps and gaps in the public sector management of the sector (ibid:2001).

The National Energy Committee was established in 1979 to report to Cabinet on energy related matters. An Energy Planning Unit (EPU) was also established in 1983. The EPU is currently responsible for energy policy implementation. The EPU currently sits within the Ministry of Lands, Survey, Natural Resources and Environment. There have also been several other government bodies involved in energy related matters however overall the general oversight of the sector was poor. Lord Sevele (2011:4) stated, “Tonga's energy sector suffered from non-transparent and complex regulatory and oversight processes with gaps and inconsistencies in the policy and legal framework".

\subsubsection{Development Partner Involvement in the Energy Sector}

Since the 1990s, there has been a shift away from the use of government structures that were established in the 1980s to donor-assisted energy projects. Donor partners focused on off-grid projects and wider infrastructure development programmes, reflecting the global energy initiatives by development partners used in Africa, where over $80 \%$ of the population were off-grid $^{15}$. However this approach was not needed in Tonga where $85 \%$ of the population was on-grid (TERM, 2010).

During the second half of the 1990s new resources (largely renewable energy projects) supplied by both donors and the private sector trickled into Tonga. However, there was no coordination among the various donor strategies. Donors divided up their assistance

\footnotetext{
14 "Tonga Electric Power Board regulates electricity production, distribution/transmission, and consumption behaviours. The Competent Authority of the Ministry of Labour, Commerce and Industries regulates/monitors the prices of imported petroleum products. The Energy Planning Unit of the Ministry of Land, Survey and Natural Resources designs, implements, evaluates renewable energy projects, and formulates policy/guidelines for the solar electrification of the rural/remote islands" (UN, 2002:6).

15 On-grid electricity is provided from an electrical grid. Off-grid electricity is generally produced from a self-contained unit and does not feed back into a system.
} 
programmes according to geographic location. For example, New Zealand took the lead role for infrastructure projects in 'Eua and the Niuas; the European Union (EU) was the lead donor in Vava'u, whilst Australia was the lead donor in Ha'apai. All donors shared the responsibility and assistance for Tongatapu. In a speech prepared for the launch of the Vanuatu Energy Road-Map, Lord Sevele stated, “projects inevitably failed as the models imposed were not sustainable. Maintenance programs were lacking and ownership of systems were not fully assumed by locals and therefore inevitably broke down" (Sevele, 2011:4).

Although Tonga had an abundance of reports and studies to illustrate what was required from the energy sector, "not one report said that this is the categorically available or technically approved off the shelf product that Tonga could move to immediately, and the most cost effective” ('Akau'ola, Director of TERM-IU). Tonga's energy sector lacked clear management and accountability, and without frameworks in place outlining institutional relationships and responsibilities, the development of the sector remained ad hoc.

\subsection{The Problem}

The Tongan economy has been exposed to excessive and volatile electricity prices over the last ten years due to the increasing cost of oil (TERM, 2010). The average cost of crude oil jumped from US\$25 per barrel to over US\$40 per barrel between 2001 and 2004. The price then doubled over the next four years to US\$100 per barrel in 2008. Towards the end of 2008 electricity rates exceeded TOP1.00/kW-h (ibid: 2010). Petroleum products accounted for $25 \%$ of imports by value and gross sales of petroleum products represented $19 \%$ of GDP (Sevele, 2011).

Tonga has over $85 \%$ of the population on grid and this accounts for $98 \%$ of electricity used in Tonga. 75\% of Tonga's energy supply comes from imported petroleum products and therefore any increase in the cost of oil has a direct impact on the individual consumer and on local businesses (TERM, 2010). Jayaraman and Lau (2011) conducted a study looking at the connection between oil prices and economic growth across five Pacific Island countries. They concluded that increases in oil prices have had serious economic repercussions on economic growth. Tonga has one of the highest costs of electricity in the Pacific region and as Jayaraman and Lau (2011) argue, this has an adverse effect on the growth of Tonga's economy. 


\subsection{The Solution}

The Government of Tonga began searching for solutions, exploring all options to combat the high electricity prices and heavy reliance on imported diesel fuel. King George Tupou V stated that Tonga had plans to follow a U.S. initiative to develop a 30-megawatt nuclear plant that would overcome high electricity costs and reduce the country's dependence on imported fuels. "The government maintains that nuclear power is our best hope ... the quicker we move in this direction the better" (George, 2010). This statement gained a lot of coverage in the global media and although parliament were not as receptive to the idea of nuclear energy, donor partners began to search for alternative options to put forward to Tonga.

Climate change was a hot topic on the global stage and with this came a push towards renewable energies as the best alternative to diesel fuel. Development agencies such as the $\mathrm{ADB}, \mathrm{EU}$ and World Bank began announcing funding for renewable energy in the Pacific. Over \$2 billion dollars was promised to the developing countries by 2012. Lord Sevele began to question where this money was going and how Pacific Island countries could get access to it. Lord Sevele recalled, "we would always receive an endless number of promises of help and access to the funds but at the end of the day the big three were only initially interested in large scale projects that achieved international attention" (Sevele, 2011).

Therefore, Lord Sevele needed a plan that would capture the world stage. He did this in 2008 by announcing a 50\% renewable energy target by 2012 . This statement captured the international attention and development partners came to Tonga to offer assistance.

In April 2009, the Pacific Energy Ministers' Meeting and the Regional Energy Officials' Meeting were held in Nuku'aolfa. In summary, the Ministers and Regional Energy Officials meeting highlighted major capacity and resource constraints, suggesting that;

- Regional and donor coordination of energy services needed to strengthen;

- The collection of energy data, information gathering and collation, management, analysis needed to increase to inform policy choices;

- More encouragement was required in the investment of renewable energy technologies, and energy efficiency and energy conservation initiatives 
- National energy policies, action plans and regulatory frameworks were required and/or needed to strengthen

(SOPAC. 2009)

During the week of the Pacific Energy Ministers' Meeting in Tonga, development partners approached the Government of Tonga about the 50\% renewable energy goal, and offered their assistance. 'Akau'ola recalls that each development partner came to the table with different plans, offering various solutions to Tonga's problem. However, there was no coordination among donor partners and everyone was advocating their own agenda. 'Akau'ola stated, "all of the project proposals were ad hoc, none of them were coordinated and all of them were based upon the development partners priorities".

The Prime Minister called a meeting requesting all donor partners in the one room. He walked into the room for five minutes and as one respondent recalled,

"He told everyone off, he said, 'I don't need your money, you come here and tell me [different things]'. He said 'I have a big issue in Tonga [the price of electricity]. What I want you to do is for you tell me how I am going to reduce it, if you can't help me on that, get out of Tonga, I don't need you here, I don't need your money. Tell me how I can reduce my energy cost, and if you can help me with that, fine, we can talk money later. But I want you to come up with an idea of how I am going to reduce it.' And then he walked out, simple as that".

'Akau'ola and Tongan officials were left in the room with the donor partners to come up with a coordinated plan that would work for both the donor partners and the Government of Tonga. 'Akau'ola suggested "lets just take off all our bloody caps, you take off you World Bank cap, you take off your Asian Development Bank Cap (etc) ... you guys are the experts of the world ... lets just go back to our university days" where they were given a problem and they had to solve it. 'Akau'ola gave a fictitious example of a country completely reliant on imported fuel and their assignment was to come up with a solution.

Each donor representative came up with various solutions with ease, unbounded by each organisations requirements. 'Akau'ola turned around to them and said,

"Well I have just described Tonga to you, now put your institutional caps back on [and tell me why we can't fix the problem] ... We met again the next day and it was a 
very different environment. Now the problem then was not how do we fix it the problem is was, let's try and tackle why we can't fix it and solve that, and then go back to the problem".

The discussions that took place considered Tonga's energy problems, considered its 50\% renewable energy target and looked at the ways donors could provide assistance. Each organisation also outlined the barriers each party faced. This included;

- The Government of Tonga needed a singular plan as currently there was no coordinated plan. This required all donors to agree upon the same thing.

- There was no information sharing. Originally donor partners just dealt bilaterally with the state therefore all information was confidential to them and the government. Therefore it was agreed that there would be an inter-change of reporting.

- The government wanted the minutes of the meeting signed as they found that when everyone went back to their own institutions they had to deal with a different person each time. As 'Akau'ola recalls, "a lot of talk can happen from government or development partners perspective and it all be lost once the individuals are out of the room".

- Development partners also stated that they found it difficult to meet and contact the relevant people. Therefore they requested that one person would be tasked with coordinating the government, whilst at the same time one donor partner would be responsible for coordinating with the other donors.

As each issue was discussed and laid out on the table, both the government and development partners came up with solutions and compromises that would allow Tonga to overcome its dependence on import fuel.

\subsection{Tonga Energy Road Map 2010-2020}

In April 2010 the Tonga Energy Road Map (TERM) was endorsed by Cabinet, documenting a 10-year plan to "reduce Tonga's vulnerability to oil price shocks and achieve an increase in quality access to modern energy services in an environmentally sustainable manner". The TERM as illustrated above was a culmination of work by the Government of Tonga, 
development partners and regional organisations ${ }^{16}$. The TERM plan includes a technical assessment of how renewable energy can be integrated into the grid connected and non-gridconnected communities. It also includes the logistics of fuel delivery from petroleum supply and storage in the Kingdom, increased efficiency (both in electricity supply and use) and improved access to quality electricity services at an affordable price (TERM, 2010).

Lord Sevele's economic and strategy advisor whom played a significant role in the development of TERM stated, "the key to early success in getting the TERM document developed and signed off by donors was the Prime Minister sitting the TERM-IU within the $P M O$, ensuring the highest support of government when dealing with development partners" (Solomon, personal communication, May 2012).

\subsubsection{Structure of TERM}

The TERM-Implementation Unit (TERM-IU) was set up as the main agency responsible for coordinating the reformation of the energy sector. The TERM-IU acts as the conduit between the Government of Tonga and development partners. A TERM-Committee (TERM-C) (a sub-committee to Cabinet) was also created as the governing body that is intended to provide overall responsibility for implementation of the Tonga Energy Road Map ${ }^{17}$. The committee is comprised of officials from Government Ministries that are currently dealing with the different aspects of the energy sector and the Public Service Commission. The TERM-C acts as the Project Management and Coordinating Committee and must approve submissions before given to Cabinet.

\subsubsection{Progress To Date}

To date, the TERM-IU has seen various projects commence in an effort to reduce the country's reliance on imported fuels. Table 6.1 outlines the projects that are currently underway $^{18}$.

\footnotetext{
${ }^{16}$ Financial assistance and technical reports were provided by ASTAE, IRENA, Pacific Region Infrastructure Facility partners (AusAID, NZAid, Asian Development Bank and World Bank). These agencies together with, SPREP, SPC, PIFS, PPA, EIB, EC, IUCN, JICA and REEEP also provided technical advice and review.

${ }^{17}$ The TERM-C also ensured in the initial stages that TERM had full buy-in by regulatory ministries.

${ }^{18}$ See www.tonga-energy.to for further information.
} 
Table 6.1 TERM-IU Projects Commenced

\begin{tabular}{|c|c|c|}
\hline $\begin{array}{l}\text { Projects currently } \\
\text { underway: }\end{array}$ & Description: & $\begin{array}{l}\text { Partnership } \\
\text { between: }\end{array}$ \\
\hline $\begin{array}{l}\text { Tonga Village Network } \\
\text { Upgrade (Four stages) }\end{array}$ & $\begin{array}{l}\text { The TVNU project will provide access } \\
\text { to a safe, efficient and reliable } \\
\text { electricity distribution network to } \\
\text { households in rural and peri-urban } \\
\text { villages on Tongatapu. } \\
\text { The first stage of } 17 \text { villages is } \\
\text { underway. }\end{array}$ & $\begin{array}{l}\text { NZAid / TPL / } \\
\text { GoT (TERM-IU) }\end{array}$ \\
\hline $\begin{array}{l}1 \mathrm{MW} \text { centralised Solar PV } \\
\text { project }\end{array}$ & $\begin{array}{l}\text { The } 1 \text { MW Solar PV Plant estimates it } \\
\text { will contribute to } 4 \% \text { of the total } \\
\text { network and reduce diesel usage by } \\
\text { approximately } 470,000 \text { litres per } \\
\text { annum. }\end{array}$ & $\begin{array}{l}\text { Meridian/ NZAid/ } \\
\text { TPL / GoT } \\
\text { (TERM-IU) }\end{array}$ \\
\hline $\begin{array}{l}\text { Solar Home System } \\
\text { Installation }\end{array}$ & $\begin{array}{l}\text { Solar home systems in the outer island } \\
\text { communities of Vava'u, 'Atata and } \\
\text { 'Eueiki. }\end{array}$ & Japan / GoT \\
\hline $\begin{array}{l}\text { Outer Island Renewable } \\
\text { Energy Project }\end{array}$ & $\begin{array}{l}\text { Connecting solar power to the } \\
\text { country's existing electricity network } \\
\text { in the outer islands of Ha'apai, 'Eua, } \\
\text { and Niuas }\end{array}$ & $\begin{array}{l}\text { ADB / Japan / } \\
\text { TPL / GoT }\end{array}$ \\
\hline $\begin{array}{l}\text { Energy Efficiency (EE) } \\
\text { Campaigns }\end{array}$ & $\begin{array}{l}\text { Newspaper, TV and Radio EE } \\
\text { Campaigns underway. }\end{array}$ & GoT / WB / DPO \\
\hline LED Streetlights Pilot & $\begin{array}{l}150 \text { LED streetlights along Vuna road, } \\
\text { Tongatapu. }\end{array}$ & $\mathrm{ADB} / \mathrm{TPL}$ \\
\hline
\end{tabular}

Source: TERM (2010) Website www.tonga-energy.to

The TERM-IU has a range of other projects in concept and proposal stages that are currently moving ahead. The TERM-IU has also initiated academic linkages with various universities to enable valuable opportunities for students to experience and learn from TERM projects. The TERM has gained vast media exposure and is being praised and applauded by the international development community. The TERM has been referred to as "a strong practical example of the application of the Cairns Compact principles to development in Tonga" (PIFS, 2010:21). 
The TERM is the first of its kind in the Pacific in the energy sector and as "Akau'ola felt, "it is changing the aid paradigm". Lord Sevele recalls, "we drove that programme, and we drove that project and set the agenda. And they [development partners] saw the value of that and then came together". Lord Sevele outlined that the TERM solution focused on:

- Strong Government leadership

- Active development partner cooperation and;

- Consideration of the whole electricity sector from start to finish to allow targeting of resources to priority areas (Sevele, 2011).

Lord Sevele also emphasised the importance of close relationships between government and respective development partner governments when promoting a plan such as TERM. Lord Sevele felt that Tonga had a very close relationship "with the New Zealand Minister of Foreign Affairs, Murray McCully, [and] that allowed [the Meridian Solar Project] to be pushed along, and I hope that that will continue and with other development partners". However, from the inception TERM-IU there have been some delays and challenges. This following section will outline just a few challenges met by the Road Map.

\subsection{Politics and a change of Government}

As Tonga underwent political transition with the change of Government in January 2011, the TERM-IU was physically moved out of the PMO to the Energy Planning Unit of the Ministry of Environment and Climate Change (MECC). TERM was then moved out of MECC and is now currently sitting outside of any government structures under the 'TERM Agency' that is governed by TERM-C.

A change in Government and the change of leadership driving the TERM created some uncertainty among the development partner community, as respondent $\mathrm{C} 2$ questioned, "it boils down to who is really driving the bus?" "Akau'ola elaborated that "the TERM has been going through this enormous political ping pong game" or as C2 stated, the TERM is involved in "a political tug of war". Respondent C2 believed that the "fundamental question relies on the political will, are they going to finish the job? Are they committed to some relatively robust institutional restructuring, if they are then we have a great story, if not, we have half a story”. 
Respondent G5 found that,

"the TERM was successful in the donor space, particularly early on because it presented high-level commitment from a coordinated Government to achieve a set of goals in an agreed manner ... as long as donors were willing to coordinate their actions around this plan ... The challenge now is to turn what was presented, into reality on the ground. The problems within the Government of Tonga with regards to coordinated energy policy and clear division of authority have yet to be addressed operationally".

Respondent G5 found that at times, there has been a lack of trust from local stakeholders in the intentions of the TERM-IU and "regardless of whether these perceptions are justified or not, the matter is that they exist and are not being addressed". These perceptions of TERM-

IU can have a negative impact on the progress of TERM as respondent G5 stated, "these perceptions mean that there is little push from either the top or the bottom of the local hierarchy to make the change necessary and without a clear and trusted direction; donors and Government are following a road map with no compass".

In August 2011, the Government of Tonga and World Bank agreed on a set of policy actions to be undertaken in the energy sector (in support of the General Budget Support programme). This included the establishment of a clear administrative body for TERM, an electricity tariff review and a petroleum action plan. 'Akau'ola emphasised the importance of having a solid and sound governance structure which is vital for the sustainability of TERM.

\subsection{Donor Coordination on the Road Map}

The World Bank was tasked with the initial coordination of each of the various donor inputs into the construction of the Road Map. Donors had their own section or study, for example, an off-grid component or the legislation. 'Akau'ola was very supportive of the World Bank's efforts stating, "World Bank who have been the center piece from the very beginning, by the sheer nature that they have coordinated all the development partners, have been fantastic with their support".

However, coordination on individual projects within TERM was an area that respondent G5 highlighted needed some revision and improvement. Although each project within TERM 
that has hit the ground has resulted with only one development partner funding it, initially this was not always the case. Some projects had two or three development partners involved in the concept stage, and each development partner required their own proposal, budget and procurement process to be followed.

Respondent G5 noted that there was "little coordination from donors on specific projects, but at a macro level, an increased coordination among donors to adopt development areas that they would focus on". Respondent G5 found that "the more donors you have on a project the more administration burden there is" as each donor has "different processes and protocols, it is much simpler to have one per project". However, Solomon stated that multi donor funding of TERM projects was never anticipated and argued that "from the beginning it is important to coordinate the donors on producing and signing up to a road map, but when it comes to implementation of individual road map projects it makes more sense to undertake these through bilateral funding”" (Solomon, personal communication, May 2012).

The Meridian Energy project to develop a 1 MW Solar PV Plant was initially going to be partly funded by the New Zealand Government, partly funded by Meridian Energy and partly funded through a third donor party. The European Investment Bank also offered funding to this project, however, what then transpired was a very delayed and cumbersome process. The processes of the EU and various other contraints meant that Tonga was unable to receive this funding. After a year and a half of going back and forth the EIB withdrew from the project all together. The World Bank then voiced that it would agree to grant fund the money that was originally promised by the EIB. However, in order to give funding to this project it had to follow World Bank procurement guidelines and therefore a review of the process had to be undertaken. In the final arrangement, it was agreed that the New Zealand Government were going to entirely grant fund the project. Development partner respondent 3 stated that this project "was an example where harmonisation takes you so far until you stump up against these individual requirements [of the donor organisation]". Lord Sevele also felt that a lesson learnt from this project was that "although the TERM is a multi-donor funded sector approach to development, when it comes down to individual projects within the TERM, these are best developed and funded by individual donors" (Sevele, 2011:5). 


\subsection{Donor Procedures and Systems}

Navigating your way through various donor processes (such as procurement or proposal or financial management procedures) was identified as a major challenge and this was found in a number of examples from the TERM. Respondent $\mathrm{C} 1$ described donor procurement guidelines as "incompatible creatures" with the ability to delay "any project". Respondent G5 found that each donor procurement system has,

"different levels of complexity and engagement ... Japanese Government procurement is almost completely handled by a private procurement agent. EU project procurement is extremely inflexible and involves a very detailed sequence of actions that must be followed exactly, while other donors seem to use a process in between these extremes and the Government of Tonga's procurement guidelines".

Two respondents noted that the key to handling donor procurement policy is on the Tongan side of the playing field. As respondent G5 stated, "a knowledge of all Tongan development partners and their policies would allow better planning and project application coordination from the Tongan side, this would take the onus off donors and bring more control from the Tongan perspective". 'Akau'ola noted that TERM-IU is currently in the process of bringing someone into this position that can act as a specialist in project application and management of all development partners.

\subsection{Stretched Capacity}

As found within the government itself, donor partners and government officials acknowledged limited capacity within the TERM-IU. The TERM-IU during the time of this research had four core staff to implement TERM and coordinate all donors and regional organisations involved. Respondent G5 acknowledged that the limited capacity is a major area that needs improvement, "you have a government without the funds to undertake its services, [or a government] without the capacity to undertake these services even when it does have the money". Respondent G5 further emphasised that the "development partner base doesn't have the patience to fix these problems because it is focused on clearing funding for projects that show results in the short term without really answering the underlying issues that go untouched through many generations of development partner desk officers, directors and sector specialists". 
However, Solomon also suggested that delays on projects were not always a result of internal limited capacity. He argued that an issue that is not often acknowledged or addressed is the capacity of donor in-country staff at embassy's and high commissions. "Too much is made of development country capacity while little is said about the donors' staff ability and capacity to undertake their role on multi-million dollar projects or numerous projects over many sectors. The capacity constraint in-country is not always related to the host country" (Solomon, personal communication, May 2012).

\subsection{Introduction of the United Arab Emirates}

Since the inception of TERM, the Government of Tonga has ventured into partnerships with donors and development actors new in the region. For one example, the United Arab Emirates (UAE) government approached the Government of Tonga in 2009 for support on its bid to host the International Renewable Energy Agency (IRENA) in Abu Dhabi. Tonga agreed to support the UAE and has been a member of IRENA since. IRENA is a relatively new organisation that was established in January 2009 and promotes the use and adoption of renewable energies. "Acting as the global voice for renewable energies, IRENA will facilitate access to all relevant renewable energy information, including technical data, economic data and renewable resource potential data" (IRENA website, 2012). Around 148 states including African, European, Asian, American and Oceania States and the European Union have signed the Statute of the Agency. The Government of Tonga has secured a seat at the 21 Member Council in April 2011, and is the only Pacific Island Council Member. The UAE, through the Abu Dhabi development fund, have recently agreed to fund the construction of a $500 \mathrm{~kW}$ solar photovoltaic power plant in Vava'u this year.

\subsection{Summary and Link}

The case study of TERM is a practical example where one country's vision for renewable energy development has led to fundamental changes to the way development partners and aid recipient countries interact and the way aid is delivered. It is an example lauded by the development community as a model for the future.

Ensuring that the government, development partners and regional organisations are working together on one sector wide plan is a positive change to development practice and highlights 
a movement away from ad hoc project or programmes approach which has occurred in the past. The inception and construction of TERM came from the former Prime Minister's drive to reduce the country's reliance on imported diesel fuel. The goal was to provide affordable and accessible electricity for the people of Tonga. The formation of this road map illustrates the way power structures can be overturned or reversed. It is where you see the principle of ownership in practice as the government drives forward its own development plan. Although you can answer what the term 'ownership' may mean in a theoretical sense, the creation of TERM is the day-to-day example, it is the practice of development that takes place in a very complex multifaceted environment.

From the inception of TERM there have been various hurdles along the way, both from within government and with development partners. Creating the TERM required some fundamental changes to the way aid was practiced by development partners and government. As stated above, it required a coordinated plan, it required open dialogue and information sharing (from both government and donors) and both sides requested a single actor to coordinate the information and responses from each side. Although these appear to be relatively straightforward requirements, what happens in reality is that this process becomes highly complicated by bureaucracy, delaying projects and placing a heavy strain on limited government capacity. The TERM gives the government a plan to work from; it enables government to make informed decisions on how they would like to see their energy sector develop. Development partners may fund individual or multiple projects within the TERM, however, they must operate within the plan.

The cooperation and coordination of development partners is not the only factor that will ensure the success of the plan, but it is also the capacity and political will of Tonga's government. As respondent G5 states, "an answer to the challenge will involve leadership from the Tongan Government to set a clear direction, with clear roles and authorities for each of the TERM stakeholders and then to have them buy-into the program in a real and meaningful way." The following chapter will bring together the findings from this chapter and Chapter 5, placing the responses in context of the relevant theory discussed in Chapter 3. This will enable the reader to reflect on what we are able to learn from the case study of TERM in respect of wider development theory. 


\section{Chapter Seven: Aid Effectiveness in Tonga - Discussion and Conclusion}

\subsection{Introduction}

The previous two chapters presented the findings of my research investigating the aid effectiveness agenda and its influence on Tongan development policy and practice. Chapter 5 included an analysis of the Paris Declaration Principles of Ownership, Alignment and Harmonisation and the extent to which these principles have been applied to development practice and policy. Chapter 6 presented a case study of the Tonga Energy Road Map (TERM). This chapter combines these findings and places them against the aid effectiveness literature presented in Chapter 3. To reiterate for the purpose of clarity, the objectives that guide this research are:

1. To evaluate the extent to which the Paris Declaration principles of Ownership, Alignment and Harmonisation have been applied in Tonga

2. To identify the responses and strategies of the Government of Tonga to the aid effectiveness agenda with particular reference to its application in practice

3. To investigate the extent to which the Tonga Energy Road Map has incorporated the principles of the aid effectiveness agenda

The analysis and conclusions drawn in this chapter will be framed through the use of three themes, Paris, Power and Participatory Practice. Through an analysis of each theme, the above objectives will be answered.

\subsection{The Paris Declaration}

Ostensibly and rhetorically the development agenda has changed in the last decade. There has been a shift in the way aid is practiced and delivered globally as development actors attempt to reform the conventional top-down relationship between recipient countries and donors. Since the inception of the Millennium Development Goals, there have been numerous policy attempts to reconcile donor conduct and improve the effectiveness of aid (UN, 2000; OECD, 2008). At present, the Paris Declaration sits at the core of the aid effectiveness agenda. On the global stage it was declared that donor driven policies do not work and in order for aid to 
be effective, recipients must be in the driver's seat exercising leadership over their development policies and procedures (OECD, 2008). In theory, the principles and objectives that were laid out in Paris are commonly agreed upon and accepted within the development community. However, their translation into policies at a local level has not always resulted with the intended outcomes (Monye, Ansah and Orakwue, 2010; Eyben, 2010a; Cramer, Stein and Weeks, 2006).

Tonga readily adopted the Paris Declaration of 2005 and has also produced its own 'Joint Declaration of Aid Effectiveness' in 2007, shaping the principles to fit the specific challenges facing Tonga (see Chapter 5, table 5.1). The Government of Tonga, alongside three of their core development partners, Australia, New Zealand and the Asian Development Bank signed this declaration to enhance effective coordination of development cooperation work in Tonga. To date, there has been no follow up on the progress of Tonga's 'Joint Declaration of Aid Effectiveness'. However, as presented in Chapter 5, an OECD survey evaluating the Paris Declaration Principles was conducted in Tonga in 2010 (OECD, 2010). This survey concluded that donor coordination in Tonga is poor. On the principle of ownership, Tonga was rated a $\mathrm{D}$ for the operational value of its national development strategy, this is significantly below the target set of a B or A. On alignment, progress had been made on Tonga's PFM systems, however, the donors' use of government PFM and procurement systems was low, averaging at $36-37 \%$. With respect to the harmonisation principle, no target was met with only $16 \%$ of donor missions being jointly coordinated (OECD, 2010).

In order to achieve the indicators set out in the Paris Declaration, it is dependent on both the Government of Tonga and development partners to make changes. The Government of Tonga has undertaken various initiatives to increase control over development practice and policy. These include new procurement laws and standardisations of their PFM system. Tonga has also formally requested that donors report back on a quarterly basis and has formalised biannual donor round-house table meetings. Tonga's core development partners have aligned to the national strategic framework (TSDF 2011-2014) and have significantly increased their total portion of untied ODA to Tonga. While the above examples highlight positive achievements to development policy and practice in Tonga, the statistics presented within the Paris Declaration survey paint a different picture. These statistics suggest that development actors are continuing to operate with the 'same as usual' practices while Tonga is continuously faced with a widely fragmented aid system. 
For purpose of clarity, I would like to reiterate the difference in responses at which the Paris Declaration Principles are interpreted and engaged with. Illustrated by the responses of former Prime Minister Sevele (in Chapter 5), the Paris Declaration Principles have not raised any major challenges and have facilitated stronger partnerships between Tonga and its development partners at the level of the nation-state. This is demonstrated through the recent partnership agreements signed with New Zealand, Australia and the Asian Development Bank. Development partners have also aligned their focus towards Tonga's national strategic framework, the TSDF 2011-2014. While at the political level there does not appear to be any major challenges, it is in considering the usefulness of the principles at the project implementation level that government officials raised numerous complications and contradictions. The aid effectiveness challenge remains at project implementation.

\subsubsection{The Principle of Ownership}

The principle of ownership requires that "partner countries exercise effective leadership over their development policies and strategies and co-ordinate development actions" (OECD, 2008:3). Despite Tonga's NDS only receiving a D rating, it was evident in the responses from Lord Sevele that he felt the Government of Tonga had strong ownership over the direction and implementation of development policy and practice in Tonga. Lord Sevele did not subscribe to the criticism that donor partners dictate or determine the direction of the country's development.

Lord Sevele maintained that he has not experienced too much in a way of where donor countries would insist their own shape and form of the project relationship. He felt that it was up to the Government to state "what we want and how we would like it done". The case study of TERM provides a strong case of Tonga exercising local ownership over the direction and control of its energy sector. However, this is not taken into account or measured within the Paris Declaration Survey. This serves to illustrate that there are multiple understandings and descriptions of what ownership is and the difficulty of trying to capture and measure this principle (Eyben, 2010b; Faust, 2010; Hyden, 2008). As Whitfield and Maipose (2008) suggest, the indicators tend to miss the complex and diverse dynamics within aid relations. 
At the line ministry level, government officials raised some concerns over the ownership of projects. The respondents emphasised the issue of capacity, which they felt decreased their ability to completely exercise their leadership role. As respondent G1 found, donors are able to influence the direction of projects because "they have the capacity to provide things". It was further stressed by this respondent that "we don't have enough capacity ... at the moment, with all these missions that are coming. But it's not only us, but with other ministries too". Smith (2005:453) questions, "what is more important, ownership of the targets or the capacity to achieve them?"

While participation and consultation pressures have increased, alongside the total amount of grant aid to Tonga (Chapter 4, figure 4.2), the capacity of the government officials to deal with these pressures has remained the same. Respondent G1 highlighted that it was a balancing act where the government has to maintain control over policies and development outcomes, whilst at the same time, "try to buy in the donors". Crocombe (2008:355) suggests, "he who pays the piper calls the tune", suggesting that although recipients are able to state their preferences, it comes down to the donors to decide what they will and will not fund. Ownership then becomes a constant negotiation between recipient governments and development actors. As Whitefield (2009:351) argues, it becomes a process where recipient governments "work their own priorities into the donors agenda or [wait] until implementation to steer the project or programme towards their preferences".

The concern of ensuring that government has the 'buy in' of development partners raises a point made by Jerve and Hansen (2008) discussed in Chapter 3. Tonga may be the "driver of the car but who decides where to go?" (ibid:8). The Government of Tonga is still subjected to a range of social controls and restrictions that complicate their ability to completely exercise 'ownership' as they operate in an environment fraught with tension and compromise. While government officials still felt they had 'ownership' over the country's development policy, being aware of the financial dependence on development partners can create what van de Walle (2005) states as a degree of ventriloquism. This is where "donors make clear what policy expectations are and governments understand what they need to say in order to get foreign assistance" (ibid:67). Van de Walle (2005) argues that in spite of the ownership rhetoric, donors will often sit behind the stage pulling the appropriate strings so that it appears the government is at the front, saying and doing what the donors require. Hellenier 
(2002:255) also suggests that donors may consider ownership to exist when recipients "do what we want them to do but they do so voluntarily".

Although the findings do not conclusively support this to be the case in Tonga, I believe there is a certain level of ventriloquism as respondent G1 stated, donors "have a big say because they have the resources to provide things". Lord Sevele suggested that if there was such a case where donors were trying to determine the shape and form of a development project then he would say, 'we don't go along with it'. However, at the different levels of engagement, from the political level to project implementation, I would question whether this attitude or notion of thinking would transpire. There are various levels of influence at different stages of development policy and practice. While at the political level of engagement (between Prime Ministers and Ministers) it might be straightforward to express and state the direction of the country's development policy, at the level where projects are implemented, I would argue that donors still maintain the ability to influence and steer development outcomes.

\subsubsection{The Principle of Alignment}

It is now widely accepted that donor-driven aid is less effective. In order for aid to be more effective development partners must make use of Tonga's national development strategies, they must align aid flows to national priorities and strengthen the capacity and reliability of Tonga's financial and procurement systems (OECD, 2008). Australia, New Zealand, and the Asian Development Bank have aligned their programmes and partnership agreements to Tonga's Strategic Development Framework (TSDF) 2011-2014. For example, the 'Government of Australia's Partnership for Development with Tonga' has selected four out of the seven outcome objectives of the TSDF 2011-2014. While the New Zealand Partnership agreement does not make any reference to this framework, there have been seven priority sectors selected for support.

The Government of Tonga has taken a proactive approach towards improving donor coordination with the establishment of the Aid Management Division as part of the Ministry of Finance and National Planning (MoFNP) restructure in 2005. The development partner respondents commended this unit as it assisted donors with improving coordination and communication with the government. The government has also undertaken various steps to strengthen the reliability of its PFM system (receiving a rating of 3.5 out of 6 for its 
reliability). However, in the OECD Paris Declaration Survey (2010) only 37\% of aid inflow utilises this system (OECD, 2010). All of the development partner respondents argued that there was an attempt to make increasing use of these systems (specifically the PFM and procurement systems), however, some of these respondents still felt that these systems were not currently at a standard that ensured there was an acceptable level of financial risk and accountability. As respondent DP3 emphasised, there must be "an appropriate level of risk and risk mitigation".

Reinhardt (2006) emphasises that within a funding relationship, donors can 'force' recipients to improve internal procedures and processes in order to give the appearance to donors that their systems are effective and robust. Government officials were aware that this appearance was essential in order to obtain and entice foreign assistance, and were working hard on improving the governments internal systems. As respondent G2 noted, "if Tonga could get its basic admin disciplines in place we would be in a position to reinforce our expectations".

Respondent DP1 acknowledged, "Tonga has to develop a system that fits for Tonga," however, will this system fit for New Zealand, or Australia, or the World Bank? In the current environment it would seem that no matter how robust and reliable Tonga's systems are, they will not meet the standards required by donors because ultimately, donors are not accountable to the ones receiving the development assistance. Donors are accountable to their own stakeholders and/or taxpayers, they operate within their own political context and are driven by their own institutional requirements (Eyben, 2005). They each have their own standards and fiduciary rules, with various responsibilities to which they will be held account. This creates an assorted 'web' of different approaches that the government must work within as donors ask Tonga to follow their own procedures to avoid risk and ensure particular financial management controls are in place (Eyben, 2006).

Even if the focal priorities of donors are the same, once you get below the surface level it appears each donor system is intricately different and this prevents full alignment or harmonisation not only with one another, but also with Tonga. However I would question whether it is the systems that are intricately different or if it is the bureaucratic nature inherent within development institutions that prevent alignment and harmonisation. 
Respondent C2 described donor agency procurement systems as "incompatible creatures," just as the majority of government officials agreed on the complexity and difficulty of following donor PFM and procurement systems. This could be a reason for such poor alignment of donor procedures and policies in Tonga. Donors align primarily to their own domestic systems and then bring that system to Tonga and very "rarely share mutual responsibility for outcomes" (Shutt, 2006:154). Not only does this contradict the donors' commitment to the principle of mutual accountability, but it also questions whether donors will ever completely utilise or rely on recipient government systems. As Fukuyama (2004) believes, donors will not relinquish control because "they don't like to give up the influence and power over client countries that dependence brings" (cited in Browne, 2006:40).

Another response from the Government of Tonga to increase the coordination of donors has been through the use of General Budget Support (GBS) as a mechanism for aid delivery. The Aid Management Division of the MoFNP has stated a preference for this in their 2010 Policy Statement, emphasising that the effectiveness of development assistance will be enhanced through the use of this mechanism. GBS was reintroduced in Tonga in 2009 at the request of government, as the effects of the global economic crisis deepened. However, it came as a series of one-off short-term commitments. The latest GBS negotiations led to the development of a single policy matrix for all donor partners providing GBS. A single policy matrix is an achievement for Tonga and has significantly reduced the administrative burden of receiving development assistance from multiple donors. The World Bank was tasked with coordinating all the donor inputs into this matrix and creating the policy conditions that all development partners could agree to. As respondent G2 recalled,

"what we want you guys to do is harmonise amongst yourselves, talk to each other as you have all promised to do under Paris Declaration, and you guys come up with a team approach rather than a whole bunch of individual donors running around doing their own thing”.

Several of the government respondents noted that the next step for Tonga was to develop Sector Investment Plans, however, this was still in the preliminary stages. The respondents also noted a number of other initiatives to further strengthen the government's role in directing development partner efforts. For example, sector investment plans or prioritised actions plans. However, respondent G2 argued that although these were great ideas the issue sat with the process, "it's the process that kills it". This emphasises Curtis and Poon's 
(2009:837) argument regarding the awkward question of means, "it is easy to define the desirable end states ... but far from easy to identify the casual mechanisms ... to achieve such desired conditions". Development partners tend to focus on the end goal or outcome, regardless of what the implications or complications are of how to get there. As Therkildsen (2005) contends, they focus on what should be done, yet lack of information of how it can be done.

\subsubsection{The Principle of Harmonisation}

The OECD Paris Declaration Survey (2010) found that harmonisation in Tonga was extremely poor. It was measured that only $16 \%$ of reported donor missions were jointly coordinated in 2010 (OECD, 2010). This does not reflect the call for harmonised efforts of development practices, routines and/or standards. It illustrates an inconsistency between what is committed to and what is done in reality (de Renzio, et al., 2008). There are only five core donors in Tonga and as respondent DP4 felt "we should be able to get our act together". However, as respondent G2 concluded, "it all boils down to the fact that they all have different missions and objectives and very rarely will they sing from the same hymn sheet".

Contrary to the results presented in the OECD Paris Declaration Survey, the responses of both government and development partner officials suggested that there was much more harmonisation between development partners than previously experienced. Illustrated in Chapter 5 table 5.4, Australia and New Zealand have joint ventures on a number of projects including Development Scholarships and the Tonga Education Support Project. They are also coordinating on the Tonga Police Development Programme. The World Bank and the Asian Development Bank are involved in joint ventures for example, the Tonga Fiji Submarine Cable Project and the Supporting Vulnerable Groups Programme. These projects alone total $\$ 80.8 \mathrm{~m}$ (TOP) of the $\$ 332.2$ million estimated as the total cash and in-kind contribution of donors for the period 2012/2013 (GoT, 2012b). Although officials reported an increase in the harmonisation among development partners, it was unclear if harmonisation of the donor practices was filtered through to the reporting, monitoring and funding of the projects/programmes.

The failure to coordinate can be related to the bureaucratic resistance within donor agencies. Respondent DP4 noted that when each aid organisation isn't getting along it was largely 
"because of the demands that each organisation places on its own practices". Respondent G2 felt that when donors did talk to each other, it became "a beauty show". This would suggest that the internal and external pressures that are placed on and within donor organisations can prevent donor coordination. Or as van de Walle (2005:76) puts it, "donors love to coordinate, but hate being coordinated". Donors willingly participate and involve themselves within the 'feel good rhetoric' of aid effectiveness, whilst at the same time, maintain a strong individual profile in each recipient country.

While the findings from this research were mixed, I argue that at the level of project implementation, donors need to be doing a lot more work to harmonise their approach. For aid to be more effective, there needs to be a major shift beyond the individual practices of each donor. There needs to be complete alignment of frameworks and systems (van de Walle, 2005). However, there are substantial costs associated with this movement as donors would have to make significant changes to their programme cycles, auditing, evaluation procedures, and much more in order to align to other donors (ibid:2005). If donors were serious about coordination then fundamental changes to the structure and process of each institution would need to occur. Or as Buiter (2007:651) contends, “we would need international standards and codes to benchmark acceptable practice".

Greater harmonisation of development actors could be improved if you task one donor to coordinate the inputs of the other donors involved in each of Tonga's priority sectors. This has occurred in two examples highlighted in Chapter 5 and 6. Firstly, the World Bank was tasked with collaborating all development partner inputs through the negotiations for Tonga's GBS. The World Bank acted on behalf of the other donor partners and produced a single policy matrix in which all partners agreed on. This style of leadership was also evident with the formation of TERM. The World Bank was tasked to coordinate with each of the development partners when putting together the 10-year plan.

While harmonisation of development actors can be successful at the initial stages of putting together a plan, Solomon argues that at the project level, coordination between the government and their development partners needs to be done through a bilateral agreement (Solomon, personal communication, May, 2012). This was also emphasised by respondent G5, "the more donors you have on a project the more administration burden there is ... [as each donor has] different processes and protocols, it is much simpler to have one per 
project". Tasking one donor to coordinate the actions of the rest reflects Little and Clifford's (2006) solution of receiving aid from a single multilateral donor. Although Tonga receives aid from multiple donors, it has recently requested a focus on sector-based approaches. This shift away from individual projects towards a coordinated sector plan will help to reduce the pressure placed on government having to deal with and manage the multitude of donors that each operate with their own systems, procedures and rules. It would significantly reduce the administrative burden of Tonga having to meet the demands of multiple donors.

However, there are two sides to this argument. If you allow each donor to have greater control over individual sectors then this could allow major donors to hold undue influence over the smaller donors and on the recipient (Eyben, 2007). On the other hand, this may provide the opportunity to significantly reduce transaction costs and create stronger and richer relationships that will foster more efficient development outcomes. Little and Clifford (2006:202) suggest, "the initiative in promoting such co-ordination, and choosing the means

of achieving it, lies primarily with the donors". However I would argue that both recipients and donors must be a part of facilitating and promoting this process.

\subsection{Power within the aid relationship}

Chambers (1995) argued that the participatory paradigm was a way of challenging the hierarchical structures involved in the aid relationship, a redistribution of power from the hands of the donor to the hands of the recipient. The Paris Declaration was also an attempt to reassign power to the recipient governments, placing the recipient in the driver's seat. While there has been a significant improvement to development practice in Tonga, many government officials are continually faced with challenges and tensions as a result of donor practices. As we have witnessed above, the aid effectiveness agenda cannot escape the concept of power that is inherent with the aid relationship "as policy is never just technical, it involves politics and power" (Eyben, 2010b:2).

Shutt (2006:254) suggests that recipients often feel that donors have the upper hand because they have control over the resources, making them the more powerful party in the relationship. This was illustrated in respondent G1's comment where they felt "it is one of the issues we [Tonga] need to strengthen. I am not saying that the Government has full 
control, [but] there is some parts that development partners take control because they have the resources".

Eyben (2010b:7) details three different forms of power within an aid relationship: visible power, which is evident in formal institutional arrangements for policy making; informal power, which can shape the policy agenda and often works behind the façade; and invisible power that works through people's internalisation of norms and beliefs. Chambers and Pettit (2004) argue that the concept of power across these three levels needs to be unpacked in order to create effective strategies for change. Donors that only address the first form of power by changing their arrangements and documents (such as the partnership agreements) at the surface level will undermine the recipient's ability to take full ownership and direct development policy and outcomes in their country. Development partners in Tonga have pledged to support country leadership and help strengthen their capacity to exercise it (GoT, 2007). However, they should question whether their practices may still influence the government on the direction, priorities and policies, exercising what Eyben (2010b) terms as 'informal power'.

Tonga's national strategic framework, the Tonga Strategic Development Framework (TSDF) 2011-2014 is the core document that all donors have signed and committed to. Development partners have agreed to follow the government's objectives and prioritised sectors. This demonstrates that donors have addressed Eyben's (2010b) first from of power, visible power. At the surface level I believe donors have aligned to Tonga's priorities and to some extent, incorporated this document into their own plans. However, below this surface a hidden reality can operate, as respondent G2 felt, "there is nothing different in donor philosophies, they are all in the pursuit of their own interests". In order for the Government of Tonga to receive development assistance, as highlighted in the example of the GBS one page policy matrix, the government must undertake specific policy actions to achieve the stated outcomes. This indicates that a certain level of informal power is at play as Tonga is circumscribed to various conditions (or policy actions) set out by donors. Donors are able to continuously assert their preferences through this conditionality and if aid can never be extended without conditions, as Cramer, Stein and Weeks (2007) question, how is full ownership possible? Or at least, how is national policy then not donor driven? Ownership can never be complete if a country retains dependency on foreign aid (ibid:431). 
Furthermore, the achievement of effective leadership should not just be seen in relation to the development of the TSDF, but in the design and implementation of strategies that will ensure the plan is sustainable and achievable. This was an area highlighted by both donors and government officials as extremely weak. Tonga simply does not "have the capacity or the capability of coordinating [donors] so that we play the music and you dance to our tune". Hyden (2008:273) argues that failing to confront the issue of power may undermine the credibility and standing of the commitments in the Paris Declaration. It also undermines the concept of 'partnership' that is technically understood as an equal relationship between the donor and the recipient. Kakande (2004) explains that there is a tension that exists between donors and recipients because any true partnership depends upon reciprocity and mutual benefit, yet as the resources sit on one side the partnership is inherently unequal. Until the concept of power is addressed and unpacked across the multiple levels, as Eyben (2010b) and Chambers and Pettit (2004) detail, then the current challenges that continue to impede development efforts will remain.

Chambers and Pettit (2004:140) have identified four action domains that are required in order address power. Firstly, it is understanding and analysing power to make it visible. Secondly, it is narrowing the gaps between words and actions. Thirdly, it is changing rules and procedures to balance power relations and fourthly, it is organisational learning and change through internal reflection. While Tonga would benefit from each and any one of these actions, what came through strongly in the responses of government officials was the importance of relationships. The individual or organisational relationships between recipients and donors can have a significant impact on the success of a project or programme and this was highlighted through the formation of TERM. Lord Sevele stated that it was because of the "personal relationship we had with the New Zealand Minister of Foreign Affairs, Murray McCully, that allowed [the Meridian Solar Project] to be pushed along, and I hope that that will continue and with other development partners". Respondent G1 also emphasised, that although "there is still more room for improvement with dialogue with the donors ... I think our relationship with them is getting better".

Strengthening and facilitating the relationship between government and their development partners would potentially create a more balanced 'partnership' and allow the space for closer alignment and harmonisation of aid policies and plans. As Eyben (2010b:6) argues, donor action should invest in long term and consistent relationships. However, there is also a 
contradiction in terms between having strong 'ownership,' which implies the recipient holds the power, versus 'partnership,' which assumes an egalitarian relationship (Jerve and Hansen, 2008:14). Regardless of the way power is manifested in the relationship, it is important to understand that it will always be there. Power can be viewed on a continuum, where it may shift back and forth but it will always exist. Instead of ignoring the power dynamics at play, development actors must acknowledge and figure out ways where power imbalances can be mitigated and/or moderated to ensure a balanced playing field (Eyben, 2010b; Hyden. 2008).

Lamour (2007:259) cautions, "donors want recipients to want what donors want," they seek to influence, not control, as they do not like to seem to be pushing governments around. Donors can still exert influence while aiming to build local self-capacity and they gloss over their influence with the feel good rhetoric of 'participation' (Eyben and Ladbury, 1995). Lamour elaborates on the ability of the powerless to deploy 'weapons of the weak', where recipients can "drag their feet, play the fool, and sabotage a process they claim to be going along with" (Lamour, 2002:252). Although there was no evidence to suggest that officials act in this manner, I would argue that Tonga has its own techniques and strategies to help steer the development process. As Browne (2005:145) suggests, "donors will not simply agree to stop offering aid, but developing countries can start to take more control" and I argue that this was evident in the case of Tonga.

\subsection{Participatory Practice?}

Since 2008, there have been significant achievements to development policy and practice in Tonga. The findings presented in Chapter 5 and 6 illustrate various examples of Tonga asserting control over development policy and practice. Tonga has taken some progressive steps towards increasing dialogue and engagement with development partners. For example, the Government of Tonga created the Aid Management Division to coordinate all development work happening in Tonga. The government has also requested donors to report quarterly to the Aid Management Division followed by the formalising of donor round house table meetings that are set to occur twice a year. These examples demonstrate the Government of Tonga taking greater control over policy discussions and planning.

The actions taken by government officials in the formation and establishment of TERM are also a clear sign of Tonga exercising ownership over its development policy. TERM is a 
significant achievement for Tonga, it represents Tonga putting its agenda on the table and as respondent $\mathrm{C} 2$ noted, it was Tonga stating, "this is our priority and this is our plan. If you like it then please come along and if you don't like it, find somebody else to give your money to because this is what we want out of the energy sector". Tonga could no longer afford the previous ad hoc approach that had continued to impede the country's energy sector. The Government of Tonga understood that in order to combat its energy problem, it required an entire sector approach. It also required a singular and coordinated plan in order to achieve the end goal of reliable and affordable electricity for the people of Tonga (TERM, 2010).

So the overarching question is, has development practice in Tonga become more participatory? On the surface level it appears that Tonga is accorded the political space to set its own development agenda. However, at the project implementation level, major donors still operate in a manner that allows them to exert strong influence. I would argue that the establishment of TERM was not a case where donors decided to let go, or "a strong practical example of the application of the Cairns Compact principles to development in Tonga" (PIFS, 2010:21). This is an example of Tonga putting its foot down, stating no 'our priorities are this'. Although donors were willing to be on board with it, they were not the ones driving it. As Lord Sevele recalls, "we drove that programme, and we drove that project and set the agenda, and they [development partners] saw the value of that and then came together".

The Government of Tonga has shifted towards strategic sector plans as a means of gaining further control over the country's development and I would argue that other core priority sectors in Tonga may benefit from a plan similar to TERM. The TERM gives Tonga a framework to work within. It outlines the necessary steps to achieve the end goal set, whether that is affordable and reliable electricity, "sound education standards" or "improved health of the people" (TSDF, 2011-2014). As government respondent G1 noted, it starts with having a robust plan that would in turn give the government control, "so we can say 'no' we don't want to do that, our priorities are this". However one major constraint as noted by all the respondents is capacity. Human and resource capacity must be strengthened to allow the space for recipient governments to say 'no'.

Development partners are at the forefront of the aid effectiveness agenda, they have recognised that their own processes and systems can decrease the effectiveness of aid. Making a commitment to the Paris Declaration is much easier than actually achieving the 
principles and objectives, and ultimately, there are no consequences for failing to meet these commitments. This lack of enforceability allows donors to continue with the same practices that have plagued the Pacific region for over 40 years. However, if the principles in the Paris Declaration create the space for recipient countries to exercise local agency over the structure and language of development, then there is an opportunity to carve out space and exercise a certain degree of local control. Respondent G1 stated that the high level commitments (such as the Paris Declaration and the Busan Partnership for Effective Co-operation) have created the foundations for further dialogue with donors, "that's our basis for us to talk with the donors". These high level commitments can then be used as a point of discussion with donors or for Tonga to use as weighting when holding donors to account.

As outlined in Chapter 5, there was a positive attitude and commitment from the donors. The rhetoric is that they want to improve the effectiveness of aid and I argue that the intent is there. However, what we see in reality is that they are unable to follow through on what they are promising. The development agencies that have the power, capability, resources and funds appear incapable of making the changes that are required to achieve full harmonisation or alignment. The Paris Declaration would like to simplify the practice of development, it would like to neatly box and outline the logical steps that are required to make aid more effective but in reality, it is not that simple. Aid is a messy and contested process (Eyben, 2010a) and despite the development actor demands for simplicity, development cannot be retrofitted into principles. As evidenced throughout this thesis, the principles then become fraught with contradictions and paradoxes. It is important to note that the Paris Declaration is only one driver within the aid effectiveness agenda. However, what is clear is that there needs to be a better understanding of what the principles mean, and what the implications of their application are in reality.

Over the past year there have been further discussions over the interpretation and application of the aid effectiveness agenda with the High Level Forum for Aid Effectiveness in Busan 2011. This has resulted in a shift from aid effectiveness, to effective development cooperation. This forum placed greater emphasis on collaboration between private sector, emerging donors (the Brazil, Russia, India and China (BRIC)) and the role of civil society. This forum emphasised the important role of civil society in the development effectiveness discussions. A greater emphasis was also placed on the 'orphan' principles of the Paris 
Declaration, Mutual Accountability, and Managing for Results (Fourth High Level Forum on Aid Effectiveness, 2011).

What remains to be seen is whether or not these high level forums will influence aid practice at the ground level, and in what way. It is argued to become a cycle where the agenda becomes continually rephrased into new cycles of assistance as the current agenda fails to achieve the declared objectives and outcomes (Browne, 2006:40). The PFIS Tracking Report in 2011 stated six key messages to policy makers to strengthen development coordination in the Pacific. Below are three of the key messages that I argue ring true for the case of Tonga:

- The crucial factor in alignment and harmonisation is strong political leadership and aid management capacity;

- The Pacific needs simpler and less fragmented aid delivery modalities;

- The pace of harmonisation and alignment is still driven by the internal regulations and preferences of some development partners rather than country needs (PFIS, 2011).

\subsection{Final Conclusions and Reflections}

At the start of the thesis, I reflected on my own experience working at the TERM-IU. I reflected on the pressures that were faced by government officials as they worked to meet the demands of multiple development actors working in the region. The challenges faced by government officials are born out of the increasing demands from the donor community that emphasise the need of full participation and consultation of recipient countries. This thesis has explored the issues experienced by government officials in context of the aid effectiveness agenda.

The aim of this study is to investigate the influence of the aid effectiveness agenda on Tongan development policy and practice. This thesis has looked at the ways in which the Paris Declaration Principles have been interpreted and engaged with. It has highlighted the many challenges and tensions associated with implementing the Paris Declaration. However, it has also provided a number of examples that illustrate positive achievements to development policy and practice in Tonga. At the political level, where policy is constructed and specified, there has been a significant shift in donor rhetoric. Tonga's core development partners have aligned to the national strategic framework (TSDF 2011-2014) and have shifted their focus to support the stated priorities of Tonga. The Government of Tonga has taken 
some remarkable strides over the past five years, furthering its relationships with development partners and increasing their control over development policy, planning and discussions. There has been a clear shift away from project and programme aid towards sector wide approaches and the use of budget support. However, I question if these outcomes are the result of systematic planning and intervention by the development community, or the result of good relationships and strong leadership exhibited by the Government of Tonga.

Many of the tensions and frustrations highlighted by government officials in this chapter illustrate the power imbalances that are embedded within the aid relationship. Though forms of 'visible power' (Eyben, 2010b) have been addressed in policy documents such as Tonga's national development framework (TSDF 2011-2014) or in the partnership agreements between Tonga and its development partners, informal forms of power continue to operate. This was highlighted by respondent G1's comment, "development partners have a big say because they have the resources to provide things". Ultimately, it was the limited capacity of the ministries that government officials felt continued to hinder progress.

Small island nations receive over nine times the amount of aid than other development countries. As Crocombe (2008) illustrates, despite being constitutionally independent, many remain reliant on outside money and services. This is exemplified by the case of Tonga and raises concerns regarding the influence of international pressures as it can create a situation where "dependence [is] wrapped in a rhetoric of self reliance" (ibid:353). The Paris Principles in their detailed unfolding, illustrate that there is a long way to go to attain the ideal outcome. In the case study of TERM, it was stated by respondent G5 that there was "little coordination from donors on specific projects," highlighting that the "more donors you have on a project the more administration burden there is". Respondents also expressed frustration with the complex and arduous procurement and financial management systems of donors that had the ability to "delay any project" (respondent C1). Several respondents suggested that it was not the wider sector programmes that added to the burden of their workload, but it was the numerous smaller projects that took up the time and resources of local staff. This was also illustrated in Chapter 5, section 5.4, where there was an inverse relationship between the number of missions to the size of the programmes. Comparably, Wrighton (2010a:141) found this to be evident in the case study of Tuvalu, emphasising that "the relationship between monetary inflow and time taken to service the relationship was an inverse one". 
Local ownership is still constrained by capacity issues as respondent G1 expressed, "the lack of our resources tend to hinder [progress]" and as respondent G2 stated, "we cannot and do not have the capacity or the capability of coordinating you guys [donors] so that we play the music and you dance to our tune". Several government officials also emphasised the lack of financial information provided on donor expenditure and intended expenditure. They questioned how they were able to be accountable for the budget when the numbers in the budget were guesses. The tensions and pressures experienced by government officials serve to illustrate that power dynamics remain asymmetrical.

Hyden (2008) argues that failing to tackle and address the concept of power will undermine the credibility of the Paris Declaration. While I argue this to be true, underneath the structural and theoretical relationship between donors and recipients lies power relations that cannot be captured in a global document such as the Paris Declaration. The day-to-day practice of aid is influenced by relationships, power relations, personalities, cultures and environments. These have to be dealt with on the ground through face-to-face negotiations every day. "It would be nice if people could make their own choices ... but in practice, much larger forces determine the parameters" (Crocombe, 2008:437). Development agencies must recognise this and act in ways that acknowledge and work with the "fluid and multi-layered processes of power that are reality, rather than the orthodox linearity portrayed in policy documents (such as the Paris Declaration)" (Eyben, 2010 cited in Collins, 2011:16).

The principles and concepts born out of the aid effectiveness agenda are at the core of important questions relating to sovereignty, control, influence and power. Translating the principles into practice is far more complicated than the Paris Declaration definition indicates, and ultimately, there is no enforceability or consequences of failing to adhere, or meet principles laid out in the Paris Declaration. Mosse (2004:640) suggests that what makes for good policy can be different to that which makes it implementable. It would appear that these principles are successful at the high level forums and at the political level of the development partnership exercised at the scale of the nation-state. At the implementation level however, they are more difficult to implement with significant challenges that remain. The bureaucratic nature of development agencies can conspire to prevent these principles being implemented and "this is where the rhetoric of aid is turfed-out the window" 
(respondent G2) because ultimately, development partners have been unable to completely harmonise with one another or align with the Government of Tonga.

The contradictions and paradoxes of the Paris Declaration Principles were also evident in Wrighton's (2010a) case study of Tuvalu. Wrighton and Overton (2012) argue that despite the development agencies obligation to international commitments such as the Paris Declaration, development practice continues to challenge Tuvaluan officials in a number of ways. The participation and consultation pressures placed on officials undermines the ability of Tuvalu to effectively govern itself (ibid:2012). I question if it is more honest for development agencies not to sign up to the international commitments but still follow principles of good practice. Or alternatively, sign up to the commitments but not meet them?

\subsection{Further Research}

Significantly more research must be undertaken in order to understand the impact of the aid effectiveness agenda and what the realities of its application are. This research is required not just across the Pacific, but across multiple regions and countries. Each place has its own unique structures, systems and processes, and the individual ways they configure to the different aid modalities differs widely. The case study of TERM illustrates a strong example of Tonga taking ownership and control over its development policy and planning. While this has only been illustrated in the one case study, I argue that it offers some useful insights into how alternatives to the current practice of aid might be developed. Research with a similar case study methodology is therefore important to ensure that policy related discussions are grounded with the experiences of those that are impacted (Yin, 2009). This will assist in reducing the gap that remains between policy and practice.

Another area of research crucial to further understand the aid effectiveness agenda would be an analysis of the development institutions themselves. Are their systems and procedures capable of complete alignment or harmonisation? What is preventing this from happening and what can be done to facilitate greater alignment and harmonisation of development institutions? This study has also focused on the interaction between government officials and donors, however, further research needs to be undertaken to facilitate a deeper understanding by and between civil society and non-government actors and broader stakeholders in the aid relationship. 


\subsection{Final Reflection}

The aid effectiveness agenda has intended consequences. While some of these consequences have eventuated in Tonga as planned in the Paris Declaration, some have not. Where the challenge lies is in picking up the principles and implementing them. The Government of Tonga has taken fundamental steps towards enhancing the effectiveness of aid. However, there is a paradox in that these steps are being made by Tonga, which sits on the smaller scale of the power asymmetry and which does not have nearly the same technical or human capacity that its development partners hold. While the size of the country can create a certain level of vulnerability to external powers, as Warrington suggests, a country's “'governing wits' may well compensate for the economic, demographic, cultural and political disadvantages that are legitimately associated with small scale" (Warrington, 1998:105).

What will be the case be for Tonga as new players enter the region and what will this mean for the geopolitical alliances? The aid environment will only be further complicated and it will be vital for Tonga to be more assertive to the donor community to ensure that development policy and practice is owned, directed and managed by Tonga. With aid effectiveness discussions at the top of everyone's agenda, I argue that now is the opportune time for Tonga to make more assertive strategies in negotiating aid and achieving control over development policy and practice. As Prime Minister Sevele stated, whatever policy goal or direction a recipient country has it must,

"sit as a priority at the highest level of government. You must tell development partners what you want, and then work with them to formulate credible framework, and finally, keep telling development partners what YOU as a country and people want" (Sevele, 2011:6). 


\section{References}

Action Aid, 2008. Making Aid Accountable and Effective. Johannesburg, Action Aid.

Asian Development Bank, 2011. Country Operations Business Plan, Tonga 2012-2014. Manila.

Angen, M., 2000. Evaluating interpretive inquiry: Reviewing the validity debate and opening the dialogue. Qualitative Health Research, 10(3): 378-395.

Armon, J., 2007. Aid Politics and Development: A Donor Perspective, Development Policy Review, 25(5): 653-656.

Bergamecschi, I., 2007. Mali: Patterns and limits of donor-driven ownership. GEG Working Paper. University of Oxford. Retrieved from www.globaleconomicgovernance.org/wpcontent/uploads/Bergamaschi_Mali_200731.pdf

Baxter, J., 2010. Case Studies. In I. Hay Qualitative Research Methods in Human Geography (3rd Ed.) London: Oxford University Press.

Bertram, G. and Watters, R., 1985. The MIRAB economy in South Pacific microstates. Pacific Viewpoint, 26(3): 497-519.

Bochner, A., 2000. Criteria Against Ourselves. Qualitative Inquiry, 6(2): 266-272.

Bradshaw, M. and Stratford, E., 2010. Qualitative research design and rigour. In I. Hay (eds.) Qualitative Research Methods in Human Geography. Meridian Series in Geography (3rd ed). Oxford University Press, Canada, pp. 69-80.

Brinkerhoff, D., 1996. Process perspectives on policy change: highlighting implementation. World Development, 24(9): 1395-1401. 
Brockington, D. and Sullivan, S., 2003. Meaning and fieldwork: Lessons from qualitative research methodologies. In R. Schevyns (ed) Field work and Development Studies. A Rough Guide. Sage: London, pp. 57-76.

Brohman, J., 1996. Popular development: rethinking the theory and practice of development. Wiley-Blackwell.

Browne, S., 2006. Aid and Influence: Do Donors Help or Hinder? London; Sterling, VA: Earthscan.

Bryman, A., 2004. Social research methods, (2nd.), Oxford: Oxford University Press.

Bryman, A. and Bell, E., 2003. Business Research Methods, Oxford: Oxford University Press.

Bulir, A., and Hamann, A. J., 2008. Volatility of Development Aid: From the Frying Pan into the Fire? World Development, 36(10): 2048-2066.

Buiter, W., 2007. Country ownership: A term whose time has gone. Development in Practice, 17(4-5): 647-652.

Burnside, C. and Dollar, D., 2000. Aid, Policies, and Growth. American Economic Review, 90(4): 847-868.

Cahill, C., 2007. Doing Research with Young People: Participatory Research and the Rituals of Collective Work, Children's Geographies, 5(3): 297-312.

Campbell, D. and Stanley, J., 1966. Experimental and Quasi-experimental Designs for Research. Chicago: Rand McNally.

Campbell, I., 1992a. A Historical Perspective on Aid and Dependency: The example of Tonga. Pacific Studies, 15(3): 59-75. 
Campbell, I., 1992b. Island Kingdom. Tonga Ancient and Modern. Canterbury: University Press.

Campbell, I., 2005. The Quest for Constitutional Reform in Tonga. The Journal of Pacific History, 40(1): 91-104.

Campbell, I., 2008. Tonga: the Constitution, the Riot, the Election and Reform. New Zealand International Review, 33(5): 2.

Campbell, I., 2011. Tonga's Way to Democracy. Christchurch [NZ]: Herodotus Press.

Chacko, E., 2004. Positionality and Praxis: Fieldwork Experiences in Rural India. Singapore Journal of Tropical Geography, 25(1): 51-63.

Chambers, R. and Pettit, J., 2004. Shifting Power to Make a Difference. In R. Groves, and L. Hinton (eds.), Inclusive Aid Changing Power and Relationships in International Development. Earthscan: London, pp. 137-162.

Chambers, R., 1995. Paradigm Shifts and the Practice of Participatory Research and Development in Nelson $\mathrm{N}$ and Wright $\mathrm{S}$ (eds.) Power and Participatory Development: Theory and Practice. Intermediate Technology Publications London, pp. $30-42$.

Chandler, D., 2007. The Other-regarding ethics of the 'empire of denial'. In D. Chandler and V. Heins, Rethinking ethical foreign policy pitfalls, possibilities and paradoxes. London; New York: Routledge pp. 161-183.

Clarke, M., Fry, T. and Mihajilo, S., 2007. Aid Allocation Volatility to Small Island States. Research Paper No. 2007/18. United Nations University: Wider.

Clemens, M., Kenny, C. and Moss, T., 2007. The Trouble with the MDGs; Confronting Expectations of Aid and Development Success. World Development, 35(5): 735-751. 
Collins, L., 2011. Unpacking Ownership at a Joint Sector Review. Unpacking aid workshop, London School of Economics.

Collins, L., 2009. Progress from Specificity: How to Monitor the Paris Declaration in the Malawi Education Sector. Prospects: Quarterly Review of Comparative Education, 39(2): 163-183.

Cooke, B. and Kothari, U., 2001. The Case for Participation as Tyranny. In B. Cooke and U. Kothari (eds.), Participation: the new tyranny. London: Zed Books, pp. 1-15.

Cornwall, A., 2008. Unpacking "Participation": Models, Meanings and Practices. Community Development Journal, 43(3), 269-283.

Cramer, C., Stein, H. and Weeks, J., 2006. Ownership and Donorship: Analytical issues and a Tanzanian case study. Journal of Contemporary African Studies, 24(3): 415-436.

Crocombe, R., 2008. The South Pacific $7^{\text {th }}$ eds. University of the South Pacific: Suva.

Curtis, D., \& Poon, Y., 2009. Why a managerialist pursuit will not necessarily lead to achievement of MDGs. Development in Practice, 19(7): 837-848.

Danish International Development Agency (DANIDA), 2006. Denmark's Participation in International Development Cooperation. Schultz: Grafisk.

de Haan, A., 2009. How the Aid Industry Works: An introduction to international development. Sterling: Kumarian Press.

De Renzio, P., 2005. Increased Aid vs Absorptive Capacity: Challenges and Opportunities Towards 2015. IDS Bulletin, 36(3): 20-27.

De Renzio, P., Whitfield L. and Bergamaschi I., 2008. Reforming Foreign Aid Practices: What Country Ownership Is and What Donors Can Do to Support It. Briefing Paper, Global Economic Governance Programme, Oxford: University of Oxford. 
Denzin, N. and Lincoln, Y., 1994. Introduction: Entering the field of qualitative research, in N. Denzin, and Y. Lincoln (eds), Handbook of Qualitative Research, Thousand Oaks: Sage publications, pp. 1-17.

Dijkstra, G., 2011. The PRSP Approach and the Illusion of Improved Aid Effectiveness: Lessons from Bolivia, Honduras and Nicaragua. Development Policy Review, 29: $110-133$.

Dunkly, G., 2007. The Reality of Aid. London: Zed Books.

Easterley, W., 2006. The White Man's Burden Why the West's Efforts to Aid the Rest Have Done So Much Ill and So Little Good. Penguin Group: New York.

Easterly, W., 2008. Reinventing Foreign Aid. Massachusetts Institute of Technology Press: Massachusetts.

Egan, A., 2008. Mutual Accountability: “Orphan” Principle of the Paris Declaration. ODE Issues Note, Office of Development Effectiveness, AusAID: Australian Government.

England, K., 1994. Getting Personal: Reflexivity Positionality and Feminist Research. Professional Geographer, 46(1): 241-256.

ESCAP, 2001. Sustainable Energy Policy: Overview Report on an Advisory Mission to Tonga. (Chris Cheatham for ESCAP \& GoT; October)

Eyben, R., 2010a. Hiding Relations: The Irony of 'Effective Aid, European Journal of Development Research, 22(3): 382-397.

Eyben, R., 2010b. Supporting Inclusive and Democratic Ownership: A 'how-to note' for donors. Report for the OECD DAC Working Party on Aid Effectiveness Cluster A 'Ownership and Accountability'. 
Eyben, R., 2008. Power, Mutual Accountability and Responsibility in the Practice of International Aid: A Relational Approach, Working Paper 305, Institute of Development Studies. Brighton: University of Sussex.

Eyben, R., 2007. Harmonisation: How is the orchestra conducted? Development in Practice, 17(4-5): 640-646.

Eyben, R., 2005. Donors' Learning Difficulties: Results, Relationships and Responsibilities. IDS Bulletin, (36): 98-107.

Eyben, R. (ed.) 2006. Relationships for Aid. London: Earthscan.

Eyben, R. and Ladbury, S., 1995. Popular participation in aid-assisted projects: why more in theory than practice? In N. Nelson and S. Wright (eds.) Power and Participatory Development Theory and Practice. Intermediate Technology Publications: London, pp. 192-200.

Faust, J., 2010. Policy Experiments, Democratic Ownership and Development Assistance. Development Policy Review, 28(5): 515-534.

Fonua, S., 2004. The inside story: Handling research on language practices in Tonga. In T. Baba, O. Mahina, N. Williams \& U. Nabobo-Baba (Eds.), Researching the Pacific and Indigenous peoples: Issues and perspective. Centre for Pacific studies. The University of Auckland, pp. 170-178.

Fourth High Level Forum on Aid Effectiveness, 2011. Busan Partnership for Effective Development Co - operation Fourth High Level Forum on Aid Effectiveness. Busan, Republic of Korea. Retrieved from http://www.aideffectiveness.org/busanhlf4/en/component/content/article/698.html

Fua, S., 2009. Ko Hota Fa'ungamatou'a Ko Jota Kaha'u: A Knowledge System for Redesigning Tongan Curriculum. In Sanga, K and Thaman, K.H. (eds) Re-thinking 
Education Curricula in the Pacific: Challenges and Prospects, Wellington: He Parekereke. pp. 196-221.

George, R., 2010, June 14. Tonga's King announces nuclear energy as an option for Tonga. Pacific Scoop. Retrieved from http://pacific.scoop.co.nz/2010/06/tongas-king-announces-nuclear-energy-as-anoption-for-tonga/.

George, A. and Bennett, A., 2004. Case Studies and Theory Development in the Social Sciences. Cambridge, MA: MIT Press.

Government of Australia, 2009. Partnership for Development between the Government of Australia and Government of Tonga. Canberra.

Government of Tonga, 2007. Joint Declaration of Aid Effectiveness Between the Government of Tonga and Development Partners. Nuku'alofa.

Government of Tonga, 2009. National Strategic Planning Framework, 2009-2014. Prime Minister's Office, Nuku'alofa.

Government of Tonga, 2010. Ko e Konisitutone 'O Tonga 1839-2010. Special Publication to mark the historical election of November 25, 2010. Nuku'alofa.

Government of Tonga, 2011. Tonga National Population Census 2011. Ministry of Information and Communications. Tonga Government Portal. Retrieved from http://www.pmo.gov.to/press-releases/3220-tonga-national-population-census-2011preliminary-count

Government of Tonga, 2012a. Tonga Energy Roadmap gets a boost from REEEP. Ministry of Information and Communications. Tonga Government Portal. Retrieved from http://www.pmo.gov.to/ministrydepartment/govt-departments/energy-term

Government of Tonga, 2012b. Government 2012/13 Budget Presented to the Prime Minister. Ministry of Finance and National Planning. Media Release 8 June 2012. Retrieved 
from http://www.pmo.gov.to/news-today/press-releases/3828-government-20122013budget-presented-to-the-prime-minister

Government of Tonga, 2012c. Budget Statement 2012-2013. Ministry of Finance and National Planning. Nuku'alofa.

Government of New Zealand, 2011. Tonga - New Zealand Joint Commitment for Development. Wellington.

Griffin, K. and Enos, J., 1970. Foreign Assistance: Objectives and Consequences. Economic Development and Cultural Change, 18(3): 313-327.

Halapua, S., 2000. Talanoa process: The case of Fiji. Honalulu, HI: East West Centre.

Hammer, M. and Whitty, B., 2011. Domestic and Mutual Accountability for Aid: Building Stronger Synergies: Case Study Report: Cameroon, One World Trust for the Commonwealth Secretariat.

Hayward, C., Simpson, L., and Wood, L., 2004. Still Left out in the Cold: Problematising Participatory Research and Development. Sociologia Ruralis, 44(1): 95-108.

Helleiner, G., 2002. Local Ownership and Donor Performance Monitoring: New Aid Relationships in Tanzania? Journal of Human Development, 3(2): 251-61.

Hopkins, P., (2007) Positionalities and knowledge: Negotiating ethics in practice. $A C M E$, 6(3): 386-394.

Hyden, G., 2008. After the Paris Declaration. Taking on the issue of power. Development Policy Review, 26(3): 259-274.

IMF, 2010. Tonga: 2010 Article IV Consultation—Staff Report, Staff Supplement, and Public Information Notice on the Executive Board Discussion. IMF Country Report No. 10/112. Retrieved from http://www.imf.org/external/country/ton/index.htm 
Iulai, L., 2010. Aid Volatility: is it a problem in Tuvalu? Research Paper submitted as partial fulfillment of the program of Master of Public Policy (Development Policy). Crawford School of Economics and Government, Australian National University.

James, K., 2002. The Recent Elections in Tonga: Democratic Supporters Win but Does Democracy Follow? The Journal of Pacific History, 37(3): 313-322.

Jayaraman, T., and Lau, E., 2011. Oil Price and Economic Growth in Small Pacific Island Countries, Modern Economy, 2(2): 153 -161.

Jerve, A. and Hansen, A., 2008. Introduction: Conceptualising Ownership in Aid Relations. In M. Jerve, Y. Shimomura, and A. S. Hansen (eds), Aid Relationships in Asia: Exploring Ownership in Japanese and Nordic Aid. London, Palgrave Macmillan, pp. $3-21$.

Kakande, M., 2004. The Donor-Government-Citizen Frame as Seen by a Government Participant. In R. Groves, and L. Hinton (eds.), Inclusive Aid Changing Power and Relationships in International Development. Earthscan: London.

Keith-Reid, R., n.d. Politics: Crown Prince Wants Out of Energy Business. But not after being reimbursed. Islands Business. Retrieved from http://www.islandsbusiness.com/islands_business/index_dynamic/containerNameToR eplace $=$ MiddleMiddle/focusModuleID=5122/overideSkinName=issueArticle-full.tpl

Kennedy, T., 1972. Geography of Tonga. Wallbank Government Printers. Nuku' Alofa.

Koeberle, S. and Stavreski, Z., 2006. Budget support: Concepts and issues. In S. Koeberle, Z. Stavreski and J. Walliser (eds.), Budget Support as More Effective Aid. World Bank, pp. 3-27.

Larmour, P., 2002. Conditionality, coercion and other forms of "Power": international financial institutions in the Pacific. Public Administration and Development, 22(3): 249-260. 
Lensink, R. and Morriessy. O,. 2001. Aid instability as a measure of uncertainty and the positive impact of aid on growth. Journal of Development Studies. 36(3): 31-49.

Leslie, H., and Storey, D., 2003. Entering the Field. In R. Scheyvens and D. Storey (eds.) Development Fieldwork: A Practical Guide, Sage: London, pp. 119-138.

Little, I. M. D. and Clifford, J. M., 2006. International Aid the Flow of Public Resources from Rich to Poor Countries. Transaction Publishers: New Brunswick.

Lomoy, J., 2010. Presentation for Do No Harm: International support for statebuilding in fragile situations. Public lecture: 6 May 2010. London School of Economics. Retrieved from http://www2.1se.ac.uk/publicEvents/events/2010/20100506t1830vOT.aspx

McGillivray, M., 2005. Is aid effective? Mimeo, Helsinki. United Nations University: Wider.

Monye, S., Ansah, E. and Orakwue, E., 2010. Easy to Declare, Difficult to Implement: The Disconnect Between the Aspirations of the Paris Declaration and Donor Practice in Nigeria. Development Policy Review, 28(6): 749-770.

Mosse, D., 2001. People's Knowledge, Participation and Patronage: Operations and Representations in Rural Development In B. Cooke and U. Kothari (eds.), Participation: the new tyranny. London: Zed Books, pp. 16-35.

Mosse, D., 2004. Is Good Policy Unimplementable? Reflections on the Ethnography of Aid Policy and Practice. Development and Change, 35(4): 639-671.

Mullings, B., 1999. Insider or outsider, both or neither: some dilemmas if interviewing in a cross-cultural setting. Geoforum, 30: 337-350.

Murray, W. and Overton, J., 2003. Designing Development Research. In R. Scheyvens, and D. Story (eds.), Development Fieldwork: A Practical Guide. Sage Publications: London, pp. 17-35. 
Murray, W. and Overton, J., 2011a. Neoliberalism Is Dead, Long Live Neoliberalism? Neostructuralism and the International Aid Regime of the 2000s. Progress in Development Studies, 11(4): 307-319.

Murray, W. and Overton, J., 2011b. The Inverse Sovereignty Effect: Aid, Scale and Neostructuralism in Oceania. Asia Pacific Viewpoint, 52(3): 272-284.

Nabobo-Baba, U., 2004. Research and Pacific Indigenous Peoples: Silenced Parts and Challenged Futures. In T. Baba, O. Mahina, N. Williams and U. Nabobo-Baba (eds.). Researching Pacific and Indigenous Peoples: Issues and Perspectives. Centre for Pacific Studies: University of Auckland, pp. 17-32.

Naidu, V. and Wood, T., 2008. A Slice of Paradise? The Millennium Development Goals in the Pacific-progress, pitfalls and potential solutions. Working Paper No 1, Oceania Development Network working paper. Apia: National University of Samoa.

Naidu, V., 1995. Whose Sea of Islands? In E. Waddell, V. Naidu and E. Hau'ofa, A New Oceania Rediscovering Our Sea of Islands. University of the South Pacific: Suva.

Narayan, K., 1993. How Native is a "Native" Anthropologist? American Anthropology, 95(3): 671-86.

Nelson, N. and Wright, S., 1995. Participation and Power. In N. Nelson and S. Wright (eds.), Power and Participatory Development Theory and Practice. Intermediate Technology Publications: London, pp. 1-18.

OECD, 2003. Harmonising Donor Practices for Effective Aid Delivery. OECD: Paris.

OECD, 2008. Paris Declaration on Aid Effectiveness and the Accra Agenda for Action. OECD: Paris.

OECD, 2010. Paris Declaration Survey. Draft Summary of Progress. Nuku'alofa, Tonga. 
OECD, 2011. Net Official Development Assistance, Tonga Data. OECD: Paris.

Okail., N., 2011. Unpacking Foreign Aid Effectiveness. Examining Donor Dynamics. Draft Paper. London School of Economics and Political Science. Retrieved from http://aidconference.files.wordpress.com/2011/05/okail-paper.pdf

PIFS, 2012. Online. Retrieved from

http://www.forumsec.org/pages.cfm/about-us/

PIFS, 2010. Development Partner Reporting. Consolidated Analysis Report. Cairns Compact for Strengthening Development Coordination in the Pacific. PIFS. Suva.

PIFS, 2009. Cairns compact on strengthening development coordination in the Pacific, Forum Communique. In: Fortieth Pacific Islands Forum, Cairns, Australia, 5-6 August, 2009. Retrieved from

www.forumsec.org/resources/uploads/attachments/documents/Cairns $\% 20$ Compact $\% 2$ 02009.pdf

PIFS, 2007. Pacific Aid Effectiveness Principles Final, PIFS. Suva. Retrieved from www.forumsec.org/.../Pacific_Aid_Effectiveness_Principles_Final_2007.pdf

PIFS, 1989. Leaders' Communiqué 1. PIFS: Suva. Retrieved from http://www.forumsec.org/pages.cfm/documents/forum-communiques/

PIFS, 1976. Leaders' Communiqué. PIFS: Suva. Retrieved from http://www.forumsec.org/pages.cfm/documents/forum-communiques/

PIFS, 1972. Leaders' Communiqué 1. PIFS: Suva. Retrieved from http://www.forumsec.org/pages.cfm/documents/forum-communiques/

PNG Government, 2008. Kavieng Declaration on Aid Effectiveness: A Joint Commitment of Principles and Actions Between the Government of Papua New Guinea and Development Partners. Retrieved from http://pngccm.org.pg/downloads/KaviengDeclarationonAidEffectiveness.pdf 
Powels, G., 2007. Testing Tradition in Tonga: Approaches to Constitutional Change. 13 Revue Juridique Polynesienne, pp. 111-142.

Powles, G., 2009. Accommodating monarchy and representative government: Tonga's political reform process. Pacific Economic Bulletin, 24(3): 140-147.

Pretty, J., 1995. Participatory learning for sustainable agriculture. World Development, 23(8): 1247-1263.

Pronk, J., 2004. Aid as a Catalyst. In J. Pronk (ed.), Catalysing Development? A Debate On Aid. Blackwell Publishing: Maldon, pp. 1-21.

Reinhardt, G. Y., 2006. Shortcuts and Signals: An Analysis of the Microlevel Determinants of Aid Allocation, with Case Study Evidence from Brazil. Review of Development Economics, 10(2): 297-312.

Robb, C., 2004. Changing Power Relations in the History of Aid. In R. Groves, and L. Hinton (eds.), Inclusive Aid Changing Power and Relationships in International Development. Earthscan: London, pp. 21-41.

Rutherford, N., 1977. Friendly Islands: A history of Tonga. Oxford University Press: New York.

Saith, A., 2006. From Universal values to Milliennium Development Goals: Lost in Translation? Development and Change, 37(5): 116-119.

Scheyvens, R. and Storey, D., 2003. Introduction. In R. Scheyvens and D. Storey (eds.) Development Fieldwork A Practical Guide. Sage Publications: London, pp. 1-13.

Sevele, F., 2011. Speech for the Launch of the Vanuatu Energy Road Map. Port Vila, Vanuatu. 
Sidaway, J., 1992. In other words on the politics of research by "First World" geographers in the "Third World". Area, 24: 403-408.

Shutt, C., 2006. Money Matters In Aid Relationships. In R. Eyben (ed.), Relationships for Aid. Earthscan: London, pp. 154-170.

Slater, D., 1993. The Geopolitical Imagination and the Enframing of Development Theory. Transactions of the Institute of British Geographers, New Series, 18(4): 419-437.

Smith, H., 2005. Ownership and capacity: Do current donor approaches help or hinder the achievement of international and national targets for education? International Journal of Educational Development, 25: 445-455.

SPC, 2012. Online. Retrieved from

https://www.spc.int/en/about-spc/history.html

SPC, 2008. Corporate Plan 2007-2012. Secretariat of the Pacific Community's headquarters, Noumea, New Caledonia. Printed by Stredder Print Ltd: New Zealand.

Sobhan, R., 2004. Aid Effectiveness and Policy Ownership. In J. Pronk (ed.) Catalysing Development? A Debate On Aid. Blackwell Publishing: Maldon, pp. 171-180.

SOPAC, 2009. Proceedings of the Pacific Energy Ministers' Meeting and Regional Energy Officials' Meeting. Joint Contribution Report 200. 20 - 24 April 2009. SOPAC Secretariat. Suva: Fiji.

Stacey, J., 1991. Can there be a feminist ethnography? In S. Gluck and D. Patai (eds) Women's Words: The Feminist Practice of Oral History, London: Routledge.

Stanley, D., 2004. South Pacific Handbook, Emeryville, CA: Avalon Travel Publishing.

Storey, D., Bulloch, H. and Overton, J., 2005. The Poverty Consensus: Some limitations of the 'popular agenda'. Progress in Development Studies, 5(1): 30-44. 
Sturton, M., 1992. Tonga: Development through Agricultural Exports. Economic Report 4. East-West Center, Pacific Islands Development Program. Honolulu.

Sultana, F., 2007. Reflexivity, Positionality and Participatory Ethics: Negotiating Fieldwork Dilemmas in International Research. ACME, 6(3): 374-385.

Tarp, F., 2010. Aid, Growth, and Development. In G. Mavrotas, Foreign Aid for Development. Oxford Scholarship Online. Retrieved from http://www.oxfordscholarship.com/view/10.1093/acprof:oso/9780199580934.001.000 1/acprof-9780199580934-chapter-2.

Thaman, K., 1992. Towards a culture-sensitive model of curriculum development for Pacific Island Countries. Directions, 13(1): 1-11.

Thaman, K., 2003. Decolonizing Pacific Studies: Indigenous perspectives, knowledge, and wisdom in higher education. The Contemporary Pacific, 15(1): 1-17.

Thapar-Björkert, S. and Henry M., 2004. Reassessing the research relationship: location, position and power in fieldwork accounts. International Journal of Social Research Methodology, 7(5): 363 - 381.

Therkildsen, O., 2005. Major Additional Funding for the MDGs- A Mixed Blessing for Capacity Development. IDS Bulletin, 36(3): 28-39.

Thrupp, L., 1989. Legitimizing local knowledge: From displacement to empowerment for third world people. Agriculture and Human Values, 6(3): 13-24.

Tolich, M, and Davidson, C., 1999. Starting Fieldwork: An Introduction to Qualitative Research in New Zealand. Oxford University Press: Melbourne.

Tonga Energy Road Map (TERM), 2010. Retrieved from http://www.tonga-energy.to/ 
Tuhiwai Smith, L., 1999. Decolonizing Methodologies Research and Indigenous People. University of Otago Press: Dunedin.

UN, 2000. A better future for all: Progress towards the International Development Goal. New York: United Nations.

UN, 2002. Country Profile: Tonga. Johannesburg Summit. Retrieved from www.un.org/esa/agenda21/natlinfo/wssd/tonga.pdf

Vaioleti, T., 2006. Talanoa Research Methodology: A Developing Position on Pacific Research. Waikato Journal of Education, 12: 21-35

van de Walle, N., 2005. Overcoming Stagnation in Aid-Dependent Countries. Washington, DC: Center for Global Development.

van Reesch, E., 2006. Ten years into the sector-wide approach: Did we do what we intended to do? In A Rich Menu for the Poor: Food for Thought on Effective Aid Politics. The Hague: Ministry of Foreign Affairs (DEK).

Warrington, E., 1998. Gulliver and Lillliput in a New World Order: the impact of external relations on the domestic policies and institutions of micro-states. Public Administration and Development, 18:101-105.

Whitfield, L., 2009. The politics of aid: African strategies for dealing with donors. Oxford: Oxford University Press.

Whitfield, L. and Maipose, G., 2008. Managing Aid Dependence: How African governments lost ownership and how they can regain it. Global Economic Governance Programme Briefing Paper. Department of Politics and International Relations. Oxford: University of Oxford.

Williams, G., 2004. Evaluating Participatory Development: Tyranny, Power and (Re) politicisation. Third World Quarterly, 25(3): 557-578. 
Winckler, O., and Therkildsen, O., 2007. Harmonization and Alignment: The Double-edge swords of Budget Support and Decentralized Aid Administration. DIIS Working Paper No. 4, Danish Institute for International Studies, Copenhagen.

Worldbank, 2011. Migration and Remittances Factbook. Washington D.C, World Bank. Retrieved from http://data.worldbank.org/data-catalog/migration-and-remittances

World Bank, 2011. East Asia and Pacific Economic Update. Vol 1. Washington D.C, World Bank.

World Bank, 2010. Country Assistance Strategy for the Kingdom of Tonga 2011-2014. Report No. 56630-TO. Washington D.C, World Bank.

Wrighton, N., 2010a. Participation, Power and Practice in Development: A Case Study of Theoretical Doctrines and International Agency Practice in Tuvalu. Master of Development Studies Thesis, Victoria University of Wellington.

Wrighton, N., 2010b. So what's the problem? International development arrivals in Tuvalu, Just Change 18: 9.

Wrighton, N. and Overton, J. 2012. Coping with participation in small island states: the case of aid in Tuvalu. Development in Practice, 22(2): 244-255.

Yin, R., 2009. Case study research: design and methods (4th edition), Sage, Thousand Oaks. 


\section{Appendix 1: Semi-Structured Interview Questions}

\section{For Government Officials:}

1) What is your position? How long have you been in this position? What are the key responsibilities you have within the Government of Tonga?

2) Who are the key development partners you work with and what are the key relationships you have with them and other development agencies?

3) Over recent years, Tonga has changed it's development processes, there has been an emphasis placed on the creation and use of national development plans and systems, increased participation and consultation with donor partners and an effort towards meeting the MDGs, what have been the key changes you have experienced in the practice of development partners? (or in GoT practices)

4) Approximately how many people from development agencies have come through your office in the past 6 months? Approximately how many would you see each week or fortnight?

5) How often are you required to travel internationally for donor requests?

6) To what extent is this typical level of engagement? Has this level of engagement from development agencies changed over time? Does this level of engagement raise any issues for you?

7) How do development partners use Government of Tonga systems? (including national planning systems, public financial management systems, procurement and monitoring and evaluation)

8) To what extent do you see donors coordinating with one another? Does this ease the burden of aid administration time? What opportunities exist to streamline development agencies interaction with the Government of Tonga?

9) To what extent do you feel donor partners align to Tonga's priorities?

\section{For Donor Officials:}

1) What is your role? How long have you been in the position? What are the key relationships you have with which sections of the Government of Tonga?

2) How has changed to your aid programme or how have your agencies operations changed over the past 5-10 years?

3) Has your relationship changed with GoT and other development partners since signing the Paris Declaration in 2005? 
4) How are the Paris Declaration principles reflected in your agencies development practise? Are there areas where you believe the principles could be improved?

5) How is your agency currently coordinating with other donors in the region and how do you involve them in programme design, budgeting, monitoring and evaluation (etc)? (please give an example).

6) How does your agency use Government systems in programme design? (such as national planning systems, public financial management systems and procurement monitoring and evaluation)

7) Approximately how many other staff from your agency have you had visit in the past 6 months? (On average how many people visit per year?)

8) What opportunities exist for streamlining development agency interactions with the Government of Tonga and other Development Partners in the region? 


\section{Appendix 2: Ethics Forms}

\section{Participant Information Sheet}

Researcher: Helen Mountfort, School of Geography, Environment and Earth Sciences, Development Studies Programme, Victoria University of Wellington.

Research: I am a masters student in the Department of Development Studies at the Victoria University of Wellington. As part of the fulfilment of this degree, I am undertaking a research thesis. The thesis that I am undertaking will examine how the Government of Tonga responds and manages multiple donor partners working in the region and specifically analyse a sector wide approach, the Tonga Energy Road Map.

Invitation: The University requires that ethics approval be obtained for research involving human participants. To participate in this study I am inviting (i) individuals from the Government of Tonga and (ii) individuals from Development Agencies involved in the Tonga Energy Road Map. All participants will be interviewed through a semi-structured interview.

Participation: Your participation in the research is entirely voluntary. The responses collected will form the basis of my research project and will be put into a written report. If you would like to withdraw from the project, you may do so at any time prior to the 4th of June 2012 when data collection and analysis is due to be completed. Please email me at helen.mountfort@vuw.ac.nz and any related material will be destroyed.

Results: The report will be submitted to the School of Earth Sciences for marking and deposited in the University Library. The collected, collated, and analysed data may be published in case studies, academic journals, and/or presented at conferences. All material collected will be kept confidential, only myself and my supervisor, Professor Warwick Murray will see this material.

Data storage and destruction: Interviews will be taped and transcribed for use as both attributable and non-attributable comments in the research. No person other than my supervisor Dr Warwick Murray and myself will see the fully transcribed material. If you do not wish to be personally identified in the final report please indicate so on the consent form. The material will be stored securely and destroyed 1 year after the completion of this project.

This project has ethics approval from the Victoria University Human Ethics Committee. If you have any questions or require further information on the project, please feel free to contact me at helen.mountfort@vuw.ac.nz or my supervisor, Professor Warwick Murray at the School of School of Geography, Environment and Earth Sciences, Victoria University, PO Box 600, Wellington, email warwick.murray@vuw.ac.nz.

Yours sincerely,

Helen Mountfort

School of Geography, Environment and Earth Sciences, Victoria University of Wellington 


\section{Participant Consent Form}

Project Title: Aid Effectiveness in the Kingdom of Tonga. A case study of Tonga's energy sector.

I have been given an explanation and have understood this research project. I have had the opportunity to ask questions and have them answered to my satisfaction. I understand that I may withdraw myself (or any information I have provided) from this project (before data collection and analysis is completed by 4 June 2012) without having to give any reason.

I agree to have the interview recorded and understand that the recording will be held for a period of up to 1 year, after which it will be destroyed or electronically wiped unless I indicate that I would like them returned to me. I understand that full interview transcripts will be kept confidential to the researcher and supervisor.

I would like the tapes returned to me.

Please circle Yes / No

I understand that I will have the opportunity to check the transcripts and any attributable quotes used before publication.

I would like to receive a summary of the results of this research when it is completed.

Please circle Yes / No

Please indicate if you do not wish to be personally identified in the final report by ticking the box below;

No, please do not personally identify me in the final report

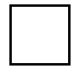

Yes, I agree to the research personally identifying me in the final report

I agree to take part in this research.

Signed:

Name of Participant:

(Please print clearly)

Date: 